\title{
NEUTRON IMPORTANCE AND FISSION DENSITY IN ENRICHED URANIUM AND PLUTONIUM METAL SPHERES
}

J. T. Mihalczo

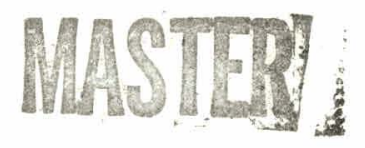

January 1975

\section{OAK RIDGE Y-12 PLANT} OAK RIDGE, TENNESSEE

prepared for the U.S. ATOMIC ENERGY COMMISSION

under U.S. GOVERNMENT Contract W.7405 eng 26 


\section{DISCLAIMER}

This report was prepared as an account of work sponsored by an agency of the United States Government. Neither the United States Government nor any agency Thereof, nor any of their employees, makes any warranty, express or implied, or assumes any legal liability or responsibility for the accuracy, completeness, or usefulness of any information, apparatus, product, or process disclosed, or represents that its use would not infringe privately owned rights. Reference herein to any specific commercial product, process, or service by trade name, trademark, manufacturer, or otherwise does not necessarily constitute or imply its endorsement, recommendation, or favoring by the United States Government or any agency thereof. The views and opinions of authors expressed herein do not necessarily state or reflect those of the United States Government or any agency thereof. 


\section{DISCLAIMER}

Portions of this document may be illegible in electronic image products. Images are produced from the best available original document. 
Printed in the United States of America. Available from National Technical Information Service

U.S. Department of Commerce

5285 Port Royal Road, Springfield, Virginia 22161

Price: Printed Copy \$4.00; Microfiche $\$ 2.25$

This report was prepared as an account of work sponsored by the United States Government. Neither the United States nor the United States Atomic Energy Commission, nor any of their employees, nor any of their contractors, subcontractors, or their employees, makes any warranty, express or implied, or assumes any legal liability or responsibility for the accuracy, completeness or usefulness of any information, apparatus, product or process disclosed, or represents that its use would not infringe privately owned rights. 


\title{
NEUTRON IMPORTANCE AND FISSION DENSITY IN ENRICHED URANIUM AND PLUTONIUM METAL SPHERES
}

\author{
J. T. Mihalczo
}

Critıcalıty Studıes Uepartment

Y-12 Development Division

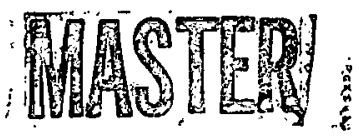

$$
\text { NOW N I C E - }
$$

This report was prepared as an account of work sponsored by the United States Government. Neither the United States nor the Unlied Siates Alumite Energy Commission, nor any of their employees, nor any of their contractors, subcontractors, or their employees, their contractors, subcontractors, or their employees, makes any warranty, express or implisd, or assumes any legal liability or responsibility for the accuracy, com pleteness or usefulness of any information, apparatus, product or process disclosed, or represents that its use would not infringe privately owned rights.

\section{Oak Ridge Y-12 Plant}

P.O. Box Y, Oak Ridge, Tennessee 37830

Prepared for the U.S. Atomic Energy Commission Under U.S. Lovernment Contràct W-74üseng- 26 


\begin{abstract}
Spatial distribution of the neutron importance in bare and natural-uranium-reflected uranium $\left(\sim 93.2 \mathrm{wt} \%{ }^{235} \mathrm{U}\right)$ and plutonium $\left(\sim 4.8\right.$ at $\left.\% .{ }^{240} \mathrm{Pu}\right)$ metal spheres was measured using ${ }^{252} \mathrm{Cf}$ neutron sources. Spatial distribution of the fission density from activation measurements in the bare spheres and those previously measured for the reflected spheres are presented.
\end{abstract}

Comparison of these distributions with those from $\mathrm{S}_{16}$ transport theory calculations showed that the measured and calculated results agreed very well for the bare spheres and in the central core of the reflected spheres. Disagreement in the natural uranium reflector increased with radius and obtained values as large as $\sim 40 \%$ at the outer surface. An analysis of the sensitivity of the calculations to the cross sections and the nuclear temperature of the fission spectrum was performed.

These measurements were undertaken to properly account for spatial effects in the point-reactor kinetics description of hossi- $\alpha$ measurements. The spatial effects factors obtained from these measurements, which multiply the correlated amplitude of the Rossi- $\alpha$ measurement, were $1.123,1.109,1.163$, and 1.214 for the bare uranium, bare plutonium, reflected uranium, and reflected plutonium spheres, respectively. The error in these values was \pm 0.010 . 


\section{CONTENTS}

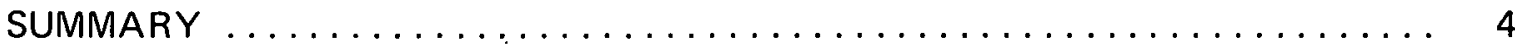

INTRODUCTION $\ldots \ldots \ldots \ldots \ldots \ldots \ldots \ldots \ldots \ldots \ldots \ldots \ldots \ldots \ldots \ldots$

NEUTRON IMPORTANCE AND FISSION DENSITY IN SPHERES $\ldots \ldots \ldots \ldots$

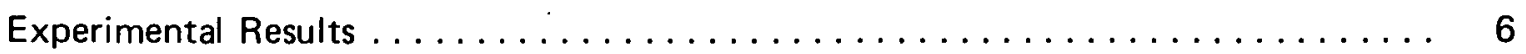

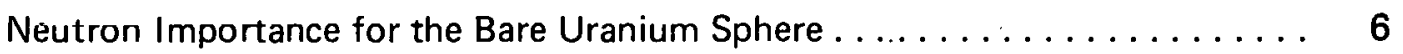

Fission Density for the Bare Uranium Sphere . . . . . . . . . . . . . 7

Neutron Importance for the Bare Plutonium Sphere $\ldots \ldots \ldots \ldots \ldots \ldots \ldots \ldots \ldots$

Fission Density for the Bare Plutonium Sphere . . . . . . . . . . . . 16

Neutron Importance for the Reflected Uranium Sphere . . . . . . . . . . 17

Fission Density for the Reflected Uranium Sphere . . . . . . . . . . . . 18

Neutron Importance for the Reflected Plutonium Sphere . . . . . . . . . 18

Fission Density for the Reflected Plutonium Sphere . . . . . . . . . . . . . 18

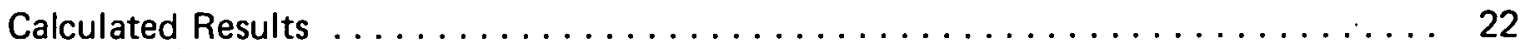

Dependence of the Neutron Importance on the Nuclear Temperature

of the Fission Spectrum . . . . . . . . . . . . . . 22

Dependence of Fission Density and Neutron Importance on

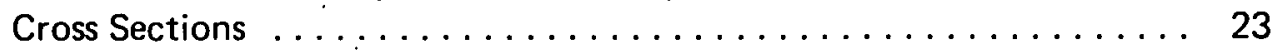

Spatial Effects Factor in Rossi- $\alpha$ Measurements . . . . . . . . . . . . . 29

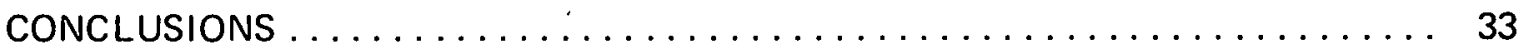

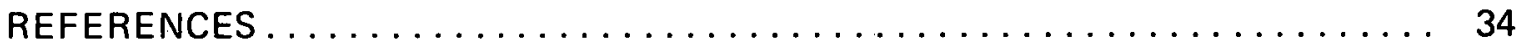

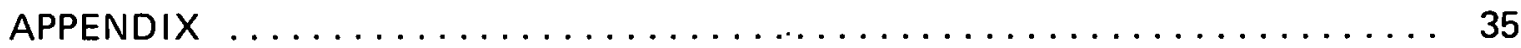

Calculated Fission Density and Neutron Importance Data $\ldots \ldots \ldots \ldots \ldots \ldots \ldots$

ACKNOWLEDGEMENTS $\ldots \ldots \ldots \ldots \ldots \ldots \ldots \ldots \ldots \ldots \ldots \ldots \ldots$ 


\section{SUMMARY}

Spatial distribution of the neutron importance in bare and natural-uranium-reflected uranium $\left(\sim 93.2 \mathrm{wt} \%{ }^{235} \mathrm{U}\right)$ and plutonium $\left(\sim 4.8\right.$ at $\left.\%{ }^{240} \mathrm{Pu}\right)$ metal spheres was measured using ${ }^{252} \mathrm{Cf}$ neutron sources. Spatial distribution of the fission density from activation measurements in the bare spheres and those previously measured for the reflected epheres are presented.

Comparison of these distributions with those from $\mathrm{S}_{16}$ transport theory calculations showed that the measured and calculated results agreed very well for the bare spheres and in the central core of the reflected spheres. Disagreement in the natural uranium reflector increased with radius and obtained values as large as $\sim 40 \%$ at the outer surface. An analysis of the sensitivity of the calculations to the cross sections and the nuclear temperature of the fission spectrum was performed.

These measurements were undertaken to properly account for spatial effects in the point-reactor kinetics description of Rossi- $\alpha$ measurements. The spatial effects factors obtained from these measurements, which multiply the correlated amplitude of the Rossi- $\alpha$ measurement, were $1.123,1.109,1.163$, and 1.214 for the bare uranium, bare plutonium, reflected uranium, and reflected plutonium spheres, respectively. The error in these values was \pm 0.010 . 


\section{INTRODUCTION}

The neutron importance distributions in bare and natural-uranium-reflected spheres of uranium ( $\left.93.2 \mathrm{wt} \%{ }^{235} \mathrm{U}\right)$ and plutonium $\left(\sim 4.8\right.$ at $\left.\%{ }^{24}{ }^{\circ} \mathrm{Pu}\right)$ metal were measured using $252 \mathrm{Cf}$ neutron sources. The fission density distribution was also measured for the bare spheres. These measurements, performed in 1971 and 1972 at the Oak Ridge Critical Experiments Facility located at the $Y-12$ Plant $^{(a)}$ and in the summers of those years at the Los Alamos Scientific Laboratory (LASL), were undertaken in order to properly account for spatial effects in the point-reactor kinetics description of Rossi- $\alpha$ measurements using measured neutron importance and fission density distributions. Some of the latter, which were previously measured at LASL by others, $(1)$ are also included for completeness.

The factor, R, accounting for spatial effects in the Rossi- $\alpha$ measurement (2) is:

$$
\left.\int F(r) d r \int F(r)\right|^{2}(r) d r /\left[\int F(r) \mid(r) d r\right]^{2}
$$

where:

$$
\begin{aligned}
& F(r)=\int \Sigma_{f}(r E) \varphi(r E) d E, \text { and } \\
& I(r)=\int \chi(r E) \varphi^{+}(r E) d E .
\end{aligned}
$$

In these two expressions:

$$
\begin{aligned}
& \Sigma_{f}(\mathrm{rE})=\text { the macroscopic fission cross section, } \\
& \chi(\mathrm{rE})=\text { the energy distribution of neutrons from fission, and } \\
& \varphi \text { and } \varphi^{+}=\text {the forward and adjoint fluxes, respectively. }
\end{aligned}
$$

The neutron importance, fission density, and the spatial effects factor are compared to values obtained from $\mathrm{S}_{16}$ transport theory calculations using the ANISN $(3)$ code with various cross section sets-Hansen-Roach, (4) ENDF-B-II,(5) and ENDF-B-III.(6)

(a) Operated by the Union Carbide Corporation's Nuclear Division for the US Atomic Energy Commission. 


\section{NEUTRON IMPORTANCE AND FISSION DENSITY IN SPHERES}

\section{EXPERIMENTAL RESULTS}

\section{Neutron Importance for the Bare Uranium Sphere}

The bare uranium (93.2 wt \% ${ }^{235} \mathrm{U}$ ) metal sphere, similar to GODIVA /(7) but with a minimum number of deviations from sphericity, is illustrated in Figure 1. Filler plugs of 1.270 and $0.965 \mathrm{~cm}$ OD and 0.345 $\mathrm{cm}$ ID could be inserted so that a $0.345-\mathrm{cm}$-diameter hole extended through the sphere. Uranium rods of $0.330 \mathrm{~cm}$ diameter were provided for filling the $0.345-\mathrm{cm}$ diameter diametral hole. Neutron importance as a function of radius was measured in this bare uranium metal sphere. The reactivity of the system was adjusted to slightly below delayed criticality, and a $0.3-\mu \mathrm{g}$ ${ }^{252} \mathrm{Cf}$ neutron source was located at different radii in the diametral hole. Count rates of the $\mathrm{BF}_{3}$ proportional counters external to the sphere were observed, and the relative count rate was assumed to be proportional to the relative importance of fission neutrons from $252 \mathrm{Cf}$ (Maxwellian neutron spectrum with a $\mathrm{T}=1.4 \mathrm{MeV}$ ). (8) The source was contained in a 0.315 $\mathrm{cm}$-diameter by $0.691-\mathrm{cm}$-long, welded, stainless steel cylinder. It was positioned remotely by a small electric-motor-powered screw drive with a $0.330-\mathrm{cm}$-diameter soliduranium metal push rod. The hole was filled with $0.330 \mathrm{~cm}$-diameter uranium metal cylinders, either 1.270 or $0.635 \mathrm{~cm}$ long. The total reactivity effect associated with source motion was less than 0.3 cent.

As the solid uranium metal rod moved the source through the bare sphere, the uranium cylinders in lengths of either 0.635 or $1.270 \mathrm{~cm}$ dropped out the end of the

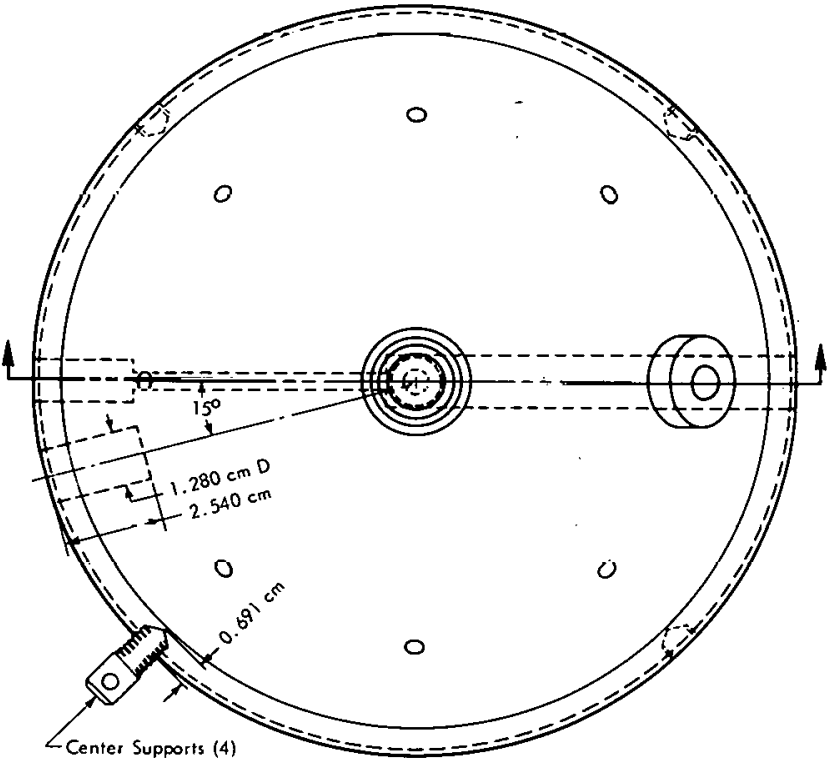

(a) Top View

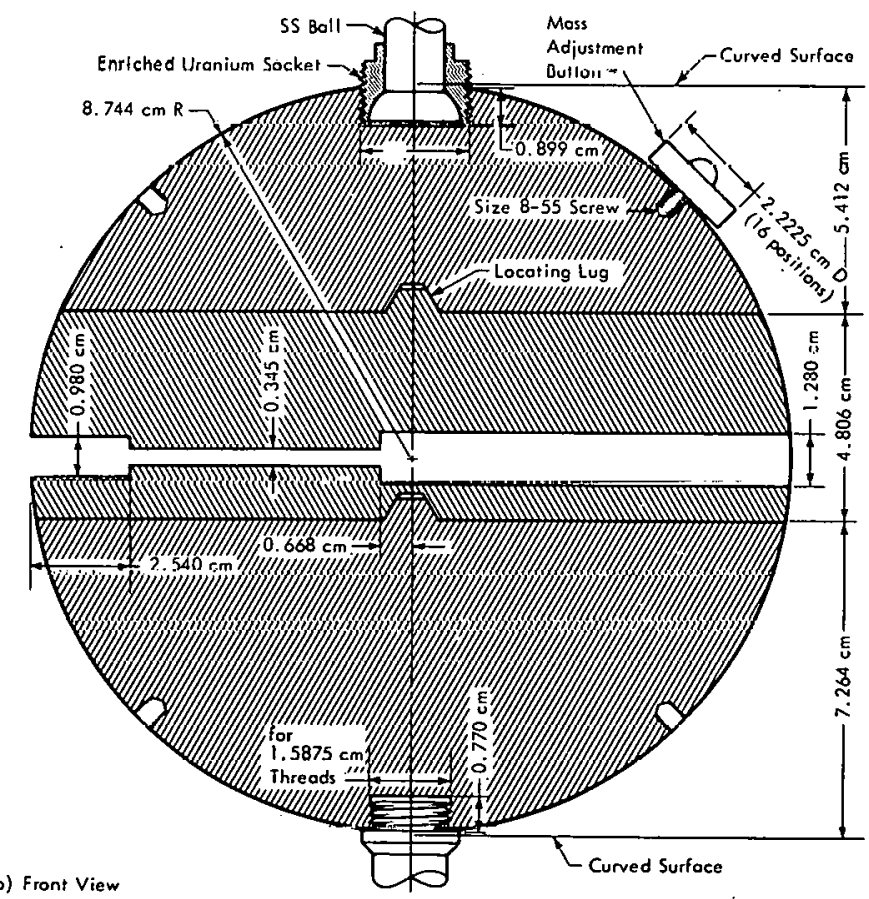

Figure 1. COMPONENTS OF THE BARE URANIUM SPHERE. (Filler Plugs were Available for all Holes) 
diametral hole so that the hole was always filled with uranium for all locations of the source. A small aluminum $(70 \mathrm{~g})$ reflector was located at various distances from the sphere surface to compensate for the reactivity effect of the source moving through the assembly. The aluminum reflector was located adjacent to a point on the surface whose radius vector was perpendicular to the diametral hole. The position of this aluminum reflector, which was used in the importance measurements to compensate for the reactivity changes associated with the position of the source, was determined by moving an empty source container through the delayed critical sphere and determining the position of the reflector that maintained the system at delayed criticality. The surface mass (each containing 42 or $22 \mathrm{~g}$ of uranium, see Figure 1) adjustment buttons that were required to achieve criticality were removed for the importance function measurement for which the sphere reactivity was - 20 cents. It was assumed that the reactivity change associated with the source position could be compensated for by positioning the aluminum reflector at the position determined in the measurements with the delayed critical system.

The locations of the three $\mathrm{BF}_{3}$ proportional counters and the aluminum reflector with respect to the sphere are indicated in Figure 2. Location of the sphere with respect to the walls and floor of the experiment room is also shown on this figure. Measurements, with the sphere orientation varied by rotation of the sphere in the room $(10.67 \times 10.67 \times 9.14 \mathrm{~m}$ high) and with a 279 by 173 by $15.9-\mathrm{cm}$ polyethylene slab placed $170 \mathrm{~cm}$ from the sphere center, were made in order to investigate the effects of the walls of the room on the neutron importance function. The neutron importance was found to be independent of the orientation of the sphere or the presence of the slab of polyethylene. Additionally, the neutron importance was found to be independent of the $\mathrm{BF}_{3}$ counter location. This independence of counter location, even with the source at the outer radius of the sphere, resulted from the high neutron multiplication of the sphere. Transport $\left(S_{16}\right)$ theory calculations with a $15.2-\mathrm{cm}$-thick spherical shell of polyethylene $(274 \mathrm{~cm}$ from the sphere) showed that, at the outer surface of the sphere, the neutron importance was increased only $0.3 \%$ by the reflection of neutrons from the polyethylene. Thus, both the measurements and calculations showed that room-return effects on the neutron importance distribution were negligible since the assembly was located $274 \mathrm{~cm}$ from the closest building structure (the floor). Measurements were also performed with the orientation of the axis of the source rotated $180^{\circ}$ in the diametral hole to evaluate the source centering in its container. Differences in the relative neutron importance in regions near the outer surface of the sphere, where the spatial gradient of the importance was largest, were $\ll 1 \%$. The relative neutron importance, which was normalized to unity at the sphere center, is given in Table 1 and plotted as a function of radius in Figure 3.

\section{Fission Density for the Bare Uranium Sphere}

The relative spatial distribution of the fission density was measured by activating 0.330 -cm-diameter uranium cylinders placed in the diametral hole and observing their resulting fission-product gamma-ray activity with a pair of $\mathrm{Nal}$ scintillation detection systems. The cylinders were 0.635 or $0.318 \mathrm{~cm}$ long. The two detections systems were adjusted to have the same response with standard sources. Each activated cylinder was always counted simultaneously with a normalizing cylinder activated in the same irradiation at the center of the sphere. To minimize the effects of slow drifts in the response of the scintillation systems over the counting period, each pair of activated cylinders was counted in each detector and the average ratio of responses calculated. 


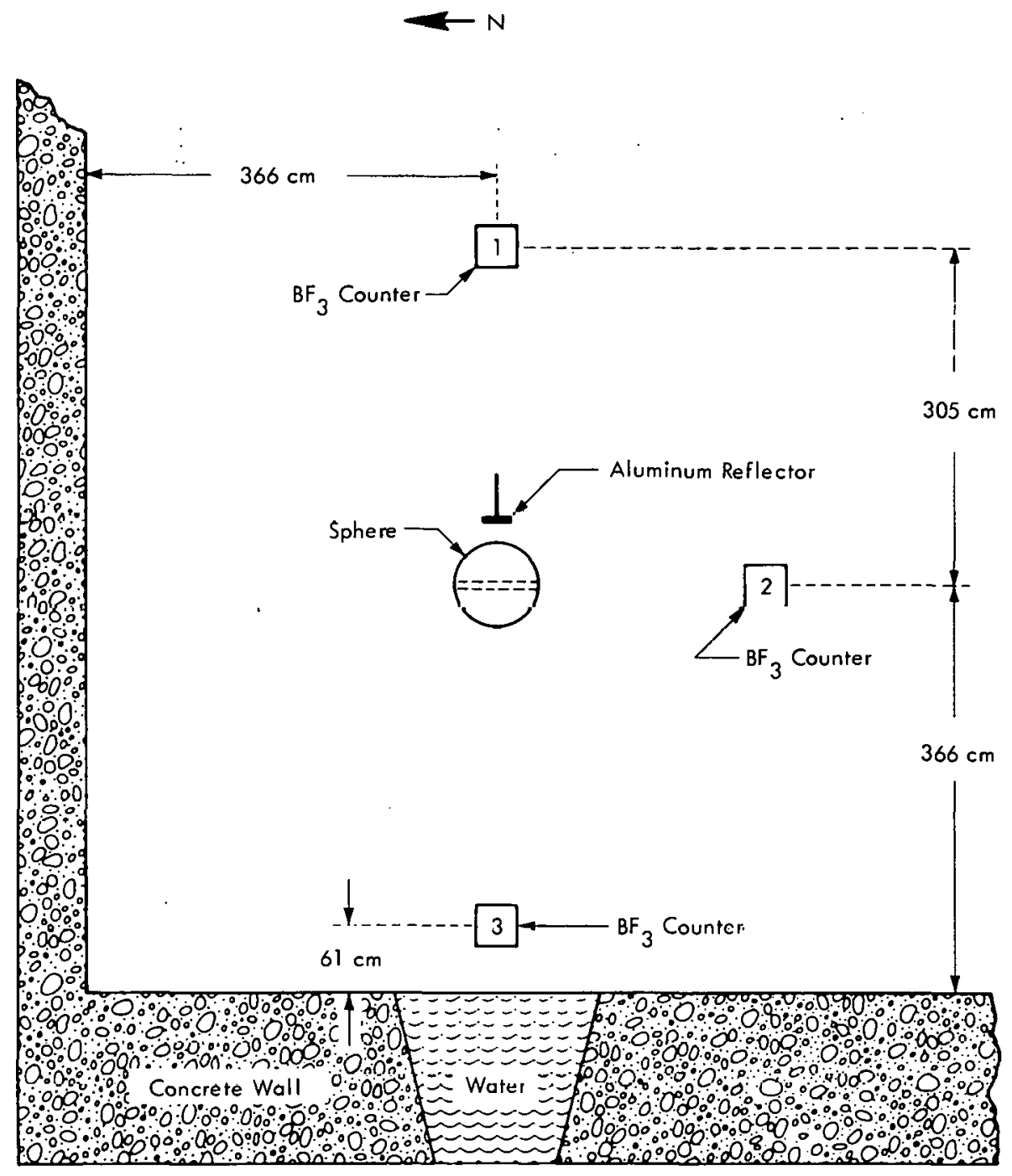

Figure 2. URANIUM-SPHERE, COUNTER, WALL CONFIGURATION IN THE ASSEMBLY CELL. (Cell is $10.67 \times 10.67 \times 9.14 \mathrm{~m}$ High; Uranium Sphere is $274 \mathrm{~cm}$ Above the Floor, the $\mathrm{BF}_{3}$ Counters are $30.5 \mathrm{~cm}$ Above the Floor)

Measurements, with the sphere orientation varied by rotation of the sphere in the room and with a 279 by 173 by $15.9-\mathrm{cm}$ polyethylene slab placed $170 \mathrm{~cm}$ from the sphere center, were made in order to investigate the effects of the walls of the room on the fission density distribution. The measured fission density distribution was found to be independent of the orientation of the sphere or the presence of the polyethylene slab.

An estimate of the effect of massive building structure was also obtained from transport theory calculations with a 15.2-cm-thick spherical shell of polyethylene, $274 \mathrm{~cm}$ from the outer surface of the sphere. These calculations provided an upper limit for this effect since the sphere was located $274 \mathrm{~cm}$ above the floor, $610 \mathrm{~cm}$ from the ceiling, and 366, 366, 701, and $701 \mathrm{~cm}$ from the walls. The fission density increased $64 \%$ in the $0.001-\mathrm{cm}$-thick interval at the surface. In the next four $0.0874-\mathrm{cm}$-thick intervals in from the surface, presence of the polyethylene increased the fission density $10.8,2.6,1.0$, and 
Table 1

RELATIVE IMPORTANCE OF NEUTRONS FROM ${ }^{252}$ Cf FISSIONS AS A FUNCTION OF RADIUS FOR A $93.2{ }^{235}$ U-ENRICHED URANIUM METAL SPHERE

\begin{tabular}{|c|c|c|c|c|c|}
\hline \multirow{2}{*}{$\begin{array}{l}\text { Radius(1) } \\
(\mathrm{cm})\end{array}$} & \multicolumn{3}{|c|}{$\begin{array}{l}\text { Relative Neutron Importance for } \\
\mathrm{BF}_{3} \text { Proportional Counter (2) }\end{array}$} & \multirow{2}{*}{\multicolumn{2}{|c|}{ Average Relative Neutron Importance }} \\
\hline & 1 & 2 & 3 & & \\
\hline-8.138 & 0.274 & 0.283 & 0.277 & $0.278 \pm 0.003$ & \\
\hline-8.105 & 0.266 & 0.274 & 0.272 & 0.271 & \\
\hline$-8.105^{(3)}$ & $0.262(0.261)^{(4)}$ & $0.271(0.270)$ & $0.261(0.268)$ & $0.265(0.267)$ & $0.267 \pm 0.002^{(5)}$ \\
\hline$-8.100^{(3)}$ & 0.287 & 0.291 & 0.290 & $0.289 \pm 0.001$ & \\
\hline-8.004 & 0.297 & 0.302 & 0.299 & $0.299 \pm 0.001$ & \\
\hline$-7.480^{(3)}$ & 0.377 & 0.377 & 0.382 & $0.379 \pm 0.002$ & \\
\hline$-6.833^{(3)}$ & 0.462 & 0.462 & 0.468 & $0.464 \pm 0.002$ & \\
\hline-6.825 & 0.454 & 0.464 & 0.455 & $0.458 \pm 0.003$ & \\
\hline-6.759 & 0.424 & 0.433 & 0.427 & 0.428 & \\
\hline$-6.759^{(3)}$ & $0.419(0.415)$ & $0.431(0.427)$ & $0.421(0.428)$ & $0.424(0.423)$ & $0.425 \pm 0.002$ \\
\hline-6.731 & 0.463 & 0.473 & 0.468 & $0.468 \pm 0.003$ & \\
\hline-5.730 & 0.569 & 0.581 & 0.575 & 0.575 & \\
\hline$-5.730^{(3)}$ & $0.571(0.573)$ & $0.582(0.584)$ & $0.575(0.589)$ & $0.576(0.582)$ & $0.578 \pm 0.002$ \\
\hline$-5.583^{(3)}$ & 0.618 & 0.618 & 0.624 & $0.620 \pm 0.002$ & \\
\hline-5.484 & 0.620 & 0.627 & 0.626 & $0.624 \pm 0.002$ & \\
\hline-5.428 & 0.628 & 0.638 & 0.633 & $0.633 \pm 0.003$ & \\
\hline-4.392 & 0.712 & 0.731 & 0.729 & 0.727 & $0.729 \pm 0.003$ \\
\hline$-4.392^{(3)}$ & $0.730(0.723)$ & $0.738(0.733)$ & $0.727(0.739)$ & $0.731(0.732)$ & \\
\hline$-4.288^{(3)}$ & 0.760 & 0.758 & 0.759 & $0.759 \pm 0.001$ & \\
\hline-4.221 & 0.768 & 0.773 & 0.769 & $0.770 \pm 0.002$ & \\
\hline-4.166 & 0.758 & 0.765 & 0.760 & $0.761 \pm 0.002$ & \\
\hline-3.208 & 0.858 & 0.862 & 0.861 & $0.860 \pm 0.001$ & \\
\hline-3.170 & 0.842 & 0.850 & 0.846 & 0.846 & \\
\hline$-3.170^{(3)}$ & $0.846(0.845)$ & $0.852(0.848)$ & $0.852(0.856)$ & $0.850(0.850)$ & $0.849 \pm 0.001$ \\
\hline$-3.012^{(3)}$ & 0.874 & 0.875 & 0.876 & $0.875 \pm 0.001$ & \\
\hline-2.891 & 0.884 & 0.884 & 0.889 & $0.886 \pm 0.002$ & \\
\hline-1.900 & 0.930 & 0.935 & 0.931 & 0.932 & \\
\hline$-1.900^{(3 !}$ & $0.936(0.932)$ & $0.938(0.939)$ & $0.936(0.943)$ & $0.937(0.938)$ & $0.936 \pm 0.001$ \\
\hline$-1.740^{13 i}$ & 0.952 & 0.955 & 0.962 & $0.956 \pm 0.003$ & \\
\hline-1.618 & 0.960 & 0.961 & 0.954 & $0.958 \pm 0.002$ & \\
\hline-0.632 & 0.986 & 0.987 & 0.987 & 0.987 & \\
\hline$-0.632^{(3) i}$ & $0.985(0.983)$ & $0.987(0.984)$ & $0.990(0.990)$ & $0.987(0.985)$ & \}$\quad 0.987 \pm 0.001$ \\
\hline-0.470 & 0.994 & 0.989 & 0.993 & $0.992 \pm 0.002$ & \\
\hline 0.660 & 0.988 & 0.987 & 0.982 & 0.986 & \\
\hline $0.660^{13 i}$ & $0.988(0.986)$ & $0.986(0.986)$ & $0.979(0.992)$ & $0.984(0.988)$ & $0.986 \pm 0.001$ \\
\hline $0.805^{13 i}$ & 0.983 & 0.984 & 0.989 & $0.985 \pm 0.002$ & \\
\hline 0.904 & 0.994 & 0.991 & 0.992 & $0.992 \pm 0.001$ & \\
\hline 1.905 & 0.949 & 0.947 & 0.948 & 0.948 & \\
\hline $1.90513 !$ & $0.957(0.956)$ & $0.949(0.947)$ & $0.947(0.962)$ & $0.949(0.955)$ & $0.951 \pm 0.002$ \\
\hline 2.024 & 0.959 & 0.953 & 0.955 & $0.956 \pm 0.001$ & \\
\hline $2.078^{(3 !}$ & 0.932 & 0.929 & 0.936 & $0.932 \pm 0.002$ & \\
\hline 3.175 & 0.864 & 0.863 & 0.862 & 0.863 & \\
\hline $3.17513 i$ & $0.866(0.857)$ & $0.865(0.862)$ & $0.862(0.873)$ & $0.864(0.867)$ & $0.864 \pm 0.001$ \\
\hline 3.449 & 0.849 & 0.848 & 0.848 & $0.848 \pm 0.001$ & \\
\hline 4.445 & 0.749 & 0.747 & 0.747 & 0.748 & \\
\hline $4.445^{(3 !}$ & $0.754(0.749)$ & $0.752(0.747)$ & $0.750(0.759)$ & $0.752(0.752)$ & $0.750 \pm 0.001$ \\
\hline $4.646^{13 !}$ & 0.717 & 0.716 & 0.716 & $0.716 \pm 0.001$ & \\
\hline 4.722 & 0.740 & 0.735 & 0.737 & $0.737 \pm 0.001$ & \\
\hline 5.712 & $0.607 \ldots$ & 0.605 & 0.603 & $0.605 \ldots$ & l $0008+0001$ \\
\hline $5.712^{(3 i}$ & $0.610(0.607)$ & $0.608(0.604)$ & $0.607(0.617)$ & $0.609(0.609)$ & $0.608 \pm 0.001$ \\
\hline $5.895(3 i$ & 0.575 & 0.575 & 0.577 & $0.576 \quad 0.001$ & \\
\hline 5.994 & 0.592 & 0.589 & 0.587 & $0.589 \pm 0.001$ & \\
\hline 7.216 & 0.420 & 0.417 & 0.417 & $0.418 \pm 0.001$ & \\
\hline $7.419(3 !$ & 0.413 & 0.412 & 0.418 & $0.414 \pm 0.002$ & \\
\hline 7.650 & 0.366 & 0.365 & 0.363 & 0.365 & \\
\hline $7.650^{13}$ & $0.365(0.364)$ & $0.363(0.363)$ & $0.362(0.369)$ & $0.363(0.365)$ & $0.364 \pm 0.001$ \\
\hline 8.273 & 0.274 & 0.273 & 0.272 & 0.273 & \\
\hline $8.273^{13 i}$ & $0.280(0.277)$ & $0.278(0.276)$ & $0.280(0.283)$ & $0.279(0.279)$ & $0.277 \pm 0.001$ \\
\hline 8.400 & 0.266 & 0.264 & 0.263 & $0.264 \pm 0.001$ & \\
\hline 8.443 & 0.242 & 0.242 & 0.246 & $0.243 \pm 0.001$ & \\
\hline $8.59013 !:$ & 0.232 & 0.231 & 0.228 & $0.230 \pm 0.001$ & \\
\hline 8.618 & 0.225 & 0.225 & 0.223 & $0.224 \pm 0.001$ & \\
\hline 8.745 & 0.198 & 0.196 & 0.197 & 0.197 & \\
\hline $8.745^{(3)}$ & $0.205(0.210)$ & $0.202(0.208)$ & $0.206(0.215)$ & $0.204(0.211)$ & $0.204 \pm 0.002$ \\
\hline $9.091(6 i$ & 0.161 & 0.165 & $0: 164$ & $0.165 \pm 0.001$ & \\
\hline
\end{tabular}

(1) Minus sign refers to values measured on the east or south half of the sphere.

(2) Average of $2-4$ measurements in which $10^{6}$ counts were obtained with each counter.

(3) Measurements made with the sphere oriented so that the diametral hole was in the north-south direction. At radii not called out by the footnote the values given are for measurements with the sphere oriented so that the diametral hole was in the east-west direction.

(4) Values in parentheses are from measurements with a $270 \times 173 \times 15.9-\mathrm{cm}$ polyethylene slab present $170 \mathrm{~cm}$ north of the sphere center.

(5) Average for the three measurement conditions given by the entries on the two lines indicated by the bracket. The error çiven is the precision based on repeated measurements.

(6) External to the sphere. 


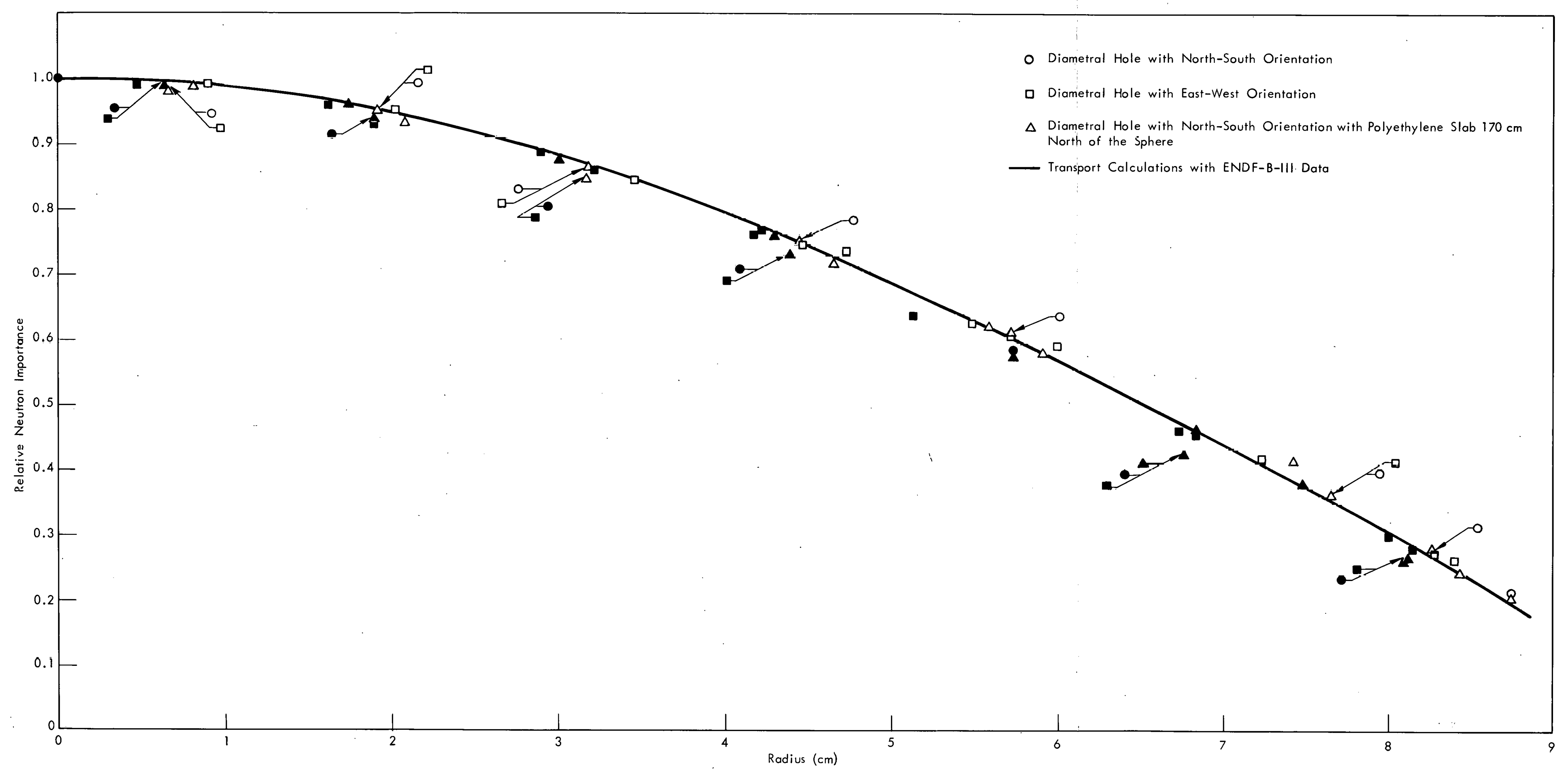

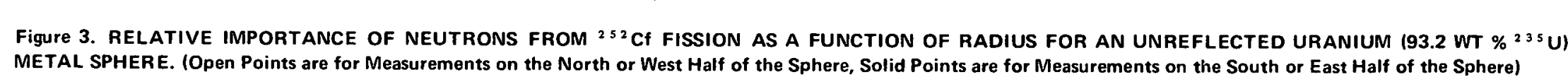


$0.6 \%$, respectively. Thus, reflection by the room only affects the fission density significantly within $\sim 0.10 \mathrm{~cm}$ of the surface of the sphere. Since the uranium cylinders used to measure the fission density were $\sim 0.63 \mathrm{~cm}$ thick, this effect could not be detected.

Results of these measurements are given in Table 2 and plotted as a function of radius in Figure 4. Average values of the measured relative fission density and neutron importance, are compared in Figure 5. The relative neutron importance has the same spatial dependence as the fission density, except near the outer surface of the sphere where it is slightly larger. Similarity of the spatial distribution of the fission density and neutron importance was also shown by calculations (see Table A-1, Appendix). Calculations indicated that the relative neutron importance was $0.18,0.32,0.55,0.93,1.68$, and $4.24 \%$ higher than the relative fission density at radii $50,60,70,80,90$, and $100 \%$ of the outer radius of the sphere, respectively.

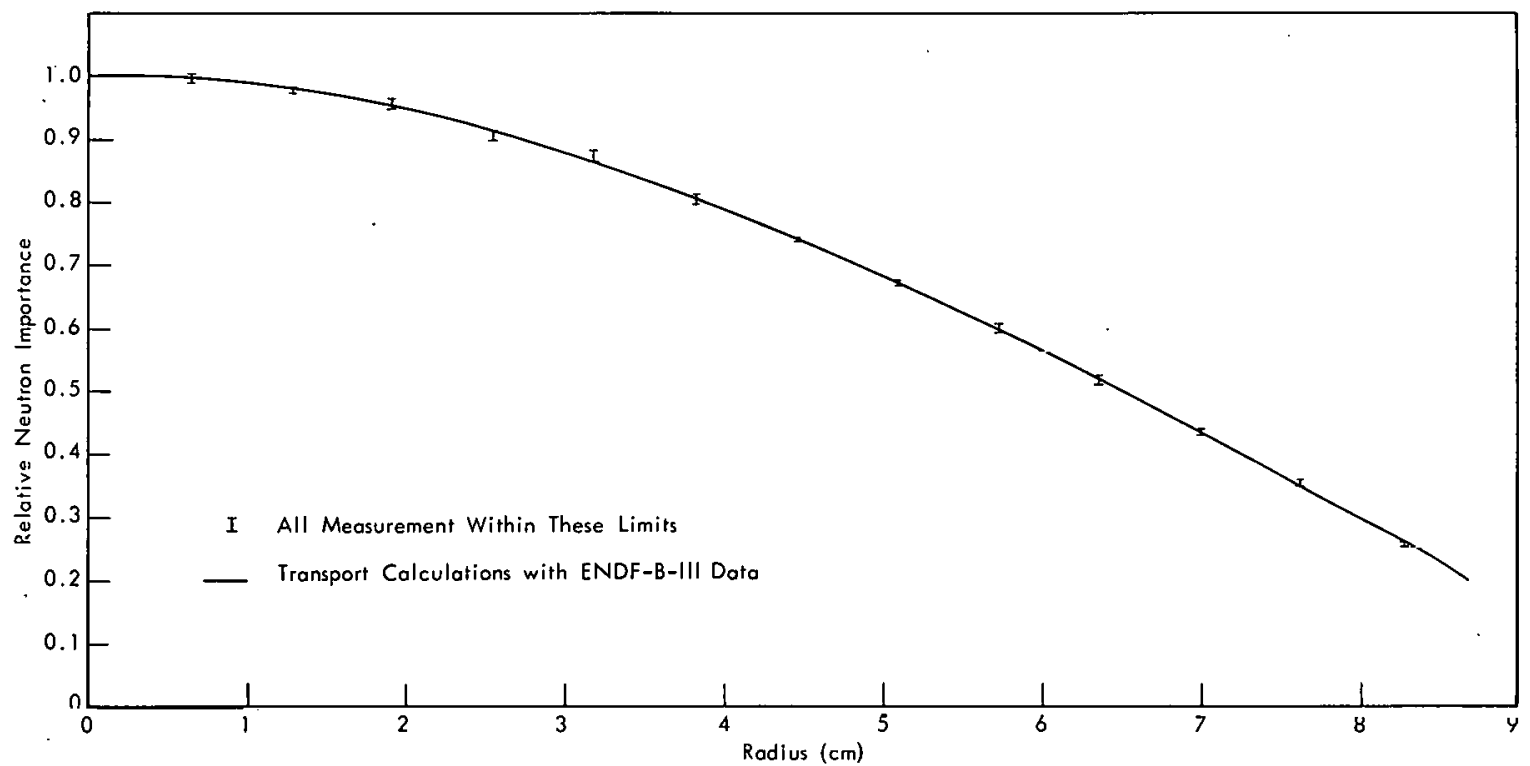

Figure 4. RELATIVE FISSION DENSITY AS A FUNCTION OF RADIUS IN AN UNREFLECTED URANIUM (93.2 WT $\%^{235}$ UI METAL SPHERE.

\section{Neutron Importance for the Bare Plutonium Sphere}

The bare plutonium $(4.50$ at $\% 240 \mathrm{Pu})$ metal sphere was the JEZEBEL(9) assembly at LASL. The neutron importance was measured by locating a $52-\mu \mathrm{g}^{252} \mathrm{Cf}$ neutron source at different radii in a $0.356-\mathrm{cm}$-diameter diametral hole in the slightly subcritical sphere and observing the count rate in four externally located BF3 proportional counters. The source was contained in a $0.318-\mathrm{cm}$-diameter, $0.716-\mathrm{cm}$-long stainless steel (magnetic) cylindrical can which was attached by a $0.318-\mathrm{cm}$-diameter, $\dot{2} .54-\mathrm{cm}$-long magnet and a thin-wall stainless steel tube to a remotely operable positioning mechanism. The diametral hole extended from the surface to $2.54 \mathrm{~cm}$ beyond the sphere center. Counters were located along extensions of the axis of the diametral hole and perpendicular to the axis about 244 to $305 \mathrm{~cm}$ from the assembly. Due to the neutron intensity of the californium source and the high neutron multiplication of the sphere $\left(\sim 25\right.$ or $\sim 50$ cents subcritical), the $B F_{3}$ 
RELATIVE FISSION DENSITY AS A FUNCTION OF RADIUS FOR AN

UNREFLECTED URANIUM $\left(93.2 \mathrm{wt} \%{ }^{235} \mathrm{U}\right)$ METAL SPHERE

\begin{tabular}{|c|c|c|c|}
\hline $\begin{array}{l}\text { Radius }(1) \\
(\mathrm{cm}) \\
\end{array}$ & Relative Fission Density (2) & $\begin{array}{c}\text { Average (3) } \\
\text { Value }\end{array}$ & $\begin{array}{c}\text { Average }(4) \\
\text { Value }\end{array}$ \\
\hline-8.265 & $\begin{array}{l}0.256,0.258,0.264,0.259,0.264(5) \\
0.261,0.264,0.269,0.266^{(5)} \\
0.259,0.260,0.258,0.261,0.255(5)\end{array}$ & $\begin{array}{l}0.260 \\
0.265 \\
0.059\end{array}$ & $0.261 \pm 0.001$ \\
\hline-7.633 & $\begin{array}{l}0.353,0.354 \\
0.356,0.355,0.358,0.357 \\
0.348,0.351\end{array}$ & $\begin{array}{l}0.354 \\
0.357 \\
0.350\end{array}$ & $0.354 \pm 0.001$ \\
\hline-6.995 & $\begin{array}{l}0.433,0.440,0.443 \\
0.438,0.442,0.446,0.443 \\
0.434,0.440\end{array}$ & $\begin{array}{l}0.439 \\
0.442 \\
0.437\end{array}$ & $0.440 \pm 0.001$ \\
\hline-6.355 & $\begin{array}{l}0.517,0.513,0.521,0.516,0.522 \\
0.522,0.527,0.523,0.527 \\
0.519,0.517,0.513,0.519,0.516\end{array}$ & $\begin{array}{l}0.518 \\
0.525 \\
0.517\end{array}$ & $0.519 \pm 0.001$ \\
\hline-5.725 & $\begin{array}{l}0.597,0.609 \\
0.603,0.608,0.6 i 1,0.606 \\
0.599,0.593\end{array}$ & $\begin{array}{l}0.603 \\
0.607 \\
0.593\end{array}$ & $0.603 \pm 0.002$ \\
\hline-5.088 & $\begin{array}{l}0.663,0.670,0.683 \\
0.671 \\
0.672,0.674\end{array}$ & $\begin{array}{l}0.672 \\
0.671 \\
0.673\end{array}$ & $0.672 \pm 0.003$ \\
\hline-4.45 & $\begin{array}{l}0.746,0.739,0.747,0.740,0.749,0.754 \\
0.746 \\
0.748,0.743,0.746,0.747,0.745,0.746\end{array}$ & $\begin{array}{l}0.746 \\
0.746 \\
0.746\end{array}$ & $0.746 \pm 0.001$ \\
\hline-3.815 & $\begin{array}{l}0.800,0.809 \\
0.817,0.811,0.8: 9,0.818 \\
0.799,0.804\end{array}$ & $\begin{array}{r}0.805 \\
0.816 \\
0.802\end{array}$ & $0.810 \pm 0.003$ \\
\hline-3.180 & $\begin{array}{l}0.871,0.871 \\
0.867,0.866,0.883,0.869 \\
0.871,0.869\end{array}$ & $\begin{array}{l}0.871 \\
0.871 \\
0.870\end{array}$ & $0.871 \pm 0.002$ \\
\hline-2.54 & $\begin{array}{l}0.908,0.917,0.89 \tau, 0.905,0.895,0.907 \\
0.911,0.921,0.931,0.891 \\
0.909,0.909,0.911,0.921,0.911,0.914\end{array}$ & $\begin{array}{l}0.904 \\
0.914 \\
0.913\end{array}$ & $0.910 \pm 0.003$ \\
\hline-1.908 & $\begin{array}{l}0.941,0.958,0.948 \\
0.946,0.955,0.957,0.960 \\
0.947,0.947\end{array}$ & $\begin{array}{l}0.949 \\
0.955 \\
0.947\end{array}$ & $0.951 \pm 0.002$ \\
\hline-1.272 & $\begin{array}{l}0.972,0.986,0.9 \varepsilon 1 \\
0.975 \\
0.977,0.978\end{array}$ & $\begin{array}{l}0.980 \\
0.975 \\
0.978\end{array}$ & $0.978 \pm 0.002$ \\
\hline-0.635 & $\begin{array}{l}0.997,0.990,0.993,0.986,0.999 \\
1.002 \\
0.999,1.011,1.028,1.012,0.993\end{array}$ & $\begin{array}{l}0.993 \\
1.002 \\
1.008\end{array}$ & $1.001 \pm 0.004$ \\
\hline 0.0 & $\begin{array}{l}1.000,1.000,1.000,1.000,1.000,1.000 \\
1.000,1.000,1.000,1.000 \\
1.000,1.000,1.000,1.000,1.000,1.000\end{array}$ & $\begin{array}{l}1.000 \\
1.000 \\
1.000\end{array}$ & $1.000 \pm 0.000$ \\
\hline 0.635 & $\begin{array}{l}1.001,0.990,0 . \varsigma 93,0.987,1.000,0.994 \\
1.001 \\
0.996,0.998,0.9 \subseteq 4,0.993,1.000\end{array}$ & $\begin{array}{l}0.994 \\
1.001 \\
0.996\end{array}$ & $0.996 \pm 0.001$ \\
\hline 1.272 & $\begin{array}{l}0.978,0.982,0.973 \\
0.976 \\
0.980\end{array}$ & $\begin{array}{l}0.978 \\
0.976 \\
0.980\end{array}$ & $0.978 \pm 0.002$ \\
\hline 1.908 & $\begin{array}{l}0.952,0.953,0.950,0.948 \\
0.950,0.963,0.975,0.966 \\
0.955,0.948\end{array}$ & $\begin{array}{l}0.951 \\
0.964 \\
0.952\end{array}$ & $0.956 \pm 0.003$ \\
\hline 2.543 & $\begin{array}{l}0.913,0.898,0.912,0.902,0.910,0.918 \\
0.899,0.914,0.934,0.951 \\
0.905,0.908,0.907 .0 .907,0.896,0.914\end{array}$ & $\begin{array}{l}0.909 \\
0.916 \\
0.906\end{array}$ & $0.910 \pm 0.002$ \\
\hline 3.180 & $\begin{array}{l}0.870,0.870,0.864 \\
0.866,0.892,0.875 \\
0.873,0.869\end{array}$ & $\begin{array}{l}0.868 \\
0.878 \\
0.871\end{array}$ & $0.872 \pm 0.003$ \\
\hline 3.815 & $\begin{array}{l}0.814,0.807,0.809 \\
0.807,0.812 \\
0.813,0.808\end{array}$ & $\begin{array}{l}0.810 \\
0.810 \\
0.811\end{array}$ & $0.810 \pm 0.001$ \\
\hline 4.450 & $\begin{array}{l}0.741,0.735,0.745,0.734,0.756,0.746 \\
0.741 \\
0.742,0.757,0.733,0.742,0.743,0.747\end{array}$ & $\begin{array}{l}0.741 \\
0.741 \\
0.744\end{array}$ & $0.742 \pm 0.002$ \\
\hline 5.088 & $\begin{array}{l}0.678,0.681,0.671 \\
0.674 \\
0.672,0.673\end{array}$ & $\begin{array}{l}0.677 \\
0.674 \\
0.673\end{array}$ & $0.675 \pm 0.002$ \\
\hline 5.725 & $\begin{array}{l}0.600,0.596 \\
0.599 \\
0.599,0.604\end{array}$ & $\begin{array}{l}0.598 \\
0.599 \\
0.602\end{array}$ & $0.600 \pm 0.001$ \\
\hline 6.355 & $\begin{array}{l}0.514,0.512,0.516,0.511,0.518 \\
0.513 \\
0.528,0.525,0.522,0.518,0.520\end{array}$ & $\begin{array}{l}0.514 \\
0.513 \\
0.523\end{array}$ & $0.518 \pm 0.005$ \\
\hline 6.995 & $\begin{array}{l}0.434,0.444,0.435 \\
0.436,0.433,0.448,0.442 \\
0.433,0.437\end{array}$ & $\begin{array}{l}0.438 \\
0.440 \\
0.435\end{array}$ & $0.438 \pm 0.002$ \\
\hline 7.633 & $\begin{array}{l}0.349,0.351 \\
0.351 \\
0.353,0.349\end{array}$ & $\begin{array}{l}0.350 \\
0.351 \\
0.351\end{array}$ & $0.351 \pm 0.001$ \\
\hline 8.265 & $\begin{array}{l}0.255,0.258,0.253,0.263,0.260 \\
0.256 \\
0.238,0.263,0.259,0.263,0.262\end{array}$ & $\begin{array}{l}0.258 \\
0.256 \\
0.257\end{array}$ & $0.257 \pm 0.002$ \\
\hline
\end{tabular}

(1) Minus sign refers to values measured on the east or south half of the sphere.

(2) Multiple entries are the results of repeated measurements. All values normalized to 1.000 at the sphere

3) Average of repeated measurements given on the same line of the table.

(4) Average of all values listed for any radius. The error given is the precision based on repeated measurements. that thes listed an the first line for a particular radius are from measurements witt the spherented so that the diametral hole was in the east-west direction; those on the second line witt: the sphere oriented so placed $170 \mathrm{~cm}$ east of the place $170 \mathrm{~cm}$ ess in 


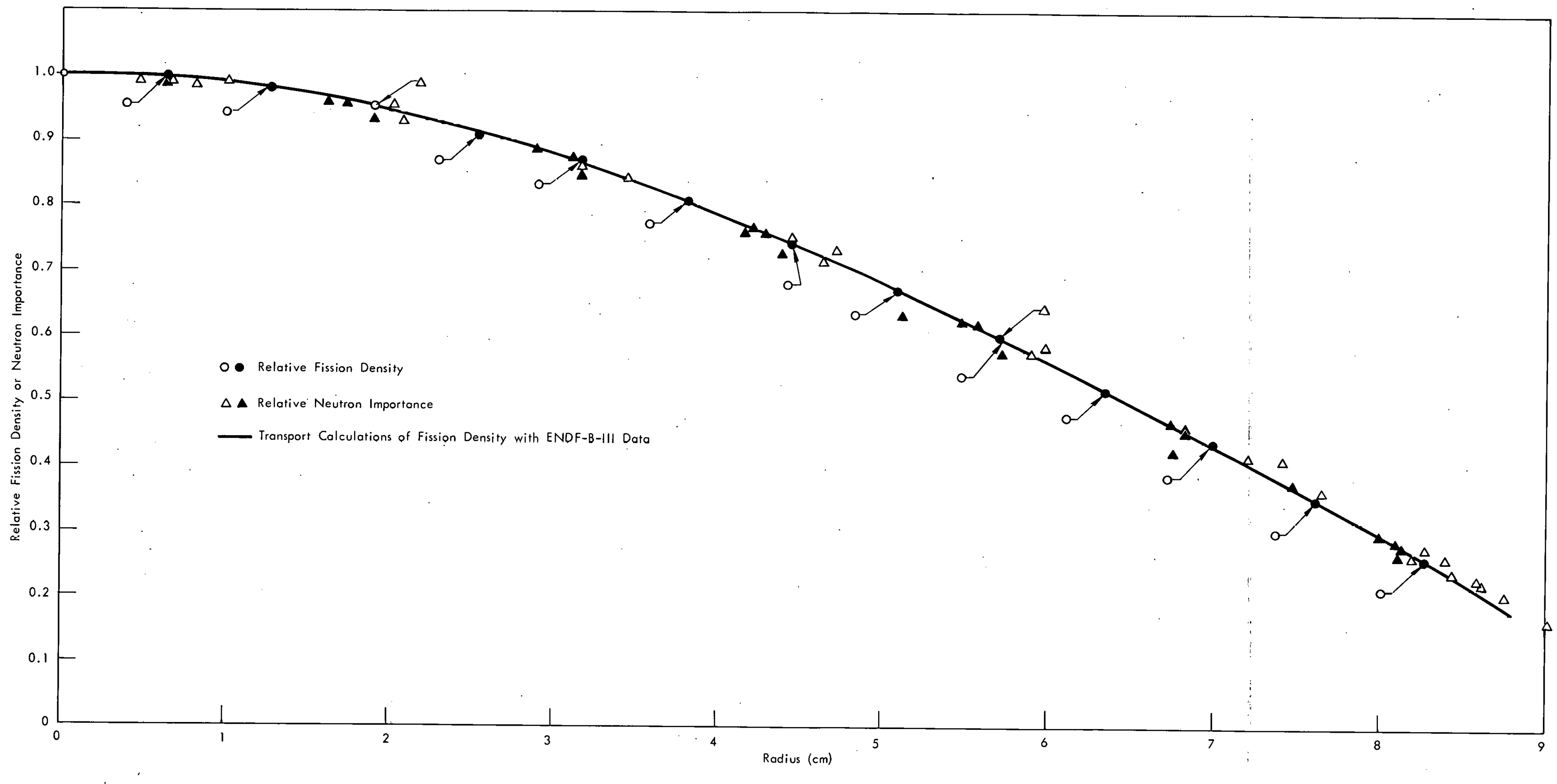

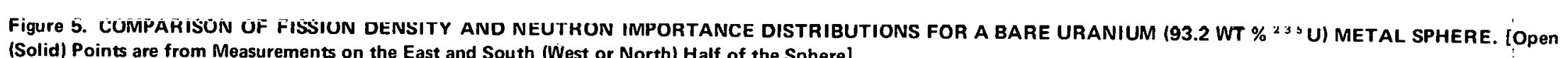


counters were surrounded with cadmium and paraffin or polyethylene shields. The shielding reduced the count rate so that the counting loss correction due to the dead time of the counting channels was $<1 \%$.

The count rate observed was proportional to the sum of the multiplication of neutrons from the spontaneous fission of $240 \mathrm{Pu}$, uniformly distributed throughout the sphere, and of $252 \mathrm{Cf}$. The count rate depended on the reactivity change associated with the californium source position and the temperature of the assembly. To correct for the latter effect, a count was taken at a fixed reference position every second or third count during the measurements. Its variation during a typical measurement at a reactivity of 25 cents subcritical, which required several hours, was less than $5 \%$. Precision of the variation was lueller lliall 3\%.

The effect of the change in redulivity is the snurse was mover thrniog the assembly was determined as follows. The count rate from the multiplication of neutrons from the spontaneous fission of ${ }^{240} \mathrm{Pu}$ was measured as a function of position with an accurate mockup of the source container. Shielding around the counters was removed for these measurements. The results were used to determine the dependence of the count rate on the position of the californium source. At some positions these corrections (known to $<3 \%$ precision) were as large as $14 \%$, with the system at a reactivity of 25 cents subcritical.

Correction for the multiplication of $240 \mathrm{Pu}$ neutrons was accomplished as follows. A count was taken at one position of the mock source with the counters in their cadmium and hydrogenous shields. The count rate due to the spontaneous fission of $240 \mathrm{Pu}$ was obtained from this count and the previously measured dependence of the count rate on position of the mock source. These resulting count rates, which were due to the multiplication of neutrons from spontaneous fission of ${ }^{240} \mathrm{Pu}(\leqslant 2 \%$ of the total), were subtracted from those with the californium sourcc in the assembly to obtain the count rate due to the multiplication of the neutrons from californium.

Measurements were made at two different system reactivities (25 and 50 cents subcritical, see footnotes to Table 3 for loading changes) since the magnitude of both the correction for the reactivity effect of the suurce container and that associated with temperature variation depender strongly on the reactivity of the assembly. Since the spatial distributions of the importance measured at both reactivities were the same, corrections for the reactivity effects were considered adequate.

The relative neutron importance as a function of radius is given in Figure 6 and reported in Table 3. The measurements were normalized to unity at the spliere ceriter. The importance distribution measured was not symmetric about the center of the sphere, since the diametral hole penetrated only $2.54 \mathrm{~cm}$ beyond the sphere center. The measurement technique for the bare uranium spliere, which resulted in symmetric distributions, was not practicable for the bare plutonium sphere due to the geometry of the hole in the assembly and the lack of small fuel pellets to fill the empty part of the hole.

An estimate of the correction for this asymmetry was obtained from Monte Carlo calculations with the MORSE code.(10) The neutron multiplication was calculated in fixed-source calculations as a function of radius in the diametral hole and as a function of 
Table 3

RELATIVE IMPORTANCE OF NEUTRONS FROM 252Cf FISSION AS A FUNCTION OF RADIUS FOR AN UNREFLECTED PLUTONIUM

(4.5 at \% 240Pu) METAL SPHERE

\begin{tabular}{|c|c|c|c|c|c|}
\hline \multirow{2}{*}{$\begin{array}{l}\text { Radius }(1) \\
(\mathrm{cm})\end{array}$} & \multicolumn{4}{|c|}{$\begin{array}{l}\text { Relative Neutron Importance }(2) \text { for } \\
\mathrm{BF}_{3} \text { Proportional Counter }(3)\end{array}$} & \multirow[b]{2}{*}{ Average } \\
\hline & $7^{1(4)}$ & $2^{(5)}$ & $3^{3(6)}$ & $4^{(6)}$ & \\
\hline \multirow[t]{4}{*}{-0.881} & 0.992 & 1.014 & 0.992 & 0.994 & $0.998(7)$ \\
\hline & 1.005 & 1.015 & 1.008 & 1.007 & 1.009 \\
\hline & 1.000 & 1.003 & 0.997 & 0.996 & 0.999 \\
\hline & 1.019 & 1.000 & 0.996 & 0.996 & $\frac{1.003}{1.002} \pm 0.002(8)$ \\
\hline \multirow[t]{4}{*}{-0.605} & 1.002 & 1.013 & 0.999 & 1.005 & 1.005 \\
\hline & 1.001 & 0.995 & 0.998 & 1.004 & 1.004 \\
\hline & 1.012 & 1.006 & 1.003 & 1.004 & 1.004 \\
\hline & 1.005 & 1.007 & 0.999 & 0.999 & $\frac{1.003}{1.003} \pm 0.001$ \\
\hline \multirow[t]{4}{*}{-0.163} & - & . & - & . & - \\
\hline & 1.001 & 1.006 & 0.998 & 1.000 & 1.001 \\
\hline & & - & - & & - \\
\hline & 1.003 & 0.992 & 0.985 & 0.983 & $\frac{0.991}{0.996} \pm 0.005$ \\
\hline 0.030 & 1.000 & 1.000 & 1.000 & 1.000 & 1.000 \\
\hline \multirow[t]{4}{*}{0.665} & 0.970 & 0.974 & 0.975 & 0.977 & 0.974 \\
\hline & 0.977 & 0.988 & 0.970 & 0.970 & 0.978 \\
\hline & 0.965 & 0.976 & 0.975 & 0.975 & 0.970 \\
\hline & 0.981 & 0.975 & 0.969 & 0.968 & $\frac{0.973}{0.975} \pm 0.001$ \\
\hline \multirow[t]{4}{*}{1.300} & 0.928 & 0.929 & 0.931 & 0.934 & 0.930 \\
\hline & 0.938 & 0.958 & 0.933 & 0.938 & 0.942 \\
\hline & 0.933 & 0.935 & 0.933 & 0.931 & 0.933 \\
\hline & 0.942 & 0.942 & 0.930 & 0.935 & $\frac{0.937}{0.936 \pm 0.003}$ \\
\hline \multirow[t]{4}{*}{1.94} & 0.868 & 0.868 & 0.872 & 0.875 & 0.871 \\
\hline & 0.866 & 0.874 & 0.868 & 0.865 & 0.868 \\
\hline & 0.872 & 0.871 & 0.871 & 0.872 & 0.871 \\
\hline & 0.865 & 0.865 & 0.866 & 0.863 & $\frac{0.865}{0.869} \pm 0.002$ \\
\hline \multirow{4}{*}{2.57} & 0.788 & 0.790 & 0.792 & 0.795 & 0.791 \\
\hline & 0.797 & 0.804 & 0.802 & 0.796 & 0.800 \\
\hline & 0.790 & 0.790 & 0.788 & 0.789 & 0.789 \\
\hline & 0.782 & 0.791 & 0.790 & 0.790 & $\frac{0.788}{0.792} \pm 0.003(8)$ \\
\hline \multirow[t]{4}{*}{3.21} & 0.699 & 0.697 & 0.701 & 0.703 & 0.700 \\
\hline & 0.697 & 0.704 & 0.696 & 0.696 & 0.698 \\
\hline & 0.694 & 0.693 & 0.691 & 0.695 & 0.693 \\
\hline & 0.693 & 0.690 & 0.687 & 0.688 & $\frac{0.690}{0.695}_{ \pm 0.002}$ \\
\hline \multirow[t]{4}{*}{3.84} & 0.600 & 0.598 & 0.602 & 0.604 & 0.601 \\
\hline & 0.587 & 0.605 & 0.589 & 0.585 & 0.592 \\
\hline & 0.594 & 0.594 & 0.591 & 0.594 & 0.593 \\
\hline & 0.582 & 0.578 & 0.579 & 0.578 & $\frac{0.579}{0.591} \pm 0.005$ \\
\hline \multirow[t]{4}{*}{4.48} & 0.493 & 0.493 & 0.495 & 0.499 & 0.495 \\
\hline & 0.485 & 0.489 & 0.486 & 0.485 & 0.486 \\
\hline & 0.487 & 0.487 & 0.486 & 0.488 & 0.487 \\
\hline & 0.501 & 0.516 & 0.514 & 0.510 & $\frac{0.510}{0.495} \pm 0.006$ \\
\hline \multirow[t]{4}{*}{5.11} & 0.382 & 0.382 & 0.384 & 0.386 & 0.384 \\
\hline & 0.373 & 0.383 & 0.372 & 0.373 & 0.375 \\
\hline & 0.378 & 0.378 & 0.376 & 0.379 & 0.378 \\
\hline & 0.366 & 0.363 & 0.361 & 0.365 & $\frac{0.364}{0.375} \pm 0.004$ \\
\hline \multirow[t]{4}{*}{5.75} & 0.273 & 0.271 & 0.273 & 0.275 & 0.273 \\
\hline & 0.265 & 0.267 & 0.264 & 0.264 & 0.265 \\
\hline & 0.265 & 0.265 & 0.263 & 0.267 & 0.265 \\
\hline & 0.255 & 0.251 & 0.251 & 0.252 & $\frac{0.253}{0.264} \pm 0.004$ \\
\hline \multirow[t]{4}{*}{6.09} & 0.216 & 0.215 & 0.216 & 0.219 & 0.216 \\
\hline & 0.209 & 0.210 & 0.210 & 0.209 & 0.209 \\
\hline & 0.212 & 0.211 & 0.210 & 0.213 & 0.212 \\
\hline & 0.199 & 0.198 & 0.195 & 0.198 & $\frac{0.198}{0.209} \pm 0.004$ \\
\hline \multirow[t]{4}{*}{6.38} & 0.185 & 0.184 & 0.184 & 0.186 & 0.185 \\
\hline & 0.177 & 0.180 & 0.178 & 0.178 & 0.178 \\
\hline & 0.179 & 0.179 & 0.178 & 0.180 & 0.179 \\
\hline & & - & - & - & $\frac{\cdot}{0.181} \pm 0.002$ \\
\hline
\end{tabular}

(1) Minus sign refers to values beyond the center of the sphere.

(2) Normalized to 1.000 at a radius of $0.030 \mathrm{~cm}$. Four traverses were made, two with the reactivity at -25 cents and two with the reactivity at -50 cents. The entries on the first two lines for any radius are for the lower reactivity while the third and fourth lines are for the higher reactivity.

(3) For each measurement, 3 to 6 counts of $>10^{5}$ were obtained in each counter. The configuration of JEZEBEL for the -50-cent reactivity was one thin polar disc on top, one thick polar disc on the bottom, all mass adjustment holes filled with plutonium except one which contained a one-half split $235 \mathrm{U}$ slug and a one-half split 239 Pu slug, control rod fully inserted.

Configuration of JEZEBEL for the-25-cent reactivity was two thin polar discs on top, one thick polar disc on the bottom, six of eight lower mass adjustment holes filled with plutonium, four of five upper mass adjustment holes filled with plutonium, control rod fully inserted.

(4) Located perpendicular to the axis of the diametral hole about $305 \mathrm{~cm}$ from the sphere and $457 \mathrm{~cm}$ above the floor.

(5) Located along the extension of the axis of the diametral hole on the side where the hole penetrates the surface, about $305 \mathrm{~cm}$ from the sphere and $30.5 \mathrm{~cm}$ from the floor.

(6) Located along the extension of the axis of the diametral hole on the side where the hole does not penetrate the surface, about $305 \mathrm{~cm}$ from the sphere and $244 \mathrm{~cm}$ above the floor.

(7) These values are the average of the previous four entries.

(8) These values are an average of all values listed at any radius. The error given is the precision based on repeated measurements. 


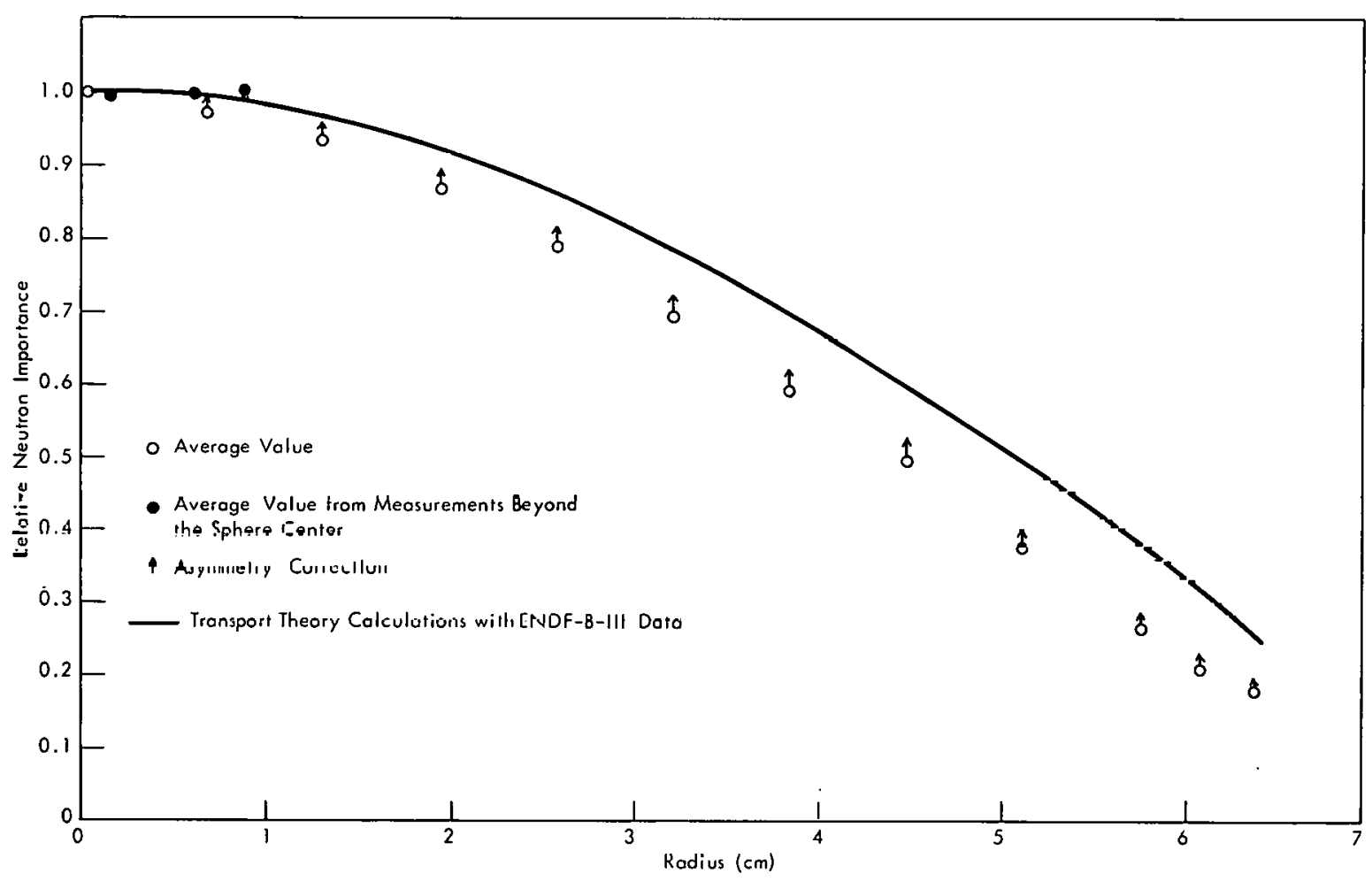

Figure 6. RELATIVE IMPORTANCE OF NEUTRONS FROM $2^{25} \mathrm{Cf}$ FISSION AS A FUNCTION OF RADIUS FOR AN UNREFLECTED PLUTONIUM (4.5 AT \% ${ }^{240}$ PU) METAL SPHERE.

position on a radius vector perpendicular to the diametral hole. The ratio of the value at a radius, $r$, perpendicular to the hole to that at the same radius in the diametral hole was used to correct the experimental results for comparison with calculated values. Comparison of the experimenl, aftẹt correctlons, with the calrulated results showed that the distribution was still asymmetric.

\section{Fission Density for the Bare Plutonium Sphere}

Spatial distribution of the fission density was obtained by Hansen and Helmick (11) from activation of $0.25-\mathrm{cm}$-diameter uranium (9.3.2 wt \% $235(\mathrm{~J})$-molybdenum alloy wire and counting the activity with a wire scanner. Fission density in the plutonium was obtained by multiplying the measured results by the ralculaten ratio of plutonium fission density to uranium fission density. These calculations showed that the relative tission density of plutonium was higher than that of uranium for radii $70,80,90,95$, and $100 \%$ of the sphere radius by $0.17,0.28,0.48,0.65$, and $1.0 \%$, respectively. Thus, the relative fission density distributions for uranium and plutonium are similar except for small differences near the outer surfaces of the spheres. The measured relative fission density distribution is compared to that calculated for uranlum (93.2) in Figure 7 and is also listed in Table 4. The measured values near the outside surface of the sphere are larger than calculated, probably due to the fact that the irradiated wire extended beyond the surface and also due to deviations of the assembly from sphericity at the equator. 


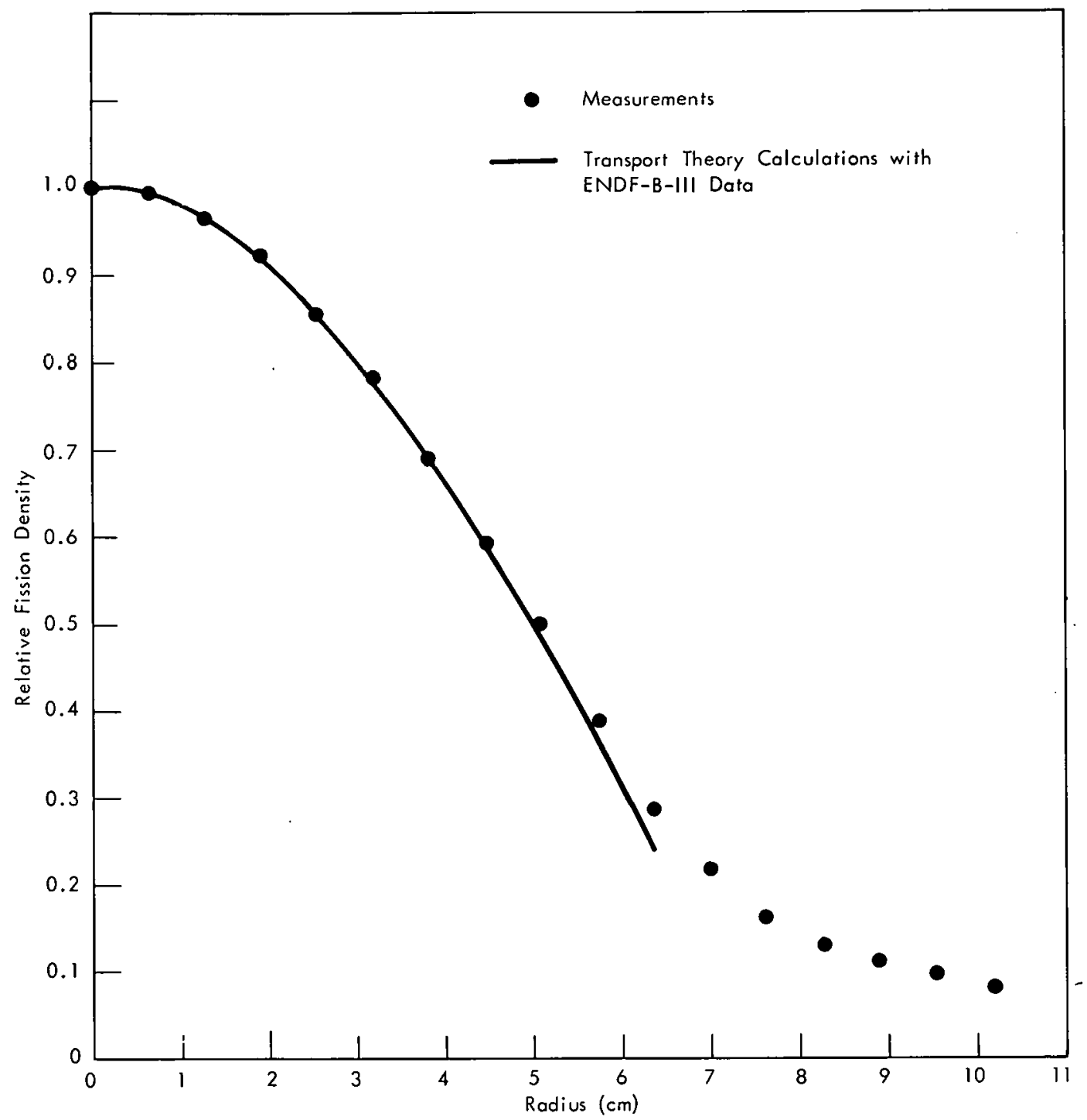

Figure 7. RELATIVE FISSION PRODUCT ACTIVITY OF URANIUM (93.2) AS A FUNCTION OF RADIUS FOR AN UNREFLECTẼ PLUUTONIUMM (4.5 AT \% « U PU) METAL SPHERE.

\section{Neutron Importance for the Reflected Uranium Sphere}

The natural-uranium-reflected uranium $\left(93.2\right.$ wt $\left.\%{ }^{235} \mathrm{U}\right)$ metal sphere was the FLATTOP(12) assembly at LASL. The natural uranium reflector was $17.78 \mathrm{~cm}$ thick. The neutron importance was measured with the $0.3-\mu \mathrm{g}{ }^{252} \mathrm{Cf}$ source located in a $0.356-\mathrm{cm}$-diameter diametral hole which penetrated through the core and one side of the reflector. The source was pushed through one side of the reflector and through the core with a thin-walled stainless steel tube attached externally to an electric-motor-powered screw drive.

Two BF 3 counters were located along the axis of the diametral hole and two perpendicular to it, each about $305 \mathrm{~cm}$ from the assembly. The count rates were corrected for the 
dependence of reactivity on the source position. This correction was obtained from measurements of the reactivity change when an empty source container was located at various positions in a delayed critical system.

The contribution to the count rate from the multiplied spontaneous fission neutron of the uranium reflector $(\ll 1 \%)$ was subtracted from the count rate with the californium source present. The relative neutron importance as a function of radius is plotted in Figure 8 and listed in Table 5. It did not depend on the location of the detectors, even with the source at the outside edge of the reflector due to the high neutron multiplication $(\sim 20$ cents subcritical) of the sphere in these measurements.

\section{Fission Density for the Reflected Uranium Sphere}

The fission density, previously measured by Barton and Jarvis(1) at LASL as a function of radius, is listed in Table 6 and plotted in Figure 9.

\section{Neutron Importance for the Reflected Pluton-} iurn Sphere

The natural-uranium-reflected plutonium $(4.8$ at $\left.\%{ }^{240} \mathrm{Pu}\right)$ metal sphere was the FLAT. TOP(12) assembly with the plutonium core at LASL. For these measurements, the $53 \mu \mathrm{g}$ ${ }^{252} \mathrm{Cf}$ source was used, and the measurement methods were identical to those used for the bare plutonium sphere. However, the corrections due to the reactivity effect of the source $(<27 \%)$ were larger, and the contribution of the multiplied neutrons from spontaneous fission of $240 \mathrm{Pu}$ was as much as $50 \%$ at the outer edge of the reflector. The correction for the temperature variation during the measurements was as large as $8 \%$. Results of these measurements are given in Figure 10 and listed in Table 7.

\section{Fission Density for the Reflected Plutonium Sphere}

The fission density, previously measured at LASL(1) as a function of radius, is listed in Table 6 and plotted in Figure 11.
Table 4

RELATIVE FISSION PRODUCT ACTIVITY OF 235U AS A FUNCTION OF RADIUS FOR AN UNREFLECTED PLUTONIUM (4.5 AT \% 240 Pu) METAL SPHERE

\begin{tabular}{cl}
\hline $\begin{array}{c}\text { Radius } \\
(\mathrm{cm})\end{array}$ & $\begin{array}{c}\text { Relative Fission } \\
\text { Density }(1)\end{array}$ \\
\hline & \\
0.00 & $1.000(1.000)(2)$ \\
0.64 & $0.994(0.994)$ \\
1.27 & $0.968(0.965)$ \\
1.91 & $0.921(0.919)$ \\
2.54 & $0.856(0.856)$ \\
3.18 & $0.784(0.778)$ \\
3.81 & $0.693(0.689)$ \\
4.45 & $0.597(0.590)$ \\
5.08 & $0.500(0.485)$ \\
5.72 & $0.389(0.372)$ \\
6.35 & $0.289(0.243)$ \\
$6.98(3)$ & 0.217 \\
7.62 & 0.164 \\
8.26 & 0.134 \\
8.89 & 0.113 \\
9.53 & 0.095 \\
10.16 & 0.081 \\
\hline
\end{tabular}

(1) Measured by Hansen and Helmick (11) using U(93.2 wt \%)-Mo wire.

(2) Values in parentheses are from transport theory calculations with ENDF-B-III cross sections.

(3) Relative fission product activity at the 6.98-10.16 radii beyond the sphere surface was obtained by activating the U-Mo wire outside the sphere. 


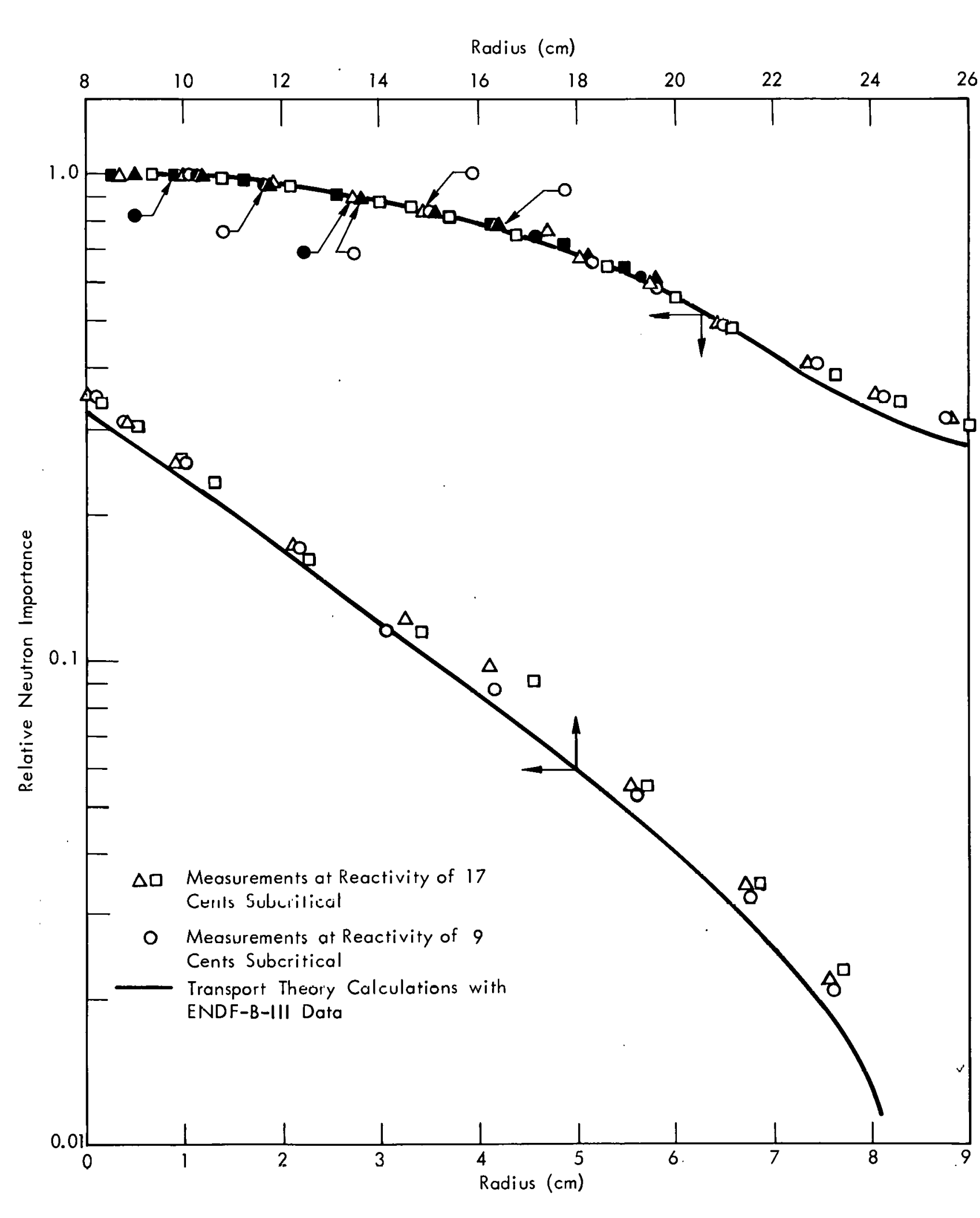

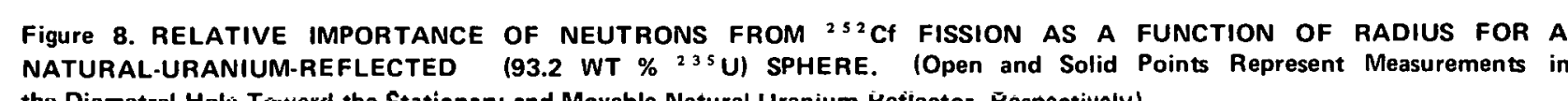

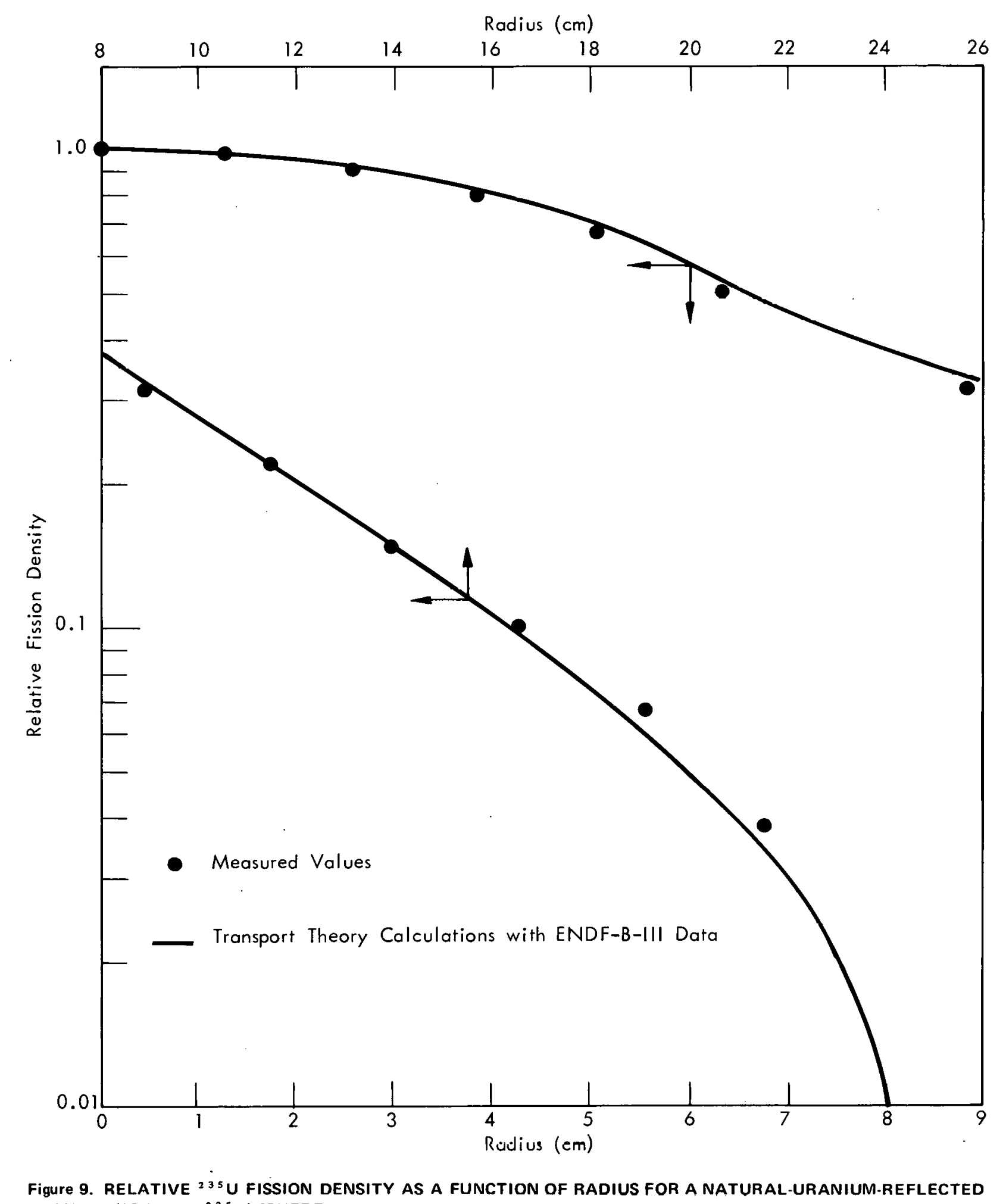

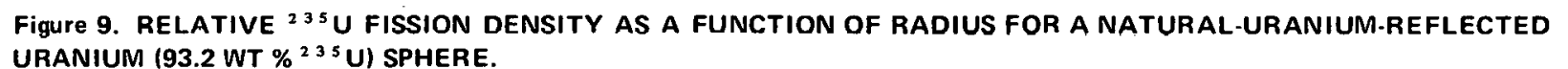

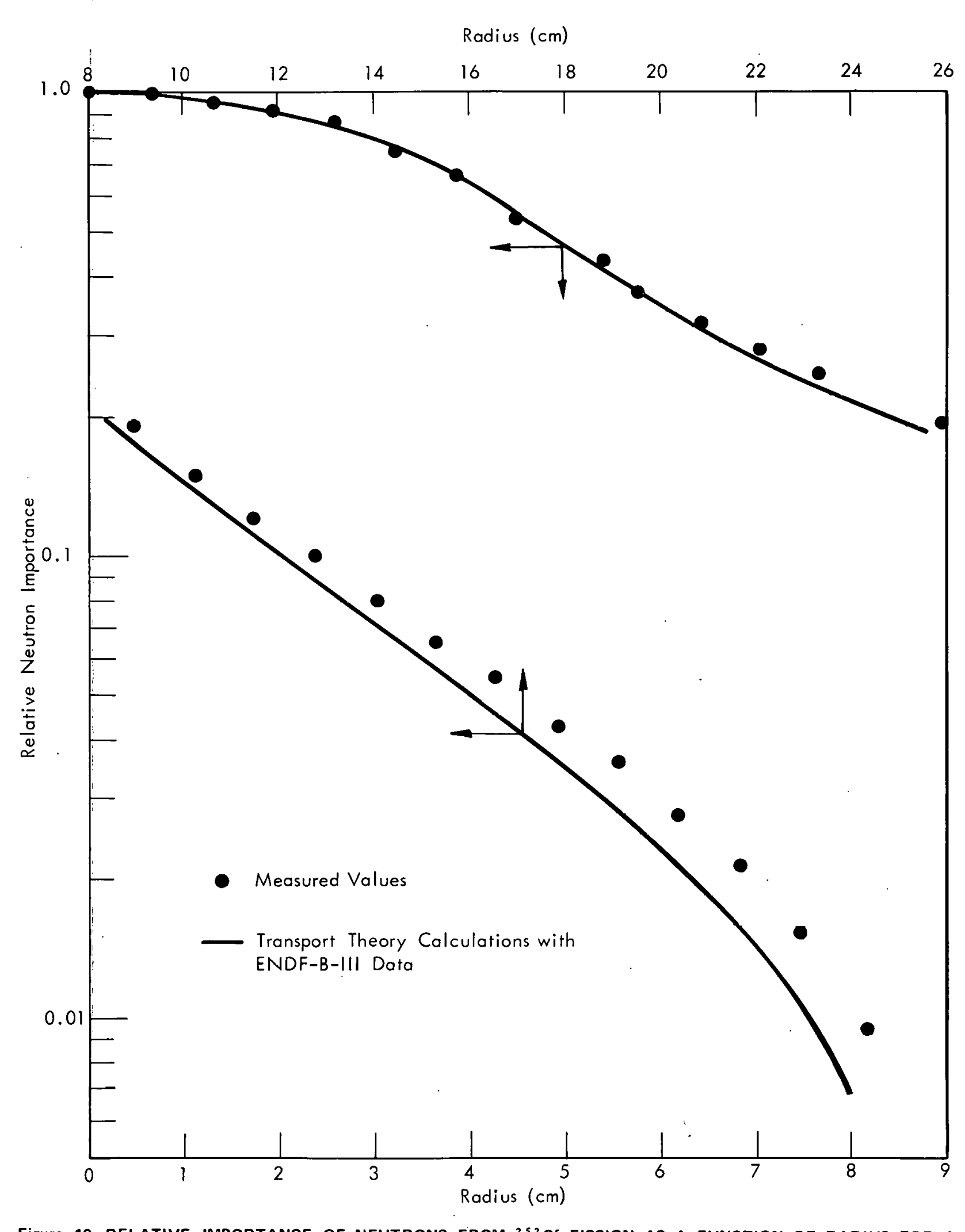

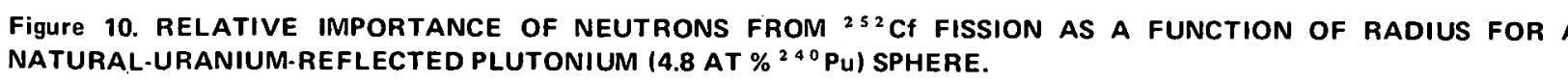


Table 5

RELATIVE IMPORTANCE OF NEUTRONS FROM ${ }^{252}$ Cf FISSION AS A FUNCTION OF RADIUS FOR A NATURAL-IJRANIUM-REFLECTED URANIUM (93.2 WT \% 235 $\mathrm{iJ}$ ) METAL SPHERE

\begin{tabular}{|c|c|c|c|c|c|c|}
\hline \multirow{2}{*}{$\begin{array}{c}\text { Radius }(1) \\
(\mathrm{cm})\end{array}$} & \multicolumn{4}{|c|}{$\begin{array}{l}\text { Relative Neutron Importance for } \\
\mathrm{EF}_{3} \text { Proportional Counter }(2)\end{array}$} & \multirow{2}{*}{\multicolumn{2}{|c|}{ Average $(5)$}} \\
\hline & $1^{(3)}$ & $2^{(3)}$ & $3^{(4)}$ & $4^{(4)}$ & & \\
\hline$-5.796(1)(6)$ & 0.612 & 0.613 & 0.610 & 0.610 & 0.611 & \pm 0.001 \\
\hline$-5.687(3)$ & 0.616 & 0.614 & 0.616 & 0.615 & 0.615 & \pm 0.001 \\
\hline$-5.492(2)$ & 0.643 & 0.643 & 0.645 & 0.640 & 0.643 & \pm 0.001 \\
\hline$-5.117(1)$ & 0.684 & 0.683 & 0.683 & 0.683 & 0.683 & \pm 0.001 \\
\hline$-4.856(2)$ & 0.721 & 0.724 & 0.724 & 0.722 & 0.723 & \pm 0.001 \\
\hline$-4.579(3)$ & C.746 & 0.744 & 0.744 & 0.744 & 0.745 & \pm 0.001 \\
\hline$-4.193(1)$ & C.784 & 0.783 & 0.780 & 0.784 & 0.783 & \pm 0.001 \\
\hline$-4.141(2)$ & C.788 & 0.795 & 0.792 & 0.791 & 0.792 & \pm 0.001 \\
\hline$-3.524(1)$ & 0.842 & 0.845 & 0.842 & 0.844 & 0.843 & \pm 0.001 \\
\hline$-3.424(3)$ & 0.849 & 0.853 & 0.853 & 0.850 & $0.85 ?$ & \pm 0.001 \\
\hline$-3.333(2)$ & 0.864 & 0.867 & 0.866 & 0.864 & 0.865 & \pm 0.001 \\
\hline$-2.808(1)$ & 0.900 & 0.900 & 0.898 & 0.902 & 0.900 & \pm 0.001 \\
\hline$-2.731(3)$ & 0.905 & 0.902 & 0.904 & 0.905 & 0.904 & \pm 0.001 \\
\hline$-2.571(2)$ & 0.915 & 0.922 & 0.919 & 0.919 & 0.919 & \pm 0.001 \\
\hline$-1.884(1)$ & 0.955 & 0.953 & 0.954 & 0.959 & 0.955 & \pm 0.001 \\
\hline$-1.831(3)$ & 0.975 & 0.959 & 0.964 & 0.958 & 0.964 & \pm 0.004 \\
\hline$-1.624(2)$ & 0.972 & 0.975 & 0.973 & 0.972 & 0.973 & \pm 0.001 \\
\hline$-1.192(1)$ & 0.982 & 0.988 & 0.982 & 0.984 & $0.98<$ & \pm 0.001 \\
\hline$-1.115(3)$ & 0.983 & 0.985 & 0.986 & 0.981 & 0.984 & \pm 0.001 \\
\hline$-0.931(2)$ & $0: 991$ & 0.996 & 0.993 & 0.992 & $0.99 \Xi$ & \pm 0.001 \\
\hline$-0.498(1)$ & 0.996 & 0.998 & 0.997 & 0.993 & 0.996 & \pm 0.001 \\
\hline$-0.447(3)$ & 0998 & 1.000 & 0.998 & 1.004 & 1.000 & \pm 0.001 \\
\hline$-0.238(2)$ & 1001 & 1.010 & 0.999 & 0.999 & $1.00 \bar{z}$ & \pm 0.003 \\
\hline$-0.088(3)$ & 1000 & 0.998 & 1.002 & 0.998 & $1.00 \mathrm{C}$ & \pm 0.001 \\
\hline $0: 0$ & 1.000 & 1.000 & 1.000 & 1.000 & $1.00 \mathrm{C}$ & \\
\hline $0.067(1)$ & 1.002 & 1.000 & 0.998 & 0.999 & $1.00 \mathrm{C}$ & \pm 0.001 \\
\hline $0.662(2)$ & 0.990 & 0.996 & 0.996 & 0.996 & 0.995 & \pm 0.002 \\
\hline $0.979(1)$ & 0.990 & 0.990 & 0.988 & 0.989 & 0.989 & \pm 0.001 \\
\hline $1.055(3)$ & 0.991 & 0.993 & 0.993 & 0.989 & 0.992 & \pm 0.001 \\
\hline $1.378(2)$ & 0.971 & 0.978 & 0.977 & 0.979 & 0.976 & \pm 0.002 \\
\hline $1.810(1)$ & G.962 & 0.963 & 0.960 & 0.962 & 0.962 & \pm 0.001 \\
\hline $1.887(3)$ & 0.955 & 0.952 & 0.955 & 0.953 & 0.954 & \pm 0.001 \\
\hline $2.071(2)$ & 0.946 & 0.951 & 0.948 & 3.951 & 0.949 & \pm 0.001 \\
\hline $2.734(1)$ & 0.901 & 0.902 & 0.902 & J.903 & 0.902 & \pm 0.001 \\
\hline $2.810(3)$ & a.891 & 0.887 & 0.888 & 3.887 & 0.888 & \pm 0.001 \\
\hline $2.994(2)$ & 0.876 & 0.882 & 0.880 & 0.878 & 0.879 & \pm 0.001 \\
\hline $3.427(1)$ & 0.851 & 0.846 & 0.855 & 0.842 & 0.849 & \pm 0.003 \\
\hline $3.503(3)$ & 0.839 & 0.835 & 0.839 & 0.837 & 0.838 & \pm 0.001 \\
\hline $3.687(2)$ & 0.817 & 0.823 & 0.822 & 0.822 & 0.821 & \pm 0.001 \\
\hline $4.196(3)$ & 0.767 & 0.767 & 0.767 & 0.764 & 0.766 & \pm 0.001 \\
\hline $4.357(2)$ & 0.756 & 0.759 & 0.759 & 0.759 & 0.758 & \pm 0.001 \\
\hline $4.703(1)$ & 0.780 & 0.781 & 0.781 & 0.782 & 0.781 & \pm 0.001 \\
\hline $5.043(1)$ & 0.576 & 0.677 & 0.675 & 0.678 & 0.677 & \pm 0.001 \\
\hline $5.118(3)$ & 0.566 & 0.665 & 0.666 & 0.662 & 0.665 & \pm 0.001 \\
\hline $5.303(2)$ & 0.544 & 0.648 & 0.646 & 0.648 & 0.647 & \pm 0.001 \\
\hline $5.736\{1\}$ & 0.592 & 0.591 & 0.614 & 0.594 & 0.598 & \pm 0.005 \\
\hline $5.312(3)$ & 0.580 & 0.578 & 0.580 & 0.579 & 0.579 & \pm 0.001 \\
\hline $5.996(2)$ & 0.556 & 0.557 & 0.556 & 0.557 & 0.557 & \pm 0.001 \\
\hline $6.428(1)$ & 0.497 & 0.497 & 0.499 & 0.498 & 0.498 & \pm 0.001 \\
\hline $6.505(3)$ & 0.492 & 0.489 & 0.491 & 0.489 & 0.490 & \pm 0.001 \\
\hline $6.573(2)$ & 0.485 & 0.484 & 0.480 & 0.484 & 0.483 & \pm 0.001 \\
\hline $7.352(1)$ & 0.404 & 0.403 & 0.404 & 0.404 & 0.404 & \pm 0.001 \\
\hline $7.429(3)$ & 0.401 & 0.406 & 0.400 & 0.399 & 0.402 & \pm 0.002 \\
\hline $7.613(2)$ & 0.388 & C.388 & 0.387 & 0.388 & 0.388 & \pm 0.001 \\
\hline $8.045(1)$ & 0.356 & C.356 & 0.357 & 0.357 & 0.357 & \pm 0.001 \\
\hline $8.118(3)$ & 0.348 & 0.348 & 0.349 & 0.348 & 0.348 & \pm 0.001 \\
\hline $8.305(2)$ & 0.342 & 0.342 & 0.340 & C. 342 & 0.342 & \pm 0.001 \\
\hline $8.737(1)$ & 0.315 & 0.312 & 0.313 & C.314 & 0.314 & \pm 0.001 \\
\hline $8.791(3)$ & 0.310 & 0.310 & 0.312 & 0.311 & 0.311 & \pm 0.001 \\
\hline $8.998(2)$ & 0.304 & 0.304 & 0.301 & 0.302 & 0.303 & \pm 0.001 \\
\hline $9.845(1)$ & 0.259 & 0.259 & 0.260 & C. 260 & 0.260 & \pm 0.001 \\
\hline $9.898(2)$ & 0.263 & 0.262 & 0.262 & 0.263 & 0.263 & \pm 0.001 \\
\hline $9.969(3)$ & 0.252 & 0.251 & 0.253 & $a .251$ & 0.252 & \pm 0.001 \\
\hline $10.614(2)$ & 0.233 & $0: 233$ & 0.231 & 0.232 & 0.232 & \pm 0.001 \\
\hline $12.201(1)$ & 0.174 & 0.173 & 0.174 & a.174 & 0.174 & \pm 0.001 \\
\hline $12.278(3)$ & 0.171 & 0.171 & 0.173 & 0.171 & 0.172 & \pm 0.001 \\
\hline $12.462(2)$ & 0.172 & 0.171 & 0.172 & 0.172 & 0.172 & \pm 0.001 \\
\hline $14.074(3)$ & 0.115 & 0.114 & 0.114 & $0: 115$ & 0.115 & \pm 0.001 \\
\hline $14.510(1)$ & 0.120 & 0.121 & 0.121 & 0.121 & 0.121 & \pm 0.001 \\
\hline $14.771(2)$ & 0.119 & 0.119 & 0.119 & 0119 & 0.119 & \pm 0.001 \\
\hline $16.219(1)$ & 0.0928 & 0.0928 & 0.0938 & 00933 & 0.0932 & \pm 0.0002 \\
\hline $16.296(3)$ & 0.0876 & $0: 0868$ & 0.0887 & 0.0879 & 0.0878 & \pm 0.0004 \\
\hline $17.080(2)$ & 0.0820 & 0.0817 & 0.0816 & 0.0818 & 0.0818 & \pm 0.0001 \\
\hline $19.128(1)$ & 0.0553 & 0.0551 & 0.0554 & 0.0556 & 0.0554 & \pm 0.0001 \\
\hline $19.205(3)$ & 0.0520 & 0.0515 & 0.0534 & 0.0529 & 0.0525 & \pm 0.0004 \\
\hline $19.366(2)$ & 0.0549 & 0.0548 & 0.0561 & 0.0551 & 0.0552 & \pm 0.0003 \\
\hline $21.437(1)$ & 0.0339 & 0.0336 & 0.0350 & 0.0342 & 0.0342 & \pm 0.0003 \\
\hline $21.514(3)$ & 0.0 .324 & 0.0316 & 0.0330 & 0.0331 & 0.0325 & \pm 0.0003 \\
\hline $21.698(2)$ & 0.0344 & 0.0345 & 0.0355 & 0.0352 & 0.0349 & \pm 0.0003 \\
\hline $23.146(1)$ & 0.0217 & 0.0212 & 0.0222 & 0.0220 & 0.0218 & \pm 0.0002 \\
\hline $23.218(3)$ & 0.0202 & 0.0202 & 0.0210 & 0.0213 & 0.0207 & \pm 0.0003 \\
\hline $23.406(2)$ & 0.0228 & 0.0224 & 0.0234 & 0.0231 & 0.0229 & \pm 0.0002 \\
\hline
\end{tabular}

(1) Minus sign refers to radii in the diametral hole between the sphere center and th:e sphere surface adjacent to the movable reflector. Positive radii in the diametral hole are between the sphere center and the sphere surface adjacent to the stationary reflector.

(2) Normalized to 1.000 at the center. Three traverses were made, two with the reactivity at -17 cents and one with the reactivity at -9 cents.

(3) Located along the extension of the diametral hole through the movable reflector about $305 \mathrm{~cm}$ from the assembly anc $\sim 183 \mathrm{~cm}$ above the floor.

(4) Located perpendicular to the axis of the diametral hole about $305 \mathrm{~cm}$ from the assembly and $\sim 183 \mathrm{~cm}$ above the floor.

(5) Average of the previous four entries.

6) Numbers in parentheses indicate in which traverse the importance was measured. Traverses with the reactivity of -17 cents are indicated by $(\hat{i})$ and $(2)$ and that for reactivity of $-9 \mathrm{c} \in \mathrm{n}$ ts by $(3)$. 
Table 6

FISSION DENSITY OF 235U AS A FUNCTION REFLECTED URANIUM AND
PLUTONIUM SPHERES

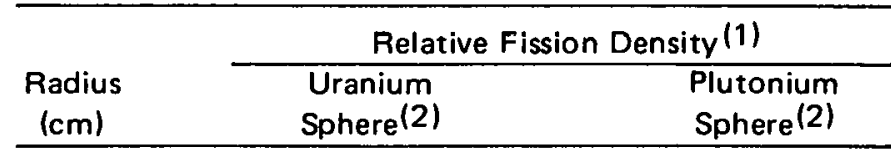

\begin{tabular}{|c|c|c|c|c|}
\hline & 1.000 & $(1.000 /(3)$ & 1.000 & \\
\hline $\begin{array}{l}1.27 \\
254\end{array}$ & 0.962 & $(0.981)$ & 0.943 & $(0.967)$ \\
\hline & & $(0.820)$ & & 0.07001 \\
\hline & & $(0.692)$ & 0.454 & $(0.484)$ \\
\hline & 0.503 & $(0.539)$ & & $(0.359)$ \\
\hline & 0.396 & $(0.409)$ & 0.265 & $(0.280)$ \\
\hline & 0.315 & (0.329) & 0.175 & \\
\hline 11.43 & 0.220 & $(0.220)$ & & $(0.180)$ \\
\hline & & & 0.123 & $(0.119)$ \\
\hline $\begin{array}{l}13.97 \\
15.24\end{array}$ & 0.147 & $(0.147)$ & 0.0843 & | 10.782$)$ \\
\hline & 0.103 & $(0.097)$ & & \\
\hline & 0.0670 & $(0.0603)$ & 0.05 & 0.498) \\
\hline 20.32 & 00385 & $(0327)$ & $\begin{array}{l}0.334 \\
0.0243\end{array}$ & $\begin{array}{l}(1.2922) \\
(0.0209\end{array}$ \\
\hline
\end{tabular}

(1) Normalized to unity at the sphere center. These values

(2) These systems were the FLATTOP assembly of LASL

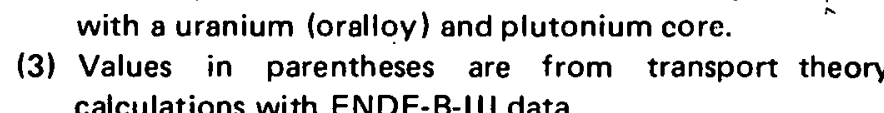

Table 7

RELATIVE IMPORTANCE OF NEUTRONS FROM 202 CF FISSION AS A FUNCTION

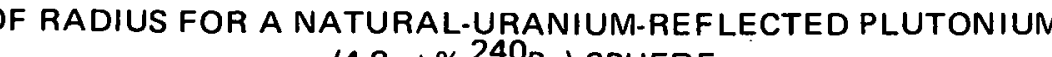

\begin{tabular}{|c|c|c|c|c|c|}
\hline \multirow{2}{*}{$\begin{array}{l}\text { Radius(1) } \\
(\mathrm{cm})\end{array}$} & \multicolumn{4}{|c|}{ 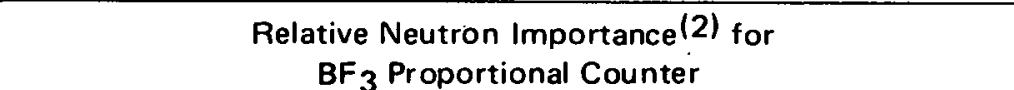 } & \multirow[b]{2}{*}{ Average } \\
\hline & $1^{(3)}$ & $\frac{2^{(3)}}{4}$ & $3^{(4)}$ & $4(5)$ & \\
\hline-2.76 & 0.833 & 0.834 & 0.833 & 0.833 & $0.833 \pm 0.001$ \\
\hline-2.48 & 0.860 & 0.855 & 0.857 & 0.857 & $0.857 \pm 0.001$ \\
\hline-1.85 & 0.915 & 0.913 & 0.912 & 0.916 & $0.914 \pm 0.001$ \\
\hline-1.21 & 0.953 & 0.958 & 0.959 & 0.959 & $0.957 \pm 0.001$ \\
\hline & 0.989 & 0.984 & 0.985 & 0.988 & $0.987 \pm 0.001$ \\
\hline 0.056 & 1.000 & 1.000 & 1.000 & 1.000 & $1.000 \pm 0.001$ \\
\hline 0.69 & 0.995 & 0.997 & 0.999 & 0.997 & $0.997 \pm 0.001$ \\
\hline & & & & & \\
\hline 1.96 & 0.932 & 0.926 & 0.929 & 0.928 & $0.929 \pm 0.001$ \\
\hline 2.60 & 0.866 & 0.864 & 0.866 & 0.864 & $0.865 \pm 0.001$ \\
\hline 3.23 & 0.745 & 0.742 & 0.745 & 0.744 & $0.744 \pm 0.001$ \\
\hline & & & & & \\
\hline 4.50 & 0.532 & 0.531 & 0.530 & 0.530 & $0.531 \pm 0.001$ \\
\hline 5.4 & & 0.431 & 0.430 & 0.432 & $0.431 \pm 0.001$ \\
\hline 5.77 & 0.370 & 0.369 & 0.367 & 0.368 & $0.369 \pm 0.001$ \\
\hline 6.41 & 0.316 & 0.315 & 0.314 & 0.315 & $0.315 \pm 0.001$ \\
\hline 7.04 & 0.278 & 0.278 & 0.277 & 0.276 & $0.277 \pm 0.001$ \\
\hline 7.68 & 0.246 & 0.245 & 0.244 & 0.245 & $0.245 \pm 0.001$ \\
\hline 8.95 & 0.193 & 0.192 & 0.191 & 0.192 & $0.192 \pm 0.001$ \\
\hline 10.22 & 0.150 & 0.149 & 0.148 & 0.148 & $0.149 \pm 0.001$ \\
\hline 11.49 & 0.122 & 0.121 & 0.120 & 0.121 & $0.121 \pm 0.001$ \\
\hline 12.76 & 0.101 & 0.099 & 0.0984 & 0.0991 & $0.0994 \pm 0.0006$ \\
\hline 14.03 & 0.0819 & 0.0801 & 0.0793 & 0.0800 & $0.0803 \pm 0.0006$ \\
\hline 15.30 & 0.0668 & 0.0648 & 0.0642 & 0.0639 & $0.0649 \pm 0.0007$ \\
\hline 16.57 & 0.0563 & 0.0545 & 0.0534 & 0.0543 & $0.0546 \pm 0.0006$ \\
\hline 17.84 & 0.0445 & 0.0426 & 0.0415 & 0.0415 & $0.0425 \pm 0.0007$ \\
\hline 19.11 & 0.0379 & 0.0356 & 0.0350 & 0.0347 & $0.0358 \pm 0.0007$ \\
\hline 20.38 & 0.0294 & 0.0270 & 0.0264 & 0.0264 & $\begin{array}{l}0.0273 \pm 0.0007 \\
0.0211 \pm 0.000\end{array}$ \\
\hline $\begin{array}{l}21.65 \\
22.92\end{array}$ & 0.0234 & 0.0208 & 0.0201 & 0.0201 & $\begin{array}{l}0.0211 \pm 0.0008 \\
0.0153 \pm 0.0008\end{array}$ \\
\hline $\begin{array}{l}22.92 \\
24.39\end{array}$ & $\begin{array}{l}0.016 \\
0.0108\end{array}$ & $\begin{array}{l}0.0150 \\
0.0095\end{array}$ & $\begin{array}{l}0.0143 \\
0.0088\end{array}$ & $\begin{array}{l}0.0144 \\
0.0086\end{array}$ & $\begin{array}{l}0.0094 \pm 0.0005 \\
0.004\end{array}$ \\
\hline
\end{tabular}

(2) Normalized to unity at a $0.056-c m$ radius.
(3) Located along an extension of the axis of the diametral hole in the direction of the movable reflector about

(4) Located perpendicular to the axis of the diametral hole about $457.5 \mathrm{~cm}$ from the sphere conter and about

(5) Located $\sim 305 \mathrm{~cm}$ above and $\sim 305 \mathrm{~cm}$ along the extension of the axis of the diametral hole in the

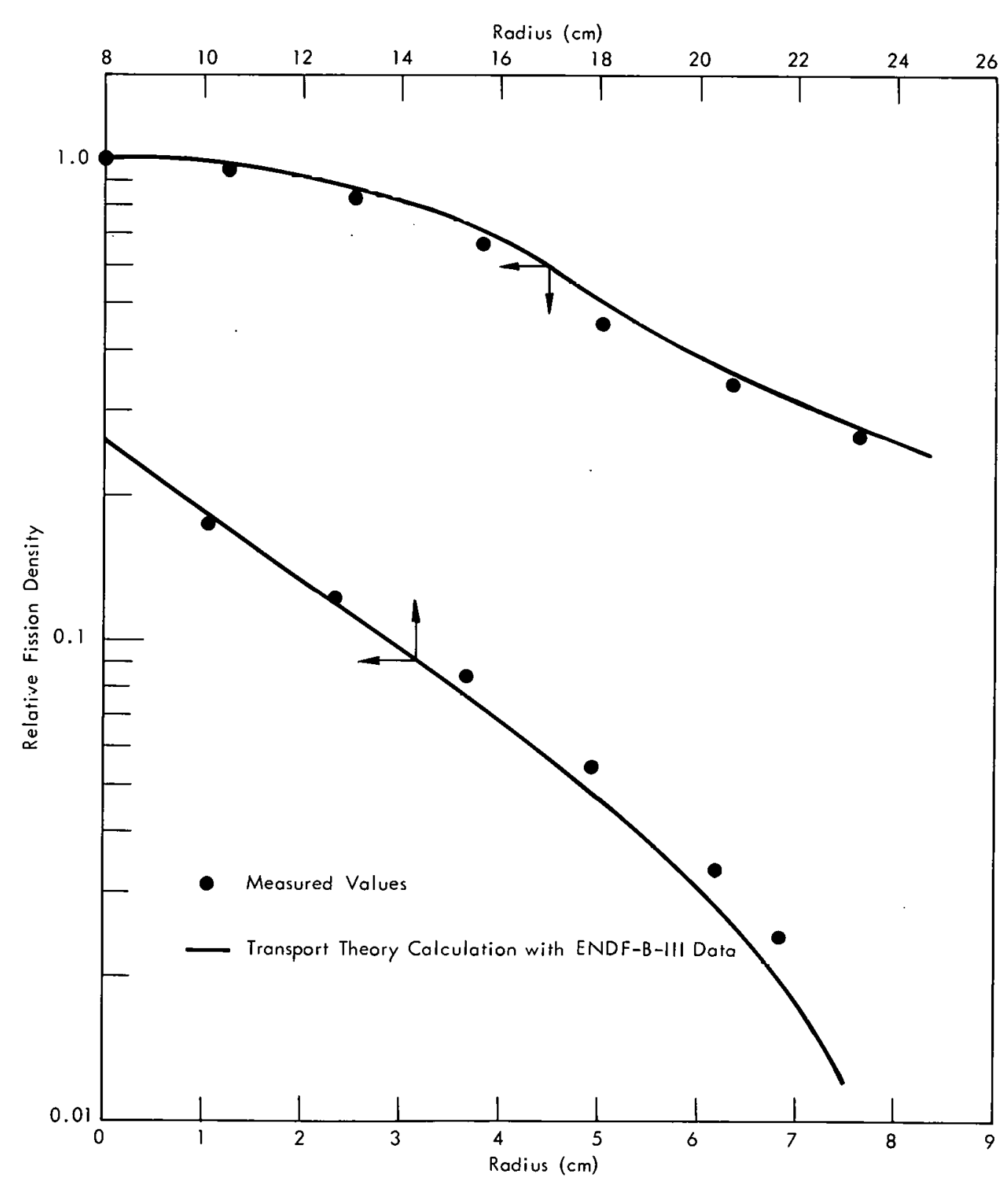

Figure 11. RELATIVE 235 U FISSION DENSITY AS A FUNCTION OO
NATURAL-URANIUM-REFLECTED PLUTTONIUM (4.8 AT\% 200 PUI SPHERE. 


\section{CALCULATED RESULTS}

Fission density and neutron importance were calculated with forward and adjoint fluxes obtained from transport theory calculations (ANISN) with Hansen-Roach 16-group (isotropic scattering) or two 100-group ( $\mathrm{P}_{3}$ scattering) sets of cross sections obtained from ENDF-B-II and ENDF-B-III data. Neutron importance and fission density distributions calculated with ENDF-B-III data are compared with the measurements in Figures 3 through 11. The calculated neutron importance-and fission density distribution are listed in the Appendix for both the bare and natural-uranium-reflected uranium and the plutonium metal spheres.

Dependence of the calculated fission deinsily arrd resutron importance on the order of $\mathrm{S}_{\mathrm{n}}$ and the number of spatial intervals was investigated. Based on this study d!! !d

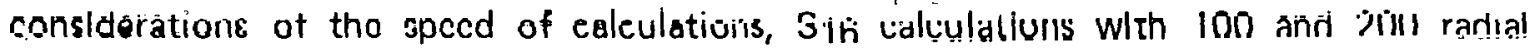
intervals for the bare and reflected spheres, respectively, were subsequently used. These choices were clearly over specifications of both the order of $S_{n}$ and the number of spatial intervals. A convergence criterion of $10^{-5}$ on the flux at all radii was used in all calculations.

Measurements and calculations are in good agreement for the bare spheres except for the neutron importance distribution in the bare plutonium sphere where the calculated values are higher than those measured as radius increased. This discrepanoy rcsultcd from the asymmetric effects in the measurements which could not be properly corrected. Measured fission densities in the reflected uranium and plutonium spheres are as much as 4 and $6 \%$ lower, respectively, than those calculated at the outer edge of the central core. In the natural uranium reflector for both uranium and plutonium spheres at radii larger than $\sim 12 \mathrm{~cm}$, the calculated valuey are lower thain iniedsured. These dlfferences increase with radius; and, at the vuler surface of the natural uranıum reflector, the calculated fission densities are abuul 20\% ligher for both spheres. I he calculated neutron importancc in the central cures of the reflected spheres agreed well with thc measured values; but, in the reflector, the calculated values were lower than the experimental. These differences increase with radius in both reflected. spheres and are as large as 31 and $36 \%$ for the uranium and plutonium spheres, respectively. These differences cannot be attributed to experimental errors, which were $<5 \%$,

\section{Deperidence of the Neutron Importance on the Nuclear Temperature of the Fission} Spectrum

In order to investigate the source of the discrepancies between the measurements and calcuslations for the reflected assemblics, the drpendence of the iruuliun importancc on the nuclear temperature of the "Maxwellian" spectrum, which represents the energy distribution of neutrons from the spontaneous fission of $252 \mathrm{Cf}$, was determined. The accepted value for the nuclear temperature is $1.4 \mathrm{MeV},(8)$ but measurements with values as high as $1.57 \mathrm{MeV}$ have been reported. (13) The ratio of the neutron importance for a temperature of 1.6 or $1.2 \mathrm{MeV}$ to that for a temperature of $1.4 \mathrm{MeV}$ as a function of radius is given for the bare and reflected spheres in Figures 12 and 13, respectively. Changes in the relative neutron importance with nuclear temperature increased with radius and attained values of $\sim 1.25$ and $0.7 \%$ at the radial surfaces for the bare uranium and plutonium spheres, respectively. The relative neutron importance at the outer surface 


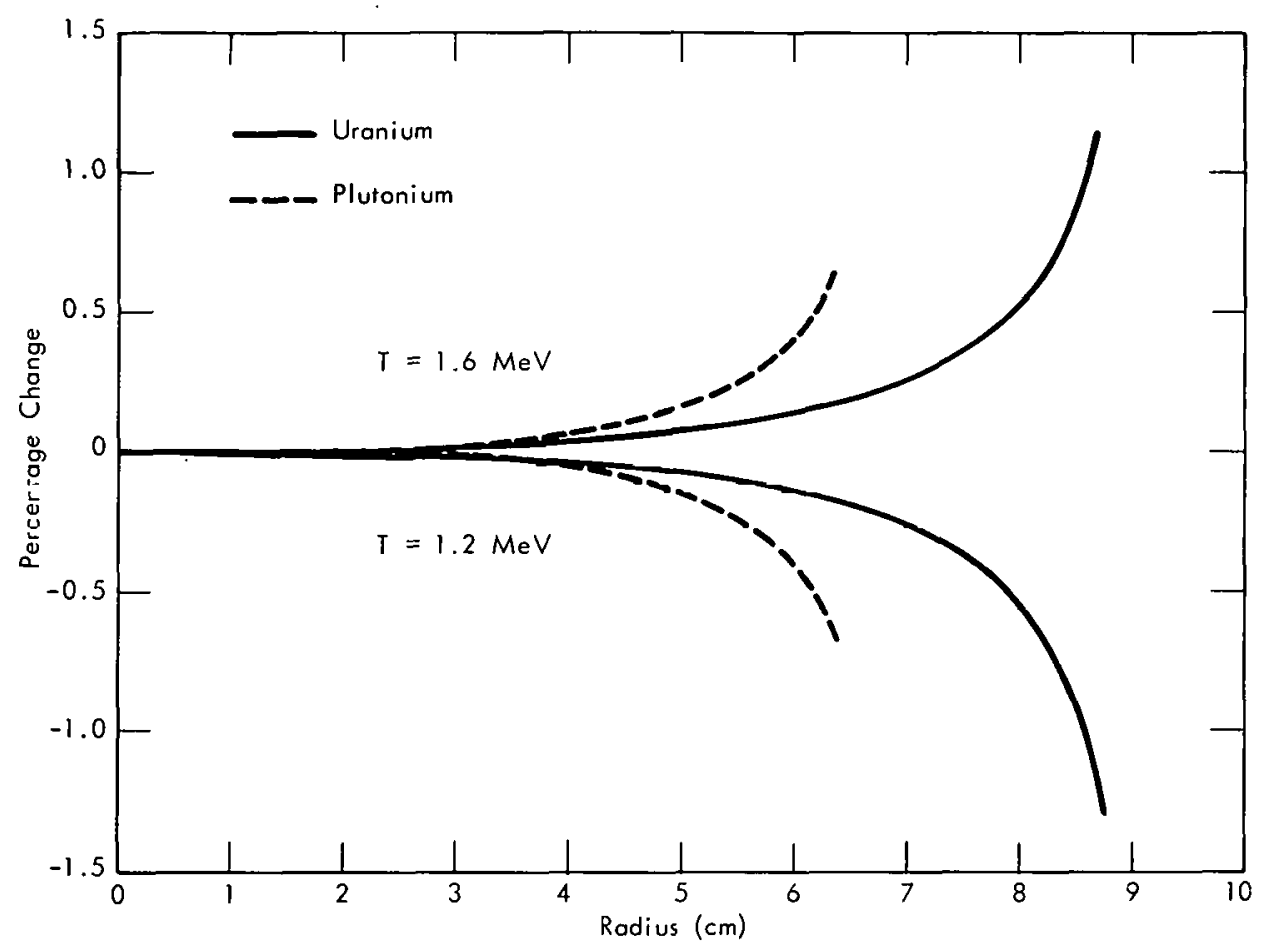

Figure 12. PERCENTAGE CHANGE IN NEUTRON IMPORTANCE WITH NUCLEAR TEMPERATURE AS A FUNCTION OF RADIUS FOR BARE URANIUM AND PLUTONIUM SPHERES.

of the sphere increases with the increasing nuclear temperature. For the reflected spheres, similar increases in the change with radius attained values of $5 \%$ at the outer edge of the reflector. Thus, the relative neutron importance distribution is not very sensitive to the value used for the nuclear temperature of ${ }^{252} \mathrm{Cf}$. Therefore, an error in the nuclear temperature could not account for the disagreement between measurements and calculations for the reflected spheres.

\section{Dependence of Fission Density and Neutron Importance on Cross Sections}

The sensitivity of the neutron importance and fission density to the cross sections used in the calculation was also investigated. Calculations were performed using all three cross section sets. The percentage change in the neutron importance due to a change in the cross sections from ENDF-B-III to other sets is shown as a function of radius in Figure 14 for the bare spheres. For the bare spheres, the percentage change in the fission density has approximately the same amplitude and spatial dependence as the neutron importance; since, for the bare system, the relative neutron importance and fission density themselves have essentially the same spatial dependence. The largest difference between the results for the various cross section sets occurred at the outer surface of the systems. Changes at the outer surface in going from ENDF-B-III cross sections to ENDF-B-II and Hansen-Roach cross sections for the bare uranium and plutonium spheres were $0.18,1.8,1.4$, and $2.3 \%$, respectively. To the significance given, changes in the tission density with cross sertions were the same. 


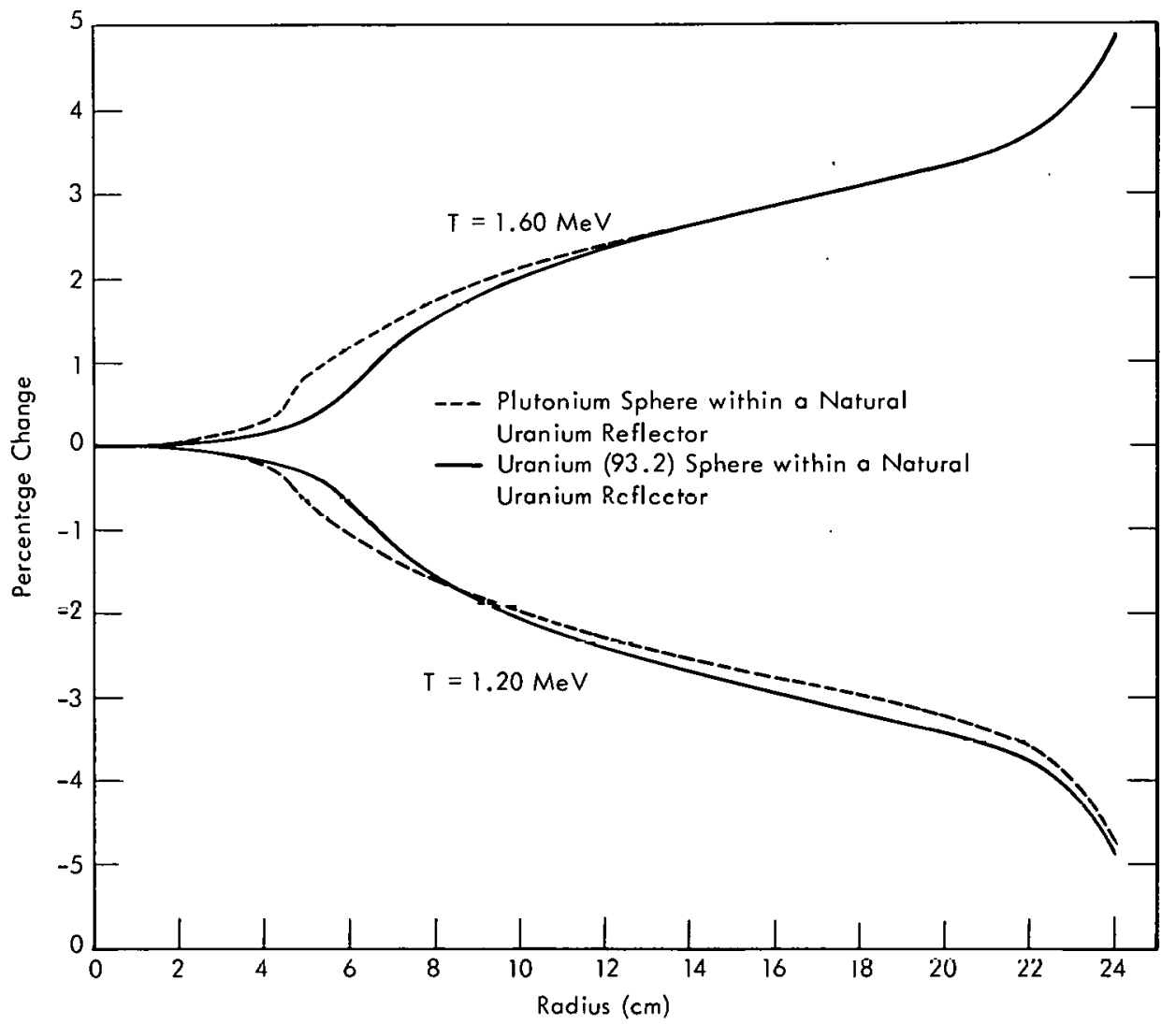

Figure 13. PERCENTAGE CHANGE IN NEUTRON IMPORTANCE WITH NUCLEAR TEMPERATURE AS A FUNCTION OF RADIUS FOR REFLECTED URANIUM AND PLUTONIUM SPHERES.

Percentage changes in the neutron imporțance with cross sertions as a funntion nf randius tor the reflected spheres are indicated in Figure 15. As with the bare sphere, dependence on the cross sections is largest at the outer surfaces of these systems. The change in going to ENDF-B-II cross setions increases with radius, attaining a value of +6 and $+7.5 \%$ for the uranium and plutonium spheres, respectively, bringing the calculated values closer to the experimental. For the Hansen-Roach cross sections, changes were $-5 \%$ at the outer surface for both assemblies; thus the discrepancies between measurements and calculations were larger. The effects far out in the reflector are of opposite sign for both cross section sets, but not large enough to account for the difference between measurements and calculations.

Percentage change in the ${ }^{235} \mathrm{U}$ fission density due to a change in the cross section from ENDF-B-III as a function of radius is shown in Figure 16 for the reflected spheres. In the central core of these assemblies, changes in the relative fission density with cross sections are small; but, in the reflector, the changes are as large as 4 to $7 \%$. Again, these differences cannot account for the discrepancy between the measurements and calculations.

Percentage changes in the fission density of the assembly with cross sections as a function of radius are given in Figures 17 and 18 for the reflected spheres. The change in going 


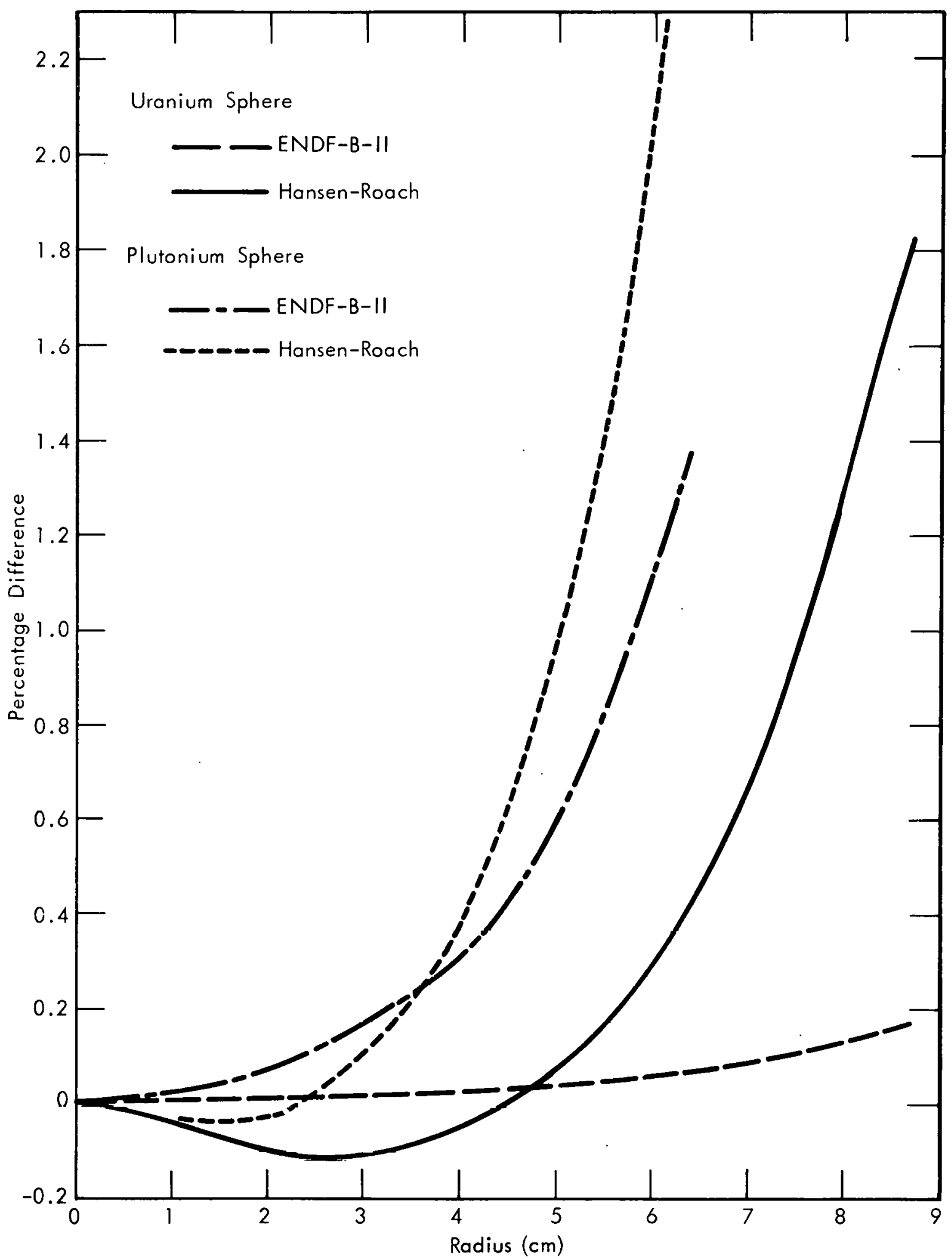

Figure 14. PERCENTAge Change in the NeUtron importance WITH CROSS SECtions as a function OF RADIUS FOR BARE URANIUM AND PLUTONIUM SPHERES. IS 16 Transport Calculations) 


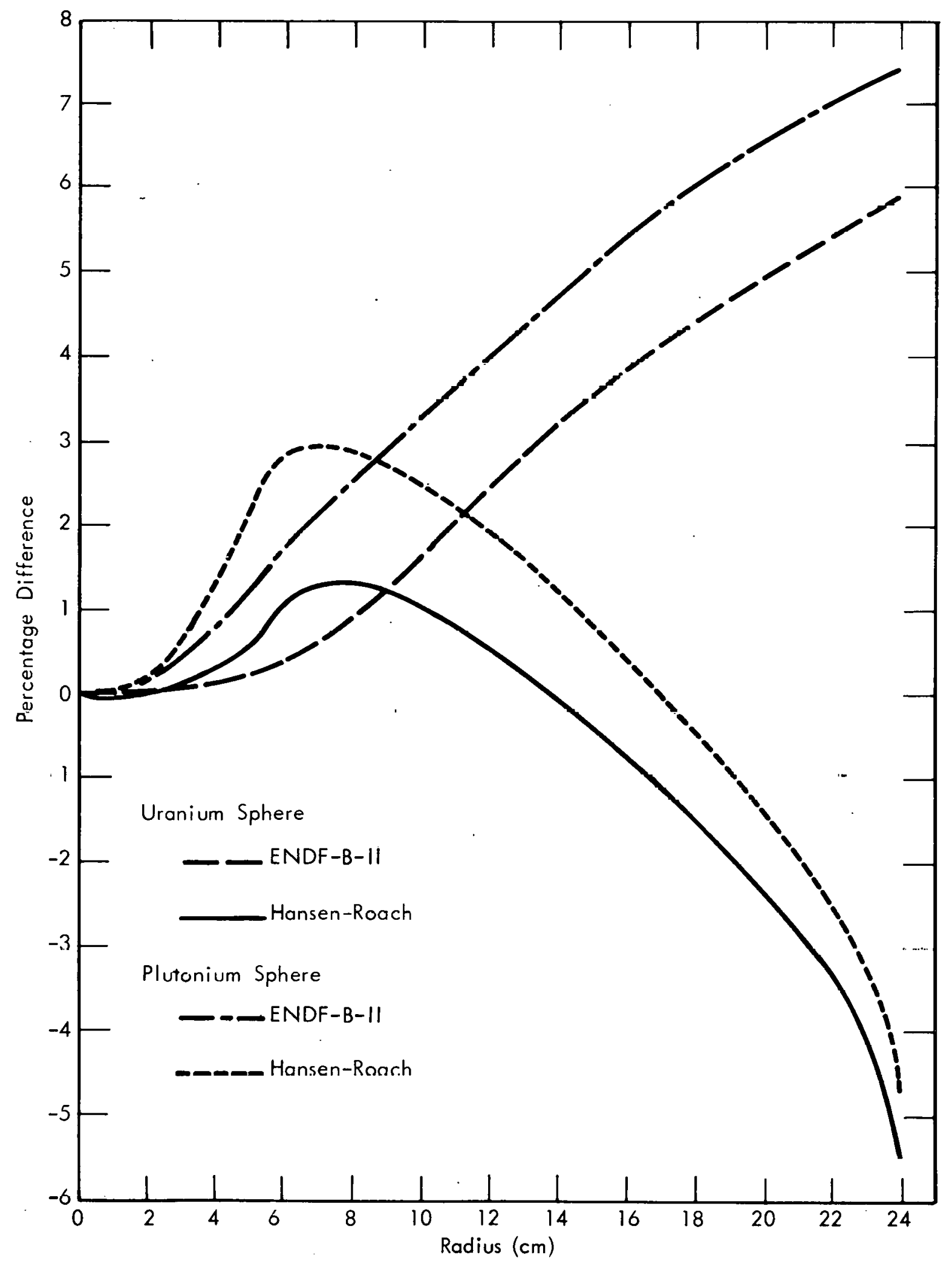

Figure 15. PERCENTAGE CHANGE IN THE NEUTRON IMPORTANCE WITH CROSS SECTIONS AS A FUNCTION OF RADIUS FOR NATURAL-URANIUM-REFLECTED URANIUM AND PLUTONIUM SPHERES. (S 16 Transport Calculations) 


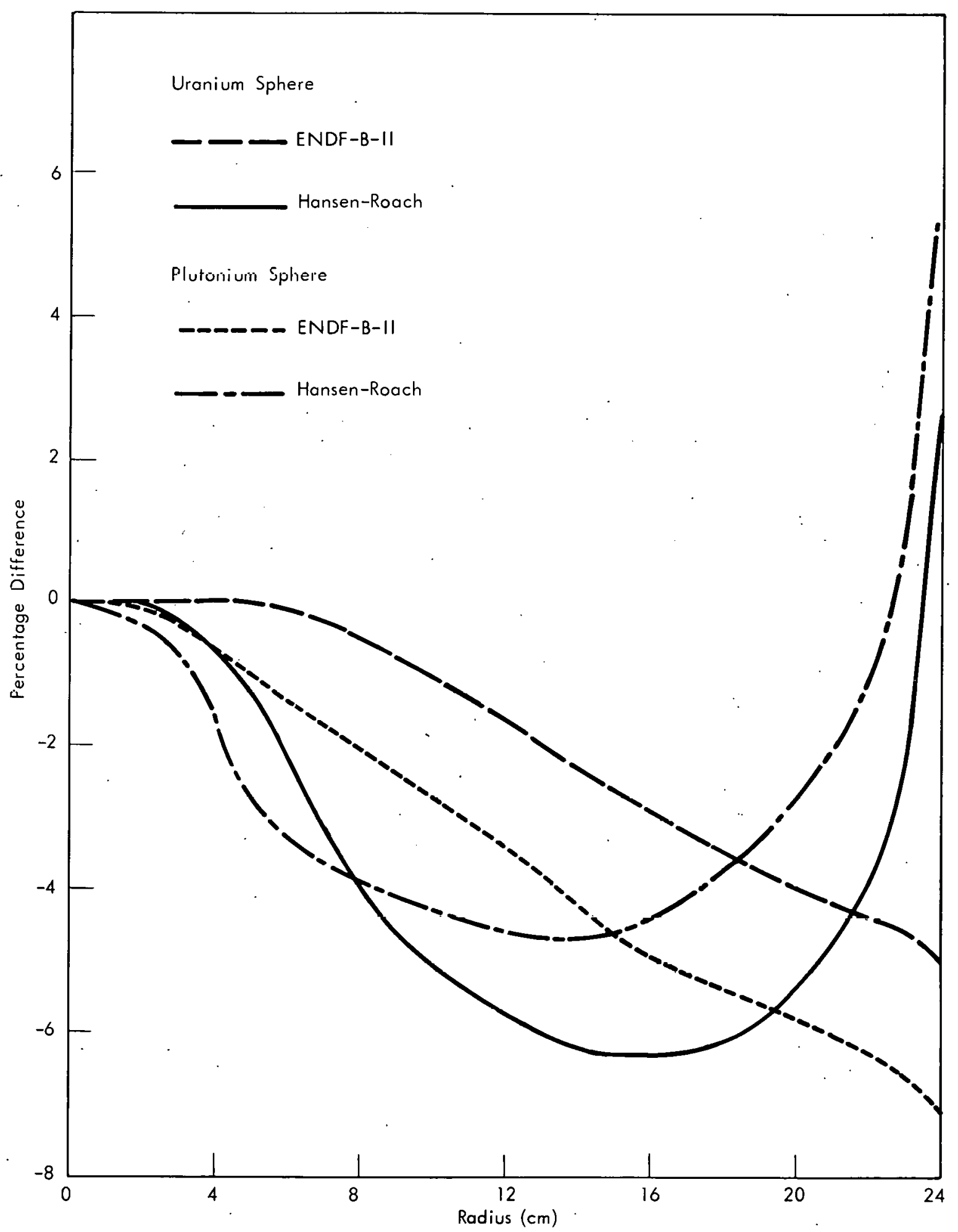

Figure 16. PERCENTAGE CHANGE IN ${ }^{235}$ U FISSION DENSITY WITH CROSS SECTIONS AS A FUNCTION OF RADIUS FOR NATURAL-URANIUM-REFLECTED URANIUM AND PLUTONIUM SPHERES. (S 16 Transport Calruılatinns) 


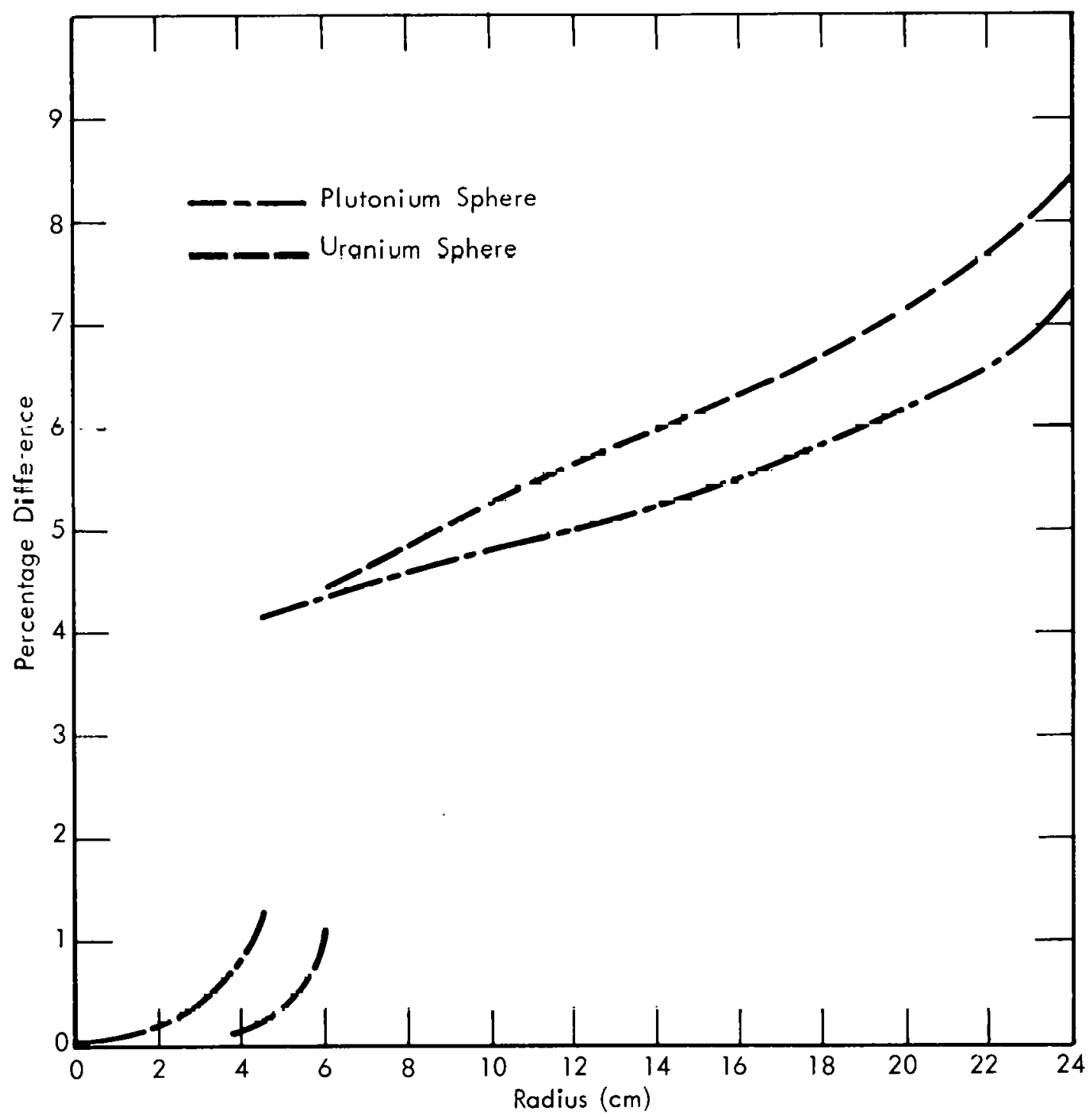

Figure 17. PERCENTAGE CHANGE IN THE FISSION DENSITY WITH ENDF-B-II DATA AS A FUNCTION OF RADIUS FOR NATURAL URANIUM, REFLECTED URANIUM, AND PLUTONIUM SPHERES. (S $_{16}$ Tinusyurul C.ah:ulialiums)

from ENDF-B-III to the Hansen-Roach data is seen in Figure 17, while that in going to the ENDF-B-II set is seen in Figure 18. The discontinuity in these curves at the core/reflector boundaries results from the change in materials at the boundary and the finite radial intervals used in the transport theory calculations at the boundary. For the Hansen-Roach cross sections, the change is $-25 \%$ at the outer boundary of the reflector; while, for the ENDF-B-II data, it is $\sim+8 \%$ for both spheres.

The variation in the nuclear temperature and the difference between the various cross section sets (Hansen-Roach, ENDF-B-II, and ENDF-B-III) cannot account for the discrepancies between the measurements and calculations for the natural-uranium-reflected spheres. These differences may indicate the inadequacy of the ${ }^{238} \mathrm{U}$ cross section for the - prediction of the fission density and neutron importance in these reflected systems. 


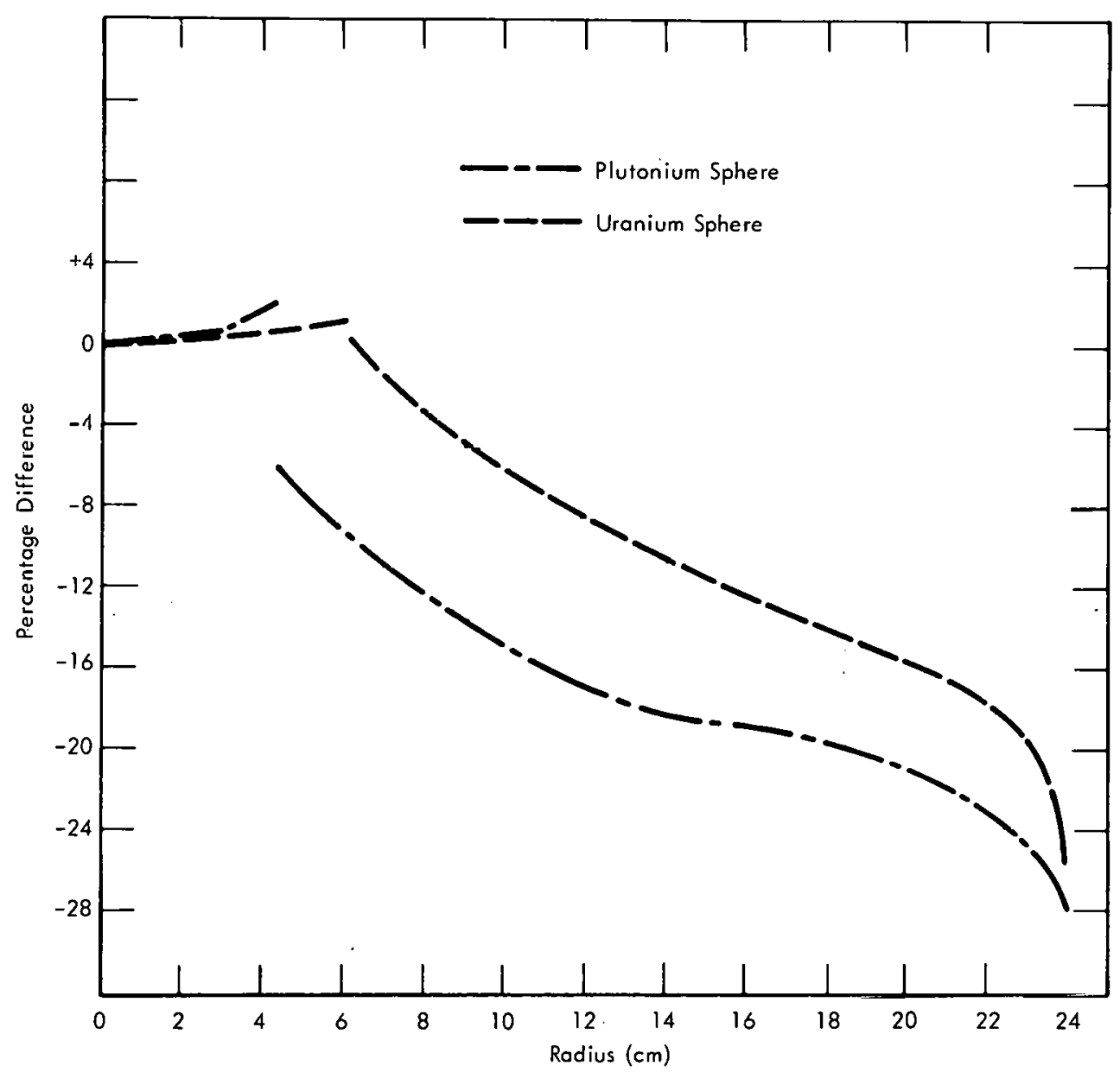

Figure 18. PERCENTAGE CHANGE IN THE FISSION DENSITY WITH HANSEN-ROACH DATA AS A FUNCTION OF RADIUS FOR NATURAL-URANIUM-REFLECTED URANIUM AND PLUTONIUM SPHERES. ( $\mathbf{S}_{16}$ Transport Calculations)

Differences of this type were independently noted by Hansen, based on early fission density measurements and calculations of the reflected systems at LASL. (14)

\section{SPATIAL-EFFECTS FACTOR IN ROSSI- $\alpha$ MEASUREMENTS}

The calculated and measured fission densities and neutron importance distributions were used to obtain the spatial-effects factor for Rossi- $\alpha$ measurements. This factor corrects point kinetic equations for spatial effects and has been discussed by lijima and others. (2) Knowledge of this factor is essential to the extraction of physical parameters from the time-correlated amplitude of the Rossi- $\alpha$ measurements. Neglect of this factor can lead to incorrect results. The spatial effects factor (Equation 1, Page 5), which appears in the time-correlated component of the amplitude of the Rossi- $\alpha$ measurement, is multiplied by the neutron dispersion number, $X$, which equals $\overline{\nu(\nu-1)} /(\bar{\nu})^{2}$. The expression for this product is:

$$
X R=[\overline{\nu(\nu-1)} /(\bar{\nu}) 2] .\left.\int \mathrm{F}(\mathrm{r}) \mathrm{dr} \int \mathrm{F}(\mathrm{r})\right|^{2}(\mathrm{r}) \mathrm{dr} /\left[\int \mathrm{F}(\mathrm{r}) \mid\langle\mathrm{r}\rangle \mathrm{dr}\right]{ }^{2}
$$


Another expression for this product is:

$$
X R=\int F(r) d r \int F(r) \nu|(r)(\nu-1)|(r) d r /\left[\int \nu F(r) \mid(r) d r\right]^{2}
$$

The value of this product was calculated using both Equations 2 and 3.

In calculating the average value, over the assembly, of the number of neutrons per fission, $\bar{\nu}$ and $\overline{\nu(\nu-1)}$, the fission density was used as the weighting function. Results of these calculations with either ENDF-B-II or ENDF-B-III cross sections are reported in Table 8 for all four assemblies. These quantities are relatively insensitive to the cross sections used. For all four assemblies, the largest difference for an assembly was $0.3 \%$ and the largest difference due to cross sections in the dispersion number for an assembly was $<0.1 \%$.

The integrals of Equation 3 were calculated with an importance function that used a Maxwellian spectrum with a fixed nuclear temperature to represent the energy distribution of fission neutrons. Values of $R$ obtained from the integrals are also given in Table 8. Variations of these values when changing the nuclear temperature from 1.2 to $1.6 \mathrm{MeV}$ were $0.2,0.1,0.4$, and $0.4 \%$ for the bare uranium, bare plutonium, reflected uranium, and reflected plutonium assemblies, respectively. Variations in the value of $R$ with the cross section for the bare uranium, bare plutonium, reflected uranium, and reflected plutonium assemblies were $0.09,0.14,1.9$, and $3.7 \%$, respectively. The dependence is largest for the reflected assemblies, where the calculations with the Hansen-Roach cross section set yielded the largest values.

The value of $R$ was also obtained with ENDF-B-III cross sections and an importance function calculated using a temperature of the fission spectrum that depended on the isotope fissioning and the energy of the neutron inducing fission. This calculation was done with fluxes obtained from calculations that assumed a fixed nuclear temperature for the fission spectrum for all isotopes fissioning and at all energies of the neutron inducing fission. The average nuclear temperature as a function of radius was also calculated. The nuclear temperature for the bare uranium sphere varied slightly with radius $-1.3463 \mathrm{MeV}$ at the center and $0.2 \%$ higher at the outer surface. Corresponding numbers for the bare plutonium were $1.4450 \mathrm{MeV}$ and $0.1 \%$ higher. For the reflected uranium sphere this value was $1.3431 \mathrm{MeV}$ at the center and $0.6 \%$ higher at the outer surface of the core, $1.3451 \mathrm{MeV}$ at the inner surface of the reflector and $0.6 \%$ lower at the outer surface of the reflector. Similar values for the reflected plutonium sphere were 1.4412 $\mathrm{MeV}$ and $0.44 \%$ lower; $1.3465 \mathrm{MeV}$ and $0.72 \%$ higher. Values of $\mathrm{R}$ accounting for the spatial variations of the nuclear temperature were essentially equal to those neglecting the spatial dependence of the nuclear temperature, and are also given in Table 8 . The largest difference was $<0.1 \%$.

The calculated value of $\mathrm{RX}$ using Equation 3 did not significantly depend on whether the nuclear temperature did or did not vary with radius. The values of $\mathrm{RX}$ using Equation 3 were $+0.29,+0.14,-0.25$, and $+1.4 \%$ different than those from Equation 2 for the bare uranium, bare plutonium, reflected uranium, and reflected plutonium assemblies, respectively. Results of these calculations are also given in Table 8.

The value of $R X$ did not depend significantly on the method of calculation, although there was some small dependence on the cross sections for the reflected spheres. Since $R X$ was 
Table 8

CALCULATED PARAMETERS FOR BARE AND NATURAL-URANIUM-REFLECTED URANIUM AND PLUTONIUM SPHERES

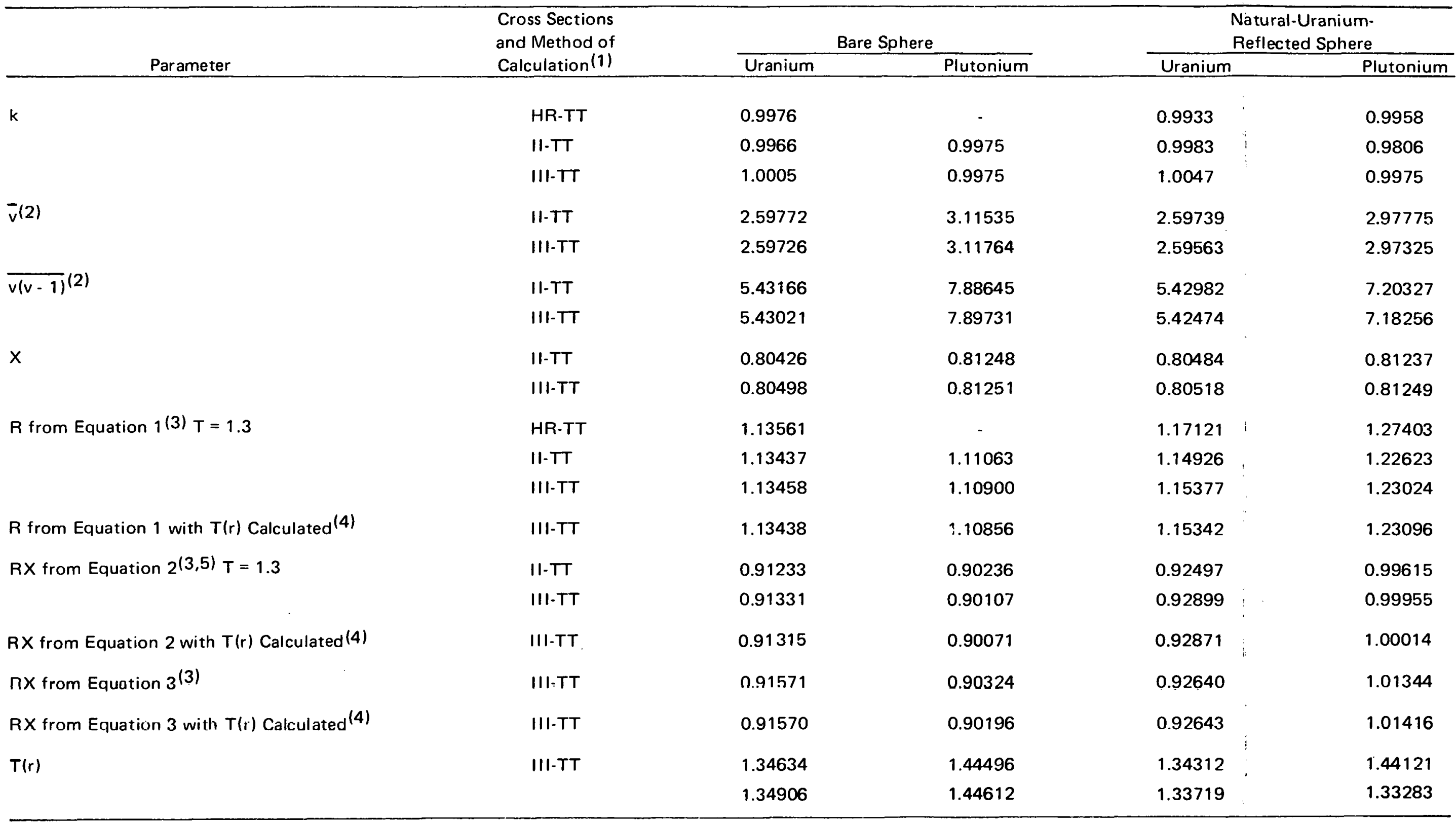

(1) One-hundred group cross sections prepared from ENDF-B-II and ENDF-B-III data files, $\mathrm{S}_{16}$ transport theory calculations with 101 spatial intervals for the bare assemblies and 200 for the reflected. The Hansen-Roach, ENDF-B-II, and ENDF-B-III cross sections are designated by HR, II, and III, respectively.

(2) Averaged with the fission density as a weighting function. The values are listed to 5 or 6 significant figures to show the sinall differentices.

(3) All values were calculated with an importance function obtained for a fission spectrum with a nuclear temperature of $1.3 \mathrm{MeV}$. Change in the value of $R$ with a variation of nuclear temperature from 1.2 to $1.6 \mathrm{MeV}$ was $0.2,0.4,0.1$, and $0.4 \%$ using ENDF-B-III data for the bare uranium, reflected uranium, bare plutonium, and the reflected plutonium assemblies, respectively.

(4) The importance function was calculated with a nuclear temperature which depended on the position in the assembly.

(5) These values are obtained from the above values of $X$ and $R$ obtained with $T=1.3 \mathrm{MeV}$.

(6) Varlation in nuclear lerriper alure of thie fission spectrum over the assembly. 
independent of the method, and the nuclear temperature of the fission spectrum in the sphere can be characterized by a temperature within $\sim 0.06 \mathrm{MeV}$ of that for the californium fission spectrum (0.04 MeV for plutonium and $0.06 \mathrm{MeV}$ for uranium), the value obtained using the measured importance distributions should be adequate.

The best values of $R$ can be obtained from the measured fission densities and neutron importance distribution. The required fission density distributions for the reflected spheres were obtaıned trom the measured ${ }^{235} \mathrm{U}$ fission density distribution by multiplying these values by the ratio of the calculated reactor material fission density to that calculated for ${ }^{2} 35 \mathrm{U}$ using ENDF-B-III cross sections. For the bare uranium sphere, the measured fission density was the reactor material fission density. The measured neutron importance distributions were ussed in these calculations exccpt for the bare plutoniuiri spliere where asymmetry effects distorted the measured distribution. In this case, the calculated neutron

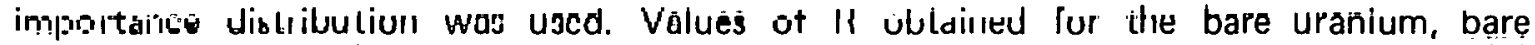
plutonlum, rejflected uranium, and reflected plutonium spheres were 1.123, 1.109, 1.163, (b) and 1.214 , (b) respectively. Measured values for the bare uranium sphere were $1 \%$ lower than those calculated; while, for the reflected uranium and plutonium spheres, the differences were +0.8 and $+1.4 \%$, respectively. Asymmetry effects in the measurements for the bare plutonium sphere, which could not be satisfactorily corrected for, precluded comparison of the value of $R$ obtained from calculation and measurements.

(b) Values 1.4 and $2.4 \%$ higher were obtained when calculations using Hansen-Roach cross sections were used to obtain the assembly fission density from the measured fission density. Similar values using ENDF-B-II cross sections were -0.3 and $-0.1 \%$. 


\section{CONCLUSIONS}

The measurements and calculations are in excellent agreement for the bare spheres except for the neutron importance distribution in the bare plutonium sphere where the measured values were lower than those calculated as the radius increased. This difference resulted from the asymmetric effects in the measurements which could not be corrected. The measured fission densities in the reflected uranium and plutonium spheres are as much as 4 and $6 \%$ lower, respectively, than those calculated at the outer edge of the central core. In the natural uranium reflector of both (for radii larger than $\sim 12 \mathrm{~cm}$ ), the measured values are higher than the calculated These differences increased with radius and, at the outer surface of the natural uranium reflector, the calculated fission densities are about $15 \%$ lower for both spheres. The calculated neutron importance in the central cores of the reflected spheres agree well with the measured values; but, in the reflector, the calculated values are lower than measured. These differences increased with radius in both reflected spheres and were as large as 31 and $36 \%$ for the uranium and plutonium spheres, respectively. These differences cannot be attributed to experimental errors which were $<5 \%$.

Investigation of the sensitivity of the calculated neutron importance and fission density to the cross sections shows that cross section differences could result in changes in the calculated importance of $<2 \%$ for the bare spheres and $<\sim 6 \%$ for the reflected spheres. Similar changes were obtained for the fission density distribution in the bare sphere and the ${ }^{235} \mathrm{U}$ fission density in the reflected sphere. Thus, the difference between the various cross-section sets (Hansen-Roach, ENDF-B-II, and ENDF-B-III) does not account for the discrepancies between measurement and calculations in the natural uranium reflector. These discrepancies may indicate the inadequacy of the ${ }^{238} \mathrm{U}$ cross sections in all three cross-section sets.

The calculated value of the spatial effects factor, $R$, for the Rossi- $\alpha$ measurement does not depend significantly on the cross sections or the nuclear temperature of the Maxwellian spectrum that characterizes the energy distribution of neutrons from ${ }^{252} \mathrm{Cf}$ fission. Values of $R$ were determined from the measured distributions for the bare uranium and the reflected spheres. For the bare plutonium sphere it was obtained from the measured fission density and calculated neutron importance distributions. Calculated importance was used due to asyirmetry effects in the measurements. These values are 1.123, 1.109, 1.163, and 1.214 for the bare uranium, bare plutonium, reflected uranium, and reflected plutonium spheres, respectively. The error in these values is $<0.01$. 


\section{REFERENCES}

(1) Hansen, G. E.; Personal Communication (of Measurements by D. M. Barton and G. A. Jarvis); Los Alamos Scientific Laboratory, Los Alamos, New Mexico.

(2) Otsuka, M. and lijima, T.; Nucleonik 7, (8), p 488 (1965); Harris, D. R.; Nucl Sci Eng 21, p 369 (1965); Bell, G. I.; Nucl Sci Eng 21, p 390 (1965).

(3) Engle, W.W., - Jr.; A User's Manual for ANISN, K-1693, Union Carbide Corporation-Nuclear Division, Oak Ridge Gaseous Diffusion Plant, Oak Ridge, Tennessee (1967).

(4) Bell, G. I., et al; Los Alamos Group-Averaged Cross Sections, LAMS-2941, Los Alamos Scientific Laboratory, Los Alamos, New Mexico (1963).

(5) ENDF-B-// Distributed by National Cross Section Center; Brookhaven National Laboratory, Upton, L.I., New York (1971).

(6) ENDF-B-III Tape 986 Distributed by National Cross Section Center; Brookhaven National Laboratory, Upton, L.I., New York (1971).

(7) Peterson, R.; Lady Godiva: An Unreflected Uranium-235 Critical Assembly, LA-1614; Los Alamos Scientific Laboratory, Los Alamos, New Mexico (1953).

(8) Green, L., Mitchell, J. A., and Steen, N. M.; Nucl Sci Eng, 50, p 257 (1973).

(9) Hansen, G. E. and Paxton, H. C.; Reevaluated Critical Specifications of Some Los Alamos Fast Neutron Systems, LA-4208; Los Alamos Scientific Laboratory, Los Alamos, New Mexico (1969); Jarvis, G. A., Linenberger, G. A., Orndoff, J. D., and Paxton, H. C.; Nucl Sci Eng, 8, p 525 (1960).

(10) Straker, E. A., Stevens, P. N., Irving, D. C., and Cain, V. R.; The MORSE Code, a Multigroup Neutron and Gamma-Ray Monte Carlo Transport Code, ORNL-4585; Union Carbide Corporation-Nuclear Division, Oak Ridge National Laboratory, Oak Ridge, Tennessee (1970).

(11) Hansen, G. E. and Helmick, B.; Personal Communication; Los Alamos Scientific Laboratory, Los Alamos, New Mexico (1974).

(12) Hansen, G. E.; "Status of Computational and Experimental Correlations for Los Alamos Fast Neutron Critical Assemblies", Physics of Fast and Intermediate Reactors, 1, p 445; IAEA, Vienna (1962).

(13) Meadows, J. W.; Phys Rev, 157, (4), p 1076 (1967).

(14) Hansen, G. E.; Personal Communication; Los Alamos Scientific Laboratory, Los Alamos, New Mexico (1973). 
APPENDIX

CALCULATED FISSION DENSITY AND NEUTRON IMPORTANCE DATA

Table A-1

CALCULATED FISSION DENSITY AND NEUTRON IMPORTANCE AS A FUNCTION OF RADIUS FOR A BARE URANIUM SPHERE

\begin{tabular}{|c|c|c|c|c|c|c|c|}
\hline $\begin{array}{c}\text { Radial } \\
\text { Interval (1) } \\
\end{array}$ & $\begin{array}{l}\text { Fission } \\
\text { Density }\end{array}$ & $\begin{array}{c}\text { Californium } \\
\text { Neutron } \\
\text { Importance }(2)\end{array}$ & $\begin{array}{c}\text { Reactor } \\
\text { Neutron } \\
\text { Importance } \\
\text { I3) }\end{array}$ & $\begin{array}{c}\text { Radial } \\
\text { Interval }(1)\end{array}$ & $\begin{array}{l}\text { Fission } \\
\text { Density } \\
\end{array}$ & $\begin{array}{c}\text { Californium } \\
\text { Neutron } \\
\text { Importance }(2)\end{array}$ & $\begin{array}{c}\text { Reactor } \\
\text { Neutron } \\
\text { Importance }(3) \\
\end{array}$ \\
\hline 1 & 1.0008 & 1.0009 & 1.0009 & 51 & 0.7459 & 0.7474 & 0.7473 \\
\hline 2 & 1.0017 & 1.0019 & 1.0018 & 52 & 0.7365 & 0.7381 & 0.7380 \\
\hline 3 & 1.0016 & 1.0017 & 1.0017 & 53 & 0.7270 & 0.7286 & 0.7285 \\
\hline 4 & 1.0011 & 1.0013 & 1.0013 & 54 & 0.7174 & 0.7191 & 0.7190 \\
\hline 5 & 1.0004 & 1.0006 & 1.0005 & 55 & 0.7077 & 0.7094 & 0.7093 \\
\hline 6 & 0.9994 & 1.0000 & 0.9996 & 56 & 0.6978 & 0.6996 & 0.6995 \\
\hline 7 & 0.9982 & 0.9984 & 0.9984 & 57 & 0.6879 & 0.6897 & 0.6896 \\
\hline 8 & 0.9968 & 0.9970 & 0.9969 & 58 & 0.6778 & 0.6798 & 0.6796 \\
\hline 9 & 0.9951 & 0.9953 & 0.9953 & 59 & 0.6677 & 0.6697 & 0.6696 \\
\hline 10 & 0.9932 & 0.9934 & 0.9934 & 60 & 0.6574 & 0.6595 & 0.6594 \\
\hline 11 & 0.9911 & 0.9913 & 0.9913 & 61 & 0.6471 & 0.6493 & 0.6491 \\
\hline 12 & 0.9888 & 0.9890 & 0.9889 & 62 & 0.6367 & 0.6389 & 0.6388 \\
\hline 13 & 0.9862 & 0.9864 & 0.9864 & 63 & 0.6261 & 0.6285 & 0.6284 \\
\hline 14 & 0.9834 & 0.9836 & 0.9836 & 64 & 0.6156 & 0.6180 & 0.6179 \\
\hline 15 & 0.9804 & 0.9806 & 0.9806 & 65 & 0.6049 & 0.6074 & 0.6073 \\
\hline 16 & 0.9772 & 0.9774 & 0.9774 & 66 & 0.5942 & 0.5968 & 0.5966 \\
\hline 17 & 0.9738 & 0.9740 & 0.9740 & 67 & 0.5833 & 0.5861 & 0.5859 \\
\hline 18 & 0.9701 & 0.9704 & 0.9704 & 68 & 0.5725 & 0.5753 & 0.5751 \\
\hline 19 & 0.9663 & 0.9666 & 0.9665 & 69 & 0.5615 & 0.5644 & 0.5642 \\
\hline 20 & 0.9622 & 0.9625 & 0.9625 & 70 & 0.5505 & 0.5535 & 0.5533 \\
\hline 21 & 0.9580 & 0.9583 & 0.9582 & 71 & 0.5395 & 0.5426 & 0.5424 \\
\hline 22 & 0.9535 & 0.9538 & 0.9538 & 72 & 0.5283 & 0.5315 & 0.5313 \\
\hline 23 & 0.9488 & 0.9491 & 0.9491 & 73 & 0.5172 & 0.5205 & 0.5202 \\
\hline 24 & 0.9439 & 0.9443 & 0.9443 & 74 & 0.5059 & 0.5093 & 0.5091 \\
\hline 25 & 0.9388 & 0.9392 & 0.9392 & 75 & 0.4947 & 0.4982 & 0.4979 \\
\hline 26 & 0.9336 & 0.9340 & 0.9339 & 76 & 0.4833 & 0.4870 & 0.4867 \\
\hline 27 & 0.9281 & 0.9285 & 0.9285 & 77 & 0.4720 & 0.4757 & 0.4754 \\
\hline 28 & 0.9225 & 0.9229 & 0.9229 & 78 & 0.4606 & 0.4644 & 0.4641 \\
\hline 29 & 0.9166 & 0.9171 & 0.9171 & 79 & 0.4491 & 0.4531 & 0.4528 \\
\hline 30 & 0.9106 & 0.9111 & 0.9111 & 80 & 0.4376 & 0.4417 & 0.4414 \\
\hline 31 & 0.9044 & 0.9049 & 0.9049 & 81 & 0.4261 & 0.4303 & 0.4300 \\
\hline 32 & 0.8980 & 0.8986 & 0.8985 & 82 & 0.4145 & 0.4188 & 0.4185 \\
\hline 33 & 0.8914 & 0.8920 & 0.8920 & 83 & 0.4029 & 0.4074 & 0.4070 \\
\hline 34 & 0.8847 & 0.8853 & 0.8853 & 84 & 0.3913 & 0.3958 & 0.3955 \\
\hline 35 & 0.8777 & 0.8784 & 0.8784 & 85 & 0.3796 & 0.3843 & 0.3840 \\
\hline 36 & 0.8707 & 0.8714 & 0.8713 & 86 & 0.3679 & 0.3727 & 0.3724 \\
\hline 37 & 0.8634 & 0.8642 & 0.8641 & 87 & 0.3561 & 0.3611 & 0.3607 \\
\hline 38 & 0.8560 & 0.8568 & 0.8567 & 88 & 0.3443 & 0.3494 & 0.3491 \\
\hline 39 & 0.8484 & 0.8492 & 0.8492 & 89 & 0.3325 & 0.3377 & 0.3374 \\
\hline 40 & 0.8407 & 0.8415 & 0.8415 & 90 & 0.3206 & 0.3260 & 0.3256 \\
\hline 41 & 0.8328 & 0.8370 & 0.8336 & 91 & 0.3086 & 0.3142 & 0.3138 \\
\hline 42 & 0.8247 & 0.8257 & 0.8256 & $92^{2}$ & 0.2966 & 0.3023 & 0.3019 \\
\hline 43 & 0.8165 & 0.8175 & 0.8175 & 93 & 0.2844 & 0.2903 & 0.2899 \\
\hline 44 & 0.8082 & 0.8093 & 0.8092 & 94 & 0.2721 & 0.2782 & 0.2778 \\
\hline 45 & 0.7997 & 0.8008 & 0.8007 & 95 & 0.2597 & 0.2659 & 0.2655 \\
\hline 46 & 0.7911 & 0.7922 & 0.7922 & 96 & 0.2470 & 0.2534 & 0.2530 \\
\hline 47 & 0.7823 & 0.7835 & 0.7835 & 97 & 0.2339 & 0.2406 & 0.2401 \\
\hline 48 & 0.7734 & 0.7747 & 0.7746 & 98 & 0.2203 & 0.2271 & 0.2266 \\
\hline 49 & 0.7644 & 0.7657 & 0.7656 & 99 & 0.2056 & 0.2127 & 0.2122 \\
\hline \multirow[t]{2}{*}{50} & 0.7552 & 0.7566 & 0.7565 & 100 & 0.1892 & 0.1967 & 0.1961 \\
\hline & & & & 101 & 0.1803 & 0.1880 & 0.1874 \\
\hline
\end{tabular}

(1) Radial intervals for the $S_{16}$ transport theory calculations were $0.08743 \mathrm{~cm}$, except for the last interval near the outer surface of the sphere where it was $0.001 \mathrm{~cm}$. All values of fission density and neutron importance are normalized to unity at the sphere center.

(2) These values were calculated with the nuclear temperature of the Maxwellian fission spectrum equal to $1.40 \mathrm{MeV}$.

(3) These values were obtained with the calculated nuclear temperature for reactor fission neutrons, which depended slightly on radius. At the sphere center this temperature is $1.3463 \mathrm{MeV}$, while at the outer surface it is $0.2 \%$ higher. 
Table A.2

CALCULATED FISSION DENSITY AND NEUTRON IMPORTANCE AS A FUNCTION OF RADIUS FOR A BARE PLUTONIUM SPHEIRE

\begin{tabular}{|c|c|c|c|c|c|c|c|}
\hline $\begin{array}{c}\text { Radial } \\
\text { Interval (1) }\end{array}$ & $\begin{array}{l}\text { Fission } \\
\text { Density }\end{array}$ & $\begin{array}{l}\text { Californium } \\
\text { Neutron } \\
\text { Importance } \\
\end{array}$ & $\begin{array}{c}\text { Reactor } \\
\text { Neutron } \\
\text { Importance (3) }\end{array}$ & $\begin{array}{c}\text { Radial } \\
\text { Interval (1) }\end{array}$ & $\begin{array}{l}\text { Fission } \\
\text { Density }\end{array}$ & $\begin{array}{l}\text { Californium } \\
\text { Neutron } \\
\text { Importance } \\
\text { (2) }\end{array}$ & $\begin{array}{c}\text { Reactor } \\
\text { Neutron } \\
\text { Importance (3) }\end{array}$ \\
\hline 1 & 1.0011 & 1.0012 & 1.0012 & 51 & 0.7734 & 0.7740 & 0.7741 \\
\hline 2 & 1.0023 & 1.0023 & 1.0023 & 52 & 0.7648 & 0.7655 & 0.7656 \\
\hline 3 & 1.0022 & 1.0023 & 1.0023 & 53 & 0.7561 & 0.7569 & 0.7569 \\
\hline 4 & 1.0019 & 1.0020 & 1.0020 & 54 & 0.7474 & 0.7481 & 0.7481 \\
\hline 5 & 1.0013 & $1.001 / 4$ & 1.0014 & 55 & 0.7384 & 0.7392 & 0.7393 \\
\hline 6 & 1.0005 & 1.0006 & 1.0006 & 56 & 0.7294 & 0.7302 & 0.7303 \\
\hline 7 & 0.9995 & 0.9996 & 0.9996 & 57 & 0.7203 & 0.7211 & 0.7212 \\
\hline 8 & 0.9983 & 0.9984 & 0.9984 & 58 & 0.7111 & 0.7120 & 0.7120 \\
\hline 9 & 0.9969 & 0.9969 & 0.9969 & 59 & 0.7018 & 0.7027 & 0.7027 \\
\hline 10 & 0.9952 & 0.9953 & 0.9953 & 60 & 0.6924 & 0.6933 & 0.6934 \\
\hline 11 & 0.9934 & 0.9935 & 0.9935 & 61 & 0.6829 & 0.6838 & 0.6839 \\
\hline 12 & 0.9914 & 0.9914 & 0.9914 & 62 & 0.6733 & 0.6743 & 0.6743 \\
\hline 13 & 0.9891 & 0.9892 & 0.9892 & 63 & 0.6636 & 0.6646 & 0.6647 \\
\hline 14 & 0.9867 & 0.9868 & 0.9868 & 64 & 0.6538 & 0.6549 & 0.6550 \\
\hline 15 & 0.9841 & 0.9842 & 0.9842 & 65 & 0.6439 & 0.6451 & 0.6451 \\
\hline 16 & 0.9812 & 0.9813 & 0.9813 & 66 & 0.6340 & 0.6352 & 0.6352 \\
\hline 17 & 0.9782 & 0.9783 & 0.9783 & 67 & 0.6240 & 0.6252 & 0.6253 \\
\hline 18 & 0.9750 & 0.9751 & 0.9751 & 68 & 0.6139 & 0.6151 & 0.6152 \\
\hline 19 & 0.9716 & 0.9717 & 0.9717 & 69 & 0.6037 & 0.6050 & 0.6051 \\
\hline 20 & 0.9680 & 0.9682 & 0.9682 & 70 & 0.5935 & 0.5948 & 0.5949 \\
\hline 21 & 0.9643 & 0.9644 & 0.9644 & 71 & 0.5832 & 0.5845 & 0.5846 \\
\hline 22 & 0.9603 & 0.9604 & 0.9604 & 72 & 0.5728 & 0.5742 & 0.5743 \\
\hline 23 & 0.9561 & 0.9563 & 0.9563 & 73 & 0.5623 & 0.5638 & 0.5639 \\
\hline 24 & 0.9518 & 0.9520 & 0.9520 & 74 & 0.5518 & 0.5533 & 0.5534 \\
\hline 25 & 0.9473 & 0.9475 & 0.9475 & 75 & 0.5412 & 0.5428 & 0.5429 \\
\hline 26 & 0.9426 & 0.9428 & 0.9428 & 76 & 0.5306 & 0.5322 & 0.5323 \\
\hline 27 & 0.9377 & 0.9379 & 0.9379 & 77 & 0.5199 & 0.5215 & 0.5217 \\
\hline 28 & 0.9327 & 0.9329 & 0.9329 & 78 & 0.5091 & 0.5108 & 0.5109 \\
\hline 29 & 0.9275 & 0.9277 & 0.9277 & 79 & 0.4983 & 0.5000 & 0.5002 \\
\hline 30 & 0.9221 & 0.9223 & 0.9223 & 80 & 0.4874 & 0.4892 & 0.4893 \\
\hline 31 & 0.9165 & 0.9168 & 0.9168 & 81 & 0.4764 & 0.4783 & 0.4785 \\
\hline 32 & 0.9108 & $0.91: 1$ & $0 . C_{111}$ & 82 & 0.4654 & 0.4674 & 0.4675 \\
\hline 33 & 0.9049 & 0.9052 & 0.9052 & 83 & 0.4544 & 0.4563 & 0.4565 \\
\hline 34 & 0.8989 & 0.8992 & 0.8992 & 84 & 0.4432 & 0.4453 & 0.4454 \\
\hline 35 & 0.8927 & 0.8930 & 0.8930 & 85 & 0.4321 & 0.4341 & 0.4343 \\
\hline 36 & 0.8863 & 0.8866 & $0.8866^{\circ}$ & 86 & 0.4208 & 0.4230 & 0.4231 \\
\hline 37 & 0.8798 & 0.8801 & $0 . \varepsilon 801$ & 87 & 0.4095 & 0.4117 & 0.4119 \\
\hline 38 & 0.8731 & 0.8734 & 0.8735 & 88 & 0.3981 & 0.4004 & 0.4006 \\
\hline 39 & 0.8663 & 0.8666 & 0.8666 & 89 & 0.3866 & 0.3890 & 0.3892 \\
\hline 40 & 0.8593 & 0.8597 & 0.8597 & 90 & 0.3751 & 0.3775 & 0.3777 \\
\hline 41 & 0.8522 & 0.8526 & 0.8526 & 91 & 0.3634 & 0.3659 & 0.3661 \\
\hline 42 & 0.8449 & 0.8453 & 0.8453 & 92 & 0.3517 & 0.3542 & 0.3544 \\
\hline 43 & 0.8375 & 0.8379 & 0.8379 & 93 & 0.3398 & 0.3424 & 0.3426 \\
\hline 44 & 0.8299 & 0.8304 & 0.8304 & 94 & 0.3277 & 0.3304 & 0.3307 \\
\hline 45 & 0.8222 & 0.8227 & 0.8228 & 95 & 0.3154 & 0.3182 & 0.3185 \\
\hline 46 & 0.8144 & 0.8149 & 0.8150 & 96 & 0.3028 & 0.3057 & 0.3060 \\
\hline 47 & 0.8065 & 0.8070 & 0.8070 & 97 & 0.2899 & 0.2928 & 0.2931 \\
\hline 48 & 0.7984 & 0.7989 & 0.7990 & 98 & 0.2761 & 0.2792 & 0.2795 \\
\hline 49 & 0.7902 & 0.7903 & 0.7908 & 99 & 0.2614 & 0.2647 & 0.2650 \\
\hline 50 & 0.7819 & 0.7825 & 0.7825 & 100 & 0.2451 & 0.2486 & 0.2489 \\
\hline
\end{tabular}

(1) Radial intervals for the $S_{16}$ transport theory calculations were $0.063849 \mathrm{~cm}$. All values of the fission density and neutron importance are normalized to unity at the sphere center.

(2) These values were calculated with the nuclear temferature of the Maxwellian fissic $r$ spectrum equal to $1.40 \mathrm{MeV}$.

(3) These values were obtained with the calculated nuclear temperature for reactor fission neutrons, which depended slightly on radius. At the sphere center this temperature is $1.445 \mathrm{MeV}$, while at the outer surface it is $0.08 \%$ higher. 
Table A-3

CALCULATED FISSION DENSITY AND NEUTRON IMPORTANCE AS A FUNCTION OF RADIUS FOR A NATURAL-URANIUM-REFLECTED URANIUM SPHERE

\begin{tabular}{|c|c|c|c|c|c|c|c|}
\hline $\begin{array}{c}\text { Radial } \\
\text { Interval }(1)\end{array}$ & $\begin{array}{l}\text { Fission } \\
\text { Density }\end{array}$ & $\begin{array}{c}\text { Californium } \\
\text { Neutron } \\
\text { Importance } \\
\text { Imp }\end{array}$ & $\begin{array}{c}\text { Reactor } \\
\text { Neutron } \\
\text { Importance }(3)\end{array}$ & $\begin{array}{c}\text { Radial } \\
\text { Interval (1) }\end{array}$ & $\begin{array}{l}\text { Fission } \\
\text { Density }\end{array}$ & $\begin{array}{c}\text { Californium } \\
\text { Neutron } \\
\text { Importance }(2)\end{array}$ & $\begin{array}{c}\text { Reactor } \\
\text { Neutron } \\
\text { Importance (3) } \\
\end{array}$ \\
\hline 1 & 1.0006 & 1.0007 & 1.0007 & 101 & 0.0589 & 0.5174 & 0.5156 \\
\hline 2 & 1.0012 & 1.0013 & 1.0013 & 102 & 0.0520 & 0.4912 & 0.4894 \\
\hline 4 & 1.0011 & 1.0012 & 1.0012 & 103 & 0.0470 & 0.4693 & 0.4673 \\
\hline 6 & 1.0004 & 1.0004 & 1.0004 & 104 & 0.0428 & 0.4494 & 0.4474 \\
\hline 8 & $0.999: 2$ & 0.9992 & 0.9992 & 105 & 0.0392 & 0.4310 & 0.4290 \\
\hline 10 & 0.9976 & 0.9976 & 0.9975 & 106 & 0.0361 & 0.4139 & 0.4119 \\
\hline 12 & 0.9956 & 0.9955 & 0.9955 & 107 & 0.0333 & 0.3980 & 0.3959 \\
\hline 14 & 0.9932 & 0.9929 & 0.9929 & 108 & 0.0308 & 0.3830 & 0.3809 \\
\hline 16 & 0.9904 & 0.9900 & 0.9900 & 109 & 0.0286 & 0.3688 & 0.3668 \\
\hline 18 & 0.9872 & 0.9866 & 0.9866 & 110 & 0.0266 & 0.3554 & 0.3534 \\
\hline 20 & 0.9836 & 0.9828 & 0.9827 & 112 & 0.0231 & 0.3306 & 0.3286 \\
\hline 22 & 0.9796 & 0.9785 & 0.9785 & 114 & 0.0203 & 0.3081 & 0.3062 \\
\hline 24 & 0.9752 & 0.9739 & 0.9739 & 116 & 0.0178 & 0.2876 & 0.2857 \\
\hline 26 & 0.9704 & 0.9688 & 0.9688 & 118 & 0.0158 & 0.2689 & 0.2670 \\
\hline 28 & 0.9652 & 0.9634 & 0.9633 & 120 & 0.0140 & 0.2516 & 0.2498 \\
\hline 30 & 0.9596 & 0.9575 & 0.9575 & 122 & 0.0125 & 0.2356 & 0.2339 \\
\hline 32 & 0.9537 & 0.9513 & 0.9512 & $124^{\circ}$ & 0.0111 & 0.2209 & 0.2192 \\
\hline 34 & 0.9474 & 0.9446 & 0.9445 & 126 & 0.0010 & 0.2072 & 0.2056 \\
\hline 36 & 0.9407 & 0.9376 & 0.9375 & 128 & 0.0090 & 0.1945 & 0.1929 \\
\hline 38 & 0.9337 & 0.9302 & 0.9301 & 130 & 0.0081 & 0.1826 & 0.1811 \\
\hline 40 & 0.9263 & 0.9224 & 0.9223 & 132 & 0.0073 & 0.1715 & 0.1701 \\
\hline 42 & 0.9186 & 0.9142 & 0.9141 & 134 & 0.0066 & 0.1612 & 0.1598 \\
\hline 44 & 0.9105 & 0.9057 & 0.9056 & 136 & 0.0060 & 0.1515 & 0.1502 \\
\hline 46 & 0.9022 & 0.8969 & 0.8967 & 138 & 0.0054 & 0.1424 & 0.1411 \\
\hline 48 & 0.8934 & 0.8877 & 0.8875 & 140 & 0.0050 & 0.1339 & 0.1327 \\
\hline 50 & 0.8844 & 0.8781 & 0.8779 & 142 & 0.0045 & 0.1259 & 0.1247 \\
\hline 52 & 0.8751 & 0.8682 & 0.8680 & 144 & 0.0041 & 0.1184 & 0.1172 \\
\hline 54 & 0.8654 & 0.8580 & 0.8578 & 146 & 0.0038 & 0.1113 & 0.1102 \\
\hline 56 & 0.8554 & 0.8475 & 0.8472 & 148 & 0.0034 & 0.1046 & 0.1035 \\
\hline 58 & 0.8452 & 0.8366 & 0.8364 & 150 & 0.0032 & 0.0983 & 0.0973 \\
\hline 60 & 0.8347 & 0.8255 & 0.8252 & 152 & 0.0029 & 0.0923 & 0.0914 \\
\hline 62 & 0.8239 & 0.8140 & 0.8137 & 154 & 0.0027 & 0.0867 & 0.0858 \\
\hline 64 & 0.8128 & 0.8023 & 0.8020 & 156 & 0.0024 & 0.0814 & 0.0805 \\
\hline 66 & 0.8014 & 0.7902 & 0.7899 & 158 & 0.0022 & 0.0763 & 0.0755 \\
\hline 68 & 0.7898 & 0.7779 & 0.7776 & 160 & 0.0021 & 0.0715 & 0.0708 \\
\hline 70 & 0.7779 & 0.7653 & 0.7649 & 162 & 0.0019 & 0.0670 & 0.0663 \\
\hline 72 & 0.7658 & 0.7524 & 0.7520 & 164 & 0.0017 & 0.0627 & 0.0621 \\
\hline 74 & 0.7534 & 0.7393 & 0.7388 & 166 & 0.0016 & 0.0587 & 0.0580 \\
\hline 76 & 0.7408 & 0.7258 & 0.7254 & 168 & 0.0015 & 0.0548 & 0.0542 \\
\hline 78 & 0.7279 & 0.7121 & 0.7116 & 170 & 0.0013 & 0.0511 & 0.0506 \\
\hline 80 & 0.7148 & 0.6982 & 0.6976 & 172 & 0.0012 & 0.0477 & 0.0471 \\
\hline 82 & 0.7014 & 0.6839 & 0.6833 & 174 & 0.0011 & 0.0443 & 0.0438 \\
\hline 84 & 0.6873 & 0.6694 & 0.6688 & 176 & 0.0010 & 0.0412 & 0.0407 \\
\hline 86 & 0.6739 & 0.6546 & 0.6539 & 178 & 0.0009 & 0.0381 & 0.0377 \\
\hline 88 & 0.6597 & 0.6394 & 0.6388 & 180 & 0.0009 & 0.0353 & 0.0348 \\
\hline 90 & 0.6452 & 0.6240 & 0.6233 & 182 & 0.0008 & 0.0325 & 0.0321 \\
\hline 92 & 0.6304 & 0.6082 & 0.6074 & $=184 \ldots$ & 0.0007 & 0.0299 & 0.0295 \\
\hline 94 & 0.6151 & 0.5919 & 0.5911 & 186 & 0.0006 & 0.0274 & 0.0270 \\
\hline 96 & 0.5992 & 0.5750 & 0.5742 & 188 & 0.0006 & 0.0249 & 0.0246 \\
\hline 98 & 0.5823 & 0.5572 & 0.5563 & 190 & 0.0005 & 0.0226 & 0.0223 \\
\hline \multirow[t]{5}{*}{100} & 0.5628 & 0.537 .4 & 0.5363 & 192 & 0.0005 & 0.0204 & 0.0201 \\
\hline & & & & 194 & 0.0004 & 0.0182 & 0.0179 \\
\hline & & & & 196 & 0.0004 & 0.0160 & 0.0158 \\
\hline & & & & 198 & 0.0003 & 0.0138 & 0.0136 \\
\hline & & & & 200 & 0.0002 & 0.0114 & 0.0112 \\
\hline
\end{tabular}

(1) Radial intervals for the $S_{16}$ transport theory calculations were $0.06115 \mathrm{~cm}$ for the inner 100 intervals and $0.1803 \mathrm{~cm}$ for the outer 200 intervals. All values of the fission density and neutron importance normalized to unity at the sphere center.

(2) These values were calculated with the nuclear temperature of the Maxwellian fission spectrum equal to $1.40 \mathrm{MeV}$.

(3) These values were obtained with the calculated nuclear temperature for reactor fission neutrons, which depended slightly on radius. At the center of the central uranium core, this temperature is $1.3431 \mathrm{MeV}$, while at the outer surface of the central core it is $0.65 \%$ lower. At the inner surface of the natural uranium reflector, the nuclear temperature is $1.3452 \mathrm{MeV}$, while at the outer surface of the reflector it is $0.60 \%$ lower. 
Table A-4

CALCULATED FISSICN DENSITY AND NEUTRON IMPORTANCE AS A FUNCTION OF RADIUS FOR A NATURAL-IJRANIUM-REFLECTED PLUTONIUM SPHERE

\begin{tabular}{|c|c|c|c|c|c|c|c|}
\hline $\begin{array}{c}\text { Radial } \\
\text { Interval (1) }\end{array}$ & $\begin{array}{l}\text { Fission } \\
\text { Density }\end{array}$ & $\begin{array}{l}\text { Calitornium } \\
\text { Neutron } \\
\text { Importance }\end{array}$ & $\begin{array}{c}\text { Reactor } \\
\text { Neutron } \\
\text { Importance } 131\end{array}$ & $\begin{array}{c}\text { Radial } \\
\text { Interval (1) }\end{array}$ & $\begin{array}{l}\text { Fission } \\
\text { Density }\end{array}$ & $\begin{array}{l}\text { Californium } \\
\text { Neutron } \\
\text { Importance(2) }\end{array}$ & $\begin{array}{c}\text { Reactor } \\
\text { Neutron } \\
\text { Importance (3) }\end{array}$ \\
\hline 1 & 1.0008 & 1.0009 & 1.0009 & 101 & 0.0571 & 0.5196 & 0.5145 \\
\hline 2 & 1.0017 & 1.0017 & 1.0017 & 102 & 0.0488 & 0.4800 & 0.4752 \\
\hline 4 & 1.0016 & 1.0017 & 1.0017 & 103 & 0.0431 & 0.4491 & 0.4445 \\
\hline 6 & 1.0010 & 1.0010 & 1.0010 & 104 & 0.0384 & 0.4221 & 0.4176 \\
\hline 8 & 0.9999 & 0.1000 & 0.1000 & 105 & 0.0344 & 0.3982 & 0.3938 \\
\hline 10 & 0.9985 & 0.9985 & 0.9985 & 106 & 0.0311 & 0.3766 & 0.3724 \\
\hline 12 & 0.9966 & 0.9966 & 0.9966 & 107 & 0.0282 & 0.3571 & 0.3530 \\
\hline 14 & 0.9943 & $0.99<2$ & 0.9942 & 108 & 0.0257 & 0.3392 & 0.3352 \\
\hline 16 & 0.9916 & 0.9915 & 0.9915 & 109 & 0.0235 & 0.3227 & 0.3189 \\
\hline 18 & 0.9885 & 0.9884 & 0.9884 & 110 & 0.0215 & 0.3074 & 0.3037 \\
\hline 20 & 0.9850 & 0.9848 & 0.9848 & 112 & 0.0183 & 0.2801 & 0.2766 \\
\hline 22 & 0.9811 & 0.9809 & 0.9809 & 114 & 0.0156 & 0.2562 & 0.2530 \\
\hline 24 & 0.9769 & 0.9766 & 0.9766 & 116 & 0.0135 & 0.2352 & 0.2321 \\
\hline 26 & 0.9722 & 0.9718 & 0.9718 & 118 & 0.0116 & 0.2165 & 0.2136 \\
\hline 28 & 0.9671 & 0.9667 & 0.9667 & 120 & 0.0102 & 0.1997 & 0.1970 \\
\hline 30 & 0.9617 & 0.9612 & 0.9612 & 122 & 0.0089 & 0.1846 & 0.1820 \\
\hline 32 & 0.9559 & 0.9553 & 0.9554 & 124. & 0.0078 & 0.1709 & 0.1685 \\
\hline 34 & 0.9497 & 0.9491 & 0.9491 & 126 & 0.0069 & 0.1585 & 0.1562 \\
\hline 36 & 0.9432 & 0.9424 & 0.9425 & 127 & 0.0061 & 0.1471 & 0.1450 \\
\hline 38 & 0.9363 & 0.9354 & 0.9355 & 130 & 0.0055 & 0.1368 & 0.1347 \\
\hline 40 & 0.9290 & 0.9280 & 0.9281 & 132 & 0.0049 & 0.1272 & 0.1253 \\
\hline 42 & 0.9213 & 0.9203 & 0.9204 & 134 & 0.0044 & 0.1185 & 0.1167 \\
\hline 44 & 0.9134 & 0.9122 & 0.9123 & 136 & 0.0039 & 0.1104 & 0.1087 \\
\hline 46 & 0.9050 & 0.9038 & 0.9039 & 138 & 0.0035 & 0.1029 & 0.1013 \\
\hline 48 & 0.8964 & 0.8950 & 0.8951 & 140 & 0.0032 & 0.0960 & 0.0945 \\
\hline 50 & 0.8873 & 0.8859 & 0.8860 & 142 & 0.0029 & 0.0895 & 0.0881 \\
\hline 52 & 0.8780 & 0.8765 & 0.8766 & 144 & 0.0026 & 0.0835 & 0.0822 \\
\hline 54 & 0.8684 & 0.8667 & 0.8668 & 146 & 0.0024 & 0.0780 & 0.0767 \\
\hline 56 & 0.8584 & 0.8566 & 0.8567 & 148 & 0.0021 & 0.0728 & 0.0716 \\
\hline 58 & 0.8481 & 0.8462 & 0.8463 & 150 & 0.0019 & 0.0679 & 0.0668 \\
\hline 60 & 0.8375 & 0.8355 & 0.8356 & 152 & 0.0018 & 0.0634 & 0.0624 \\
\hline 62 & 0.8266 & 0.8244 & 0.8246 & 154 & 0.0016 & 0.0592 & 0.0582 \\
\hline 64 & 0.8154 & 0.8131 & 0.8133 & 156 & 0.0015 & 0.0552 & 0.0543 \\
\hline 66 & 0.8039 & 0.8015 & 0.8016 & 158 & 0.0013 & 0.0515 & 0.0506 \\
\hline 68 & 0.7921 & 0.7896 & 0.7897 & 160 & 0.0012 & 0.0480 & 0.0472 \\
\hline 70 & 0.7800 & 0.7773 & 0.7775 & 162 & 0.0011 & 0.0447 & 0.0439 \\
\hline 72 & 0.7676 & 0.7648 & 0.7650 & 164 & 0.0010 & 0.0416 & 0.0409 \\
\hline 74 & 0.7549 & 0.7520 & 0.7522 & 166 & 0.0009 & 0.0387 & 0.0380 \\
\hline 76 & 0.7419 & 0.7389 & 0.7391 & 168 & 0.0009 & 0.0360 & 0.0353 \\
\hline 78 & 0.7287 & 0.7255 & 0.7257 & 170 & 0.0008 & 0.0334 & 0.0328 \\
\hline 80 & 0.7150 & 0.7118 & 0.7120 & 172 & 0.0007 & 0.0309 & 0.0304 \\
\hline 82 & 0.7011 & 0.6977 & 0.6980 & 174 & 0.0007 & 0.0286 & 0.0281 \\
\hline 84 & 0.6869 & 0.6834 & 0.6837 & 176 & 0.0006 & 0.0265 & 0.0260 \\
\hline 86 & 0.6722 & 0.6686 & 0.6690 & 178 & 0.0005 & 0.0244 & 0.0239 \\
\hline 88 & 0.6572 & 0.6536 & 0.6539 & .180 & 0.0005 & 0.0224 & 0.0220 \\
\hline 90 & 0.6418 & 0.6381 & 0.6384 & 182. & 0.0004 & 0.0206 & 0.0202 \\
\hline 92 & 0.6259 & 0.6221 & 0.6225 & 184 & 0.0004 & 0.0188 & 0.0185 \\
\hline 94 & 0.6094 & 0.6056 & 0.6060 & 186 & 0.0004 & 0.0171 & 0.0168 \\
\hline 96 & 0.5921 & 0.5883 & 0.5887 & 188 & 0.0003 & 0.0155 & 0.0152 \\
\hline 98 & 0.5734 & 0.5696 & 0.5701 & 190 & 0.0003 & 0.0140 & 0.0137 \\
\hline \multirow[t]{5}{*}{100} & 0.5519 & 0.5484 & 0.5489 & 192 & 0.0003 & 0.0125 & 0.0123 \\
\hline & & & & 194 & 0.0002 & 0.0111 & 0.0109 \\
\hline & & & & 196 & 0.0002 & 0.0097 & 0.0095 \\
\hline & & & & 198 & 0.0002 & 0.0083 & 0.0082 \\
\hline & & & & 200 & 0.0001 & 0.0068 & 0.0066 \\
\hline
\end{tabular}

(1) Radial intervals for the $S_{16}$ transport theory calculations were $0.04533 \mathrm{~cm}$ for the inner 100 intervals and $0.19608 \mathrm{~cm}$ for the outer 200 intervals. All values of the fission density and neutron importance are normalized to unity at the sphere center.

(2) These values were calculated witt the nuclear temperature of the Maxwellian fission spectrum equal to $1.40 \mathrm{MeV}$.

(3) These values were obtained with the calculated nuclear temperature for reactor fission neutrons, which depended slightly on radius. At the center of the central uranium core, this temperature is $1.4412 \mathrm{MeV}$, while at the outer surface of the central core it is $0.44 \%$ lower. At the inner surface of the natural uranium reflector, the nuclear temperature is $1.3465 \mathrm{MeV}$, while at the outer surface of the reflector it is $0.72 \%$ lawer. 


\section{ACKNOWLEDGEMENTS}

Appreciation is expressed to the staff of the Oak Ridge Critical Experiments Facility; in particular, the work of J. R. Taylor and J. J. Lynn in performing the bare uranium experiment and processing the data. The work of J. R. Knight of the Oak Ridge National Laboratory, who performed the calculations, is acknowledged.

I am also indebted to J.D. Orndoff and H. C. Paxton of the Los Alamos Scientific Laboratory for allowing me to perform the measurements with the FLATTOP and JEZEBEL assembly machines at LASL. Their cooperation and that of others at the Pajarito Critical Mass Laboratory; particularly, A. A. Usner, M. B. Diaz, R. H. White, and B. Bernard, is deeply appreciated. G. E. Hansen and H. H. Helmick (LASL) provided unpublished data on the fission density distributions for the bare plutonium and natural-uranium-reflected spheres. 


\section{DISTRIBUTION}

Aerojet Nuclear Corporation

Morfitt, J. W.

Argonne National Laboratory - Idaho

Brunson, G.

Argonne National Laboratory - Illino is

Bennett, $E$.

Redman, W. C.

Atomic Energy Commission - Oak Ridge

Hick.man, H. D.

Keller, C. A.

Lenhard, J.

Pidkowicz, J.

Zachry, D. S., Jr

Atomic Energy Commission - Washington

Buhl, A. R.

Hanauer, S. H.

Hannum, W. H.

Hemmig, P. B.

Legler. F, C.

Drndoff, J. C.

Ballistics Research Laboratory

Kazi, A. H.

Battelle-Northwest Laboratory

Clayton, E. D.

Dow Chemical - Rocky Flats

Harlan, R. A.

Intelcom Rad Tech

Gozani, T.

Preskitt, C. A.

Lawrence Livermore Laboratory

Hampel, V. R.

Kloverstrom F. R.
Los Alamos Scientific Laboratory

Fluharty, R. G.

Hansen, G. E.

Keepin, G. R.

Paxton, H. C.

Oak Ridge Gaseous Diffusion Plant

Barton, J. C.

Magnuson, D. W.

Newlon, C. E.

Wilcox, W. J., Jr

Winkel, R. A.

Oak Ridge National Laboratory

Ackerman, N. J.

Binford, F. T.

Borkowski, C. J.

Culler, F. L.

de Saussure, G.

Flanagan, G. F.

Knight, J. R.

Maienschein, F. C.

Mihalczo, J. T. (20)

Mynatt, F. R.

Perez, H. B.

Oak.es, L. C.

Robinson, J. C.

Thomas, J. T.

Whitesides, G. E.

Oak Ridge Y -12 Plant

Alvey, H. E.

Burditt, R. B.

Briscoe, O.W.

Burkhart, L. E.

Butturini, W. G.

Callitian, A. D.

Denny, A. (2)

Ebert, J.W.

Ellingson, R. D.

Fraser, R. J.

Gritzner, V. B.

Hensley, C. E. 
Johnson, C. E.

Johnson, E. B.

Kahl, K. G.

Keith, A.

Kite, H. T.

Lundin, M. I.

McLendon, J. D.

Oliphant, G. W.

Perry, A. E.

Phillips, L. R.

Smith, H. F., Jr

Smith, R. D.

Snyder, H. G. P.

Strohecker, J. W.

Weathersby, W. E.

Whitson, W. K.

Wilkinson, P. E. (2)

Yaggi, W. J./Googin, J. M.

$Y-12$ Central Files (10)

$Y-12$ Central Files (master copy)

Y.12 Central Files (route copy)

$Y-12$ Central Files (Y-12RC)

Paducah Gaseous Diffusion Plant

Edwards, A. K.

Levin, R. B.

Rensselaer Polytechnic Institute

Block, R. C.

Sandia - Albuquerque

Coats; R. L.

Savannah River Laboratory

Clark, H. K.

Bauman, N. P.

Dessauer, $\mathrm{G}$.

Science Applications

Beyster, J. R.

University of California - Berkeley

Corngold, N.

Pigford, T. H.
University of California - Santa Barbara

Profio, A. E.

University of Illinois - Urbana

Dorning, A.

Gunnison, F.

University of New Mexico - Albuquerque

Long, R. L.

University of Tennessee - Knoxville

Pasqua, P. F.

University of Washington - Seattle

Albrecht, R. W.

Bhabha Atomic-Research Centre, Nuclear Physics Division,

Trombay, Bombay, India

Basu, T. K.

Pasupathy, C. S.

Elektrik Fakultesi

Teknik Universite

Istanbul, Turkey

Dalfes, A.

Central Research Institute for Physics, Budapest, Hungary

Kosaly, G.

CNEN, Laboratorio Fisico E Calcol

Reattori, Rome, Italy

Pacilio, N.

EURATOM - Ispra - Italy

Hass, R.

Kistner, $\mathrm{G}$.

Institut Fur Kerntechnik - Germany

Stegemann, D. 
Institute of Experimental Physics,

Kossuth University

Debrecen, Hungary

Csikai, J.

Institute of Nuclear Research,

Warszawa, Poland

Zoltowski, T.

Interuniversitair Reactor

Instituut - The Netherlands

Bode, P.

Queen Mary College - London, England

Mansfield, W. K.

Gesellschaft Fur Kernforschung MBH

Karlsruhe, Germany

Edelmann, M. F.

United Kingdom Atomic Energy Agency

Winfrith, England

Sanders, J.

DeLapparent, D.

DRNR - SEDC

C.E.N. C.ADARACHE/R. P. I

13 Saint Paul Lcz Durance

France

Thie, Joseph A.

P. O. Box 517

Barrington, lllinois bU010

In addition, this report is distributed in accordance with the category UC-46, Criticality Studies, as given in the USAEC Standard Distribution Lists for Unclassified Scientific and Technical Reports, TID-4500. 